\title{
Trenzando sueños
}

DIAGNÓSTICO DE LOS PROCESOS COMUNICACIONALES DESARROLLADOS EN LA UNIDAD DE INVESTIGACIÓN Y DESARROLLO PARA LA CALIDAD DE LA EDUCACIÓN EN INGENIERÍA (UNITEC), FACULTAD DE INGENIERÍA DE LA UNIVERSIDAD NACIONAL DE LA PLATA, ARGENTINA.

Estrategias comunicativas en la planificación del mejoramiento de la calidad de vida e inclusión de la población en situación de discapacidad.

JOAN CAROLINA AMÉZQUITA CASTRO.

Abril 2019.

DIRECTOR: Dr. CARLOS GIORDANO

UNIVERSIDAD NACIONAL DE LA PLATA.

FACULTAD DE PERIODISMO Y COMUNICACIÓN SOCIAL MAESTRÍA EN PLANIFICACIÓN Y GESTIÓN DE PROCESOS

COMUNICACIONALES

LA PLATA, ARGENTINA 


\section{ÍNDICE GENERAL}

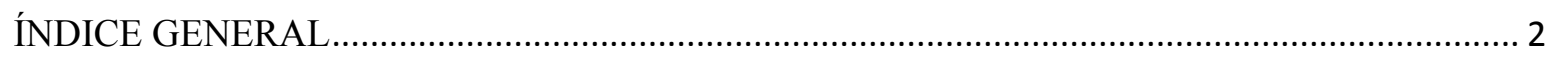

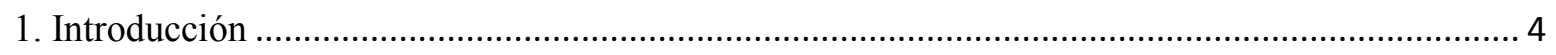

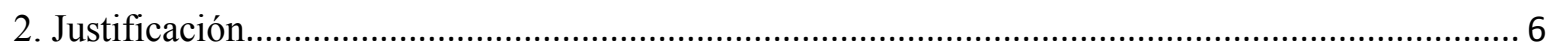

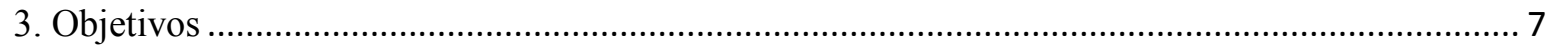

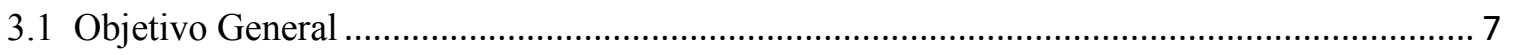

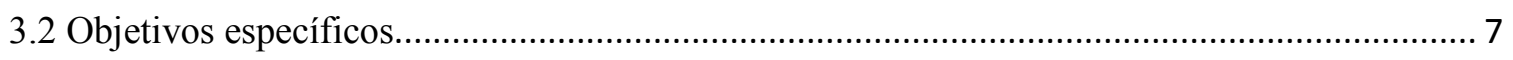

4. Planteamiento del problema ……………............................................................................... 7

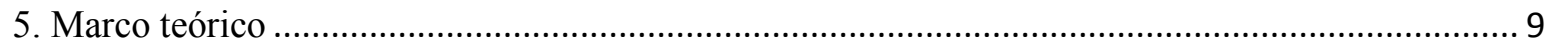

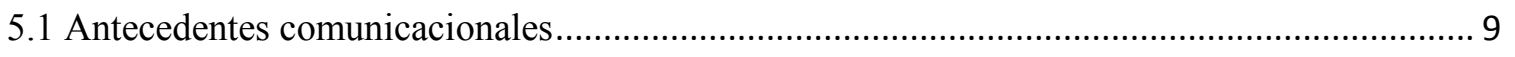

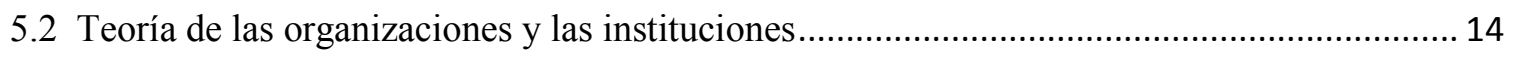

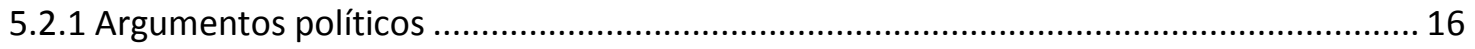

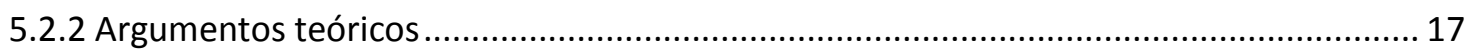

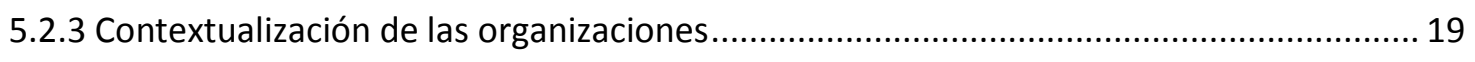

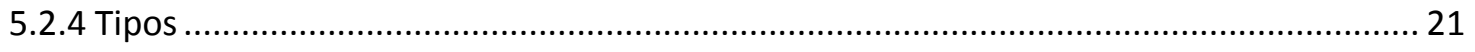

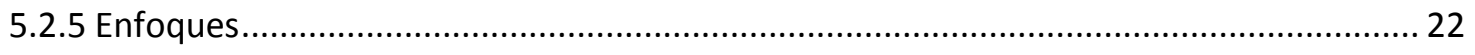

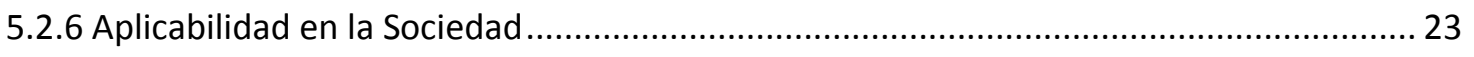

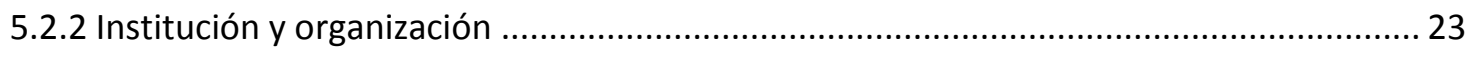

5.2.2.1 Procesos dentro de las instituciones y organizaciones ............................................... 24

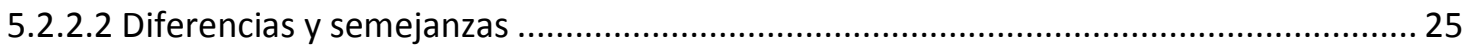

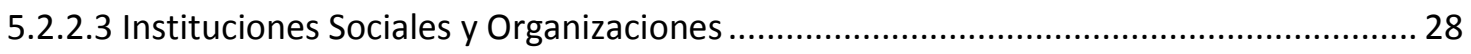

5.2.3 Concepciones teóricas acerca de organizaciones e instituciones.................................... 30

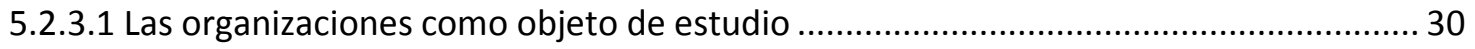

5.2.3.2 El poder y la dominación dentro de las organizaciones .............................................. 31

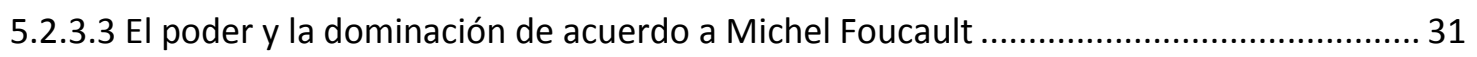

5.2.3.4 El enfoque de Bourdieu y su entendimiento de los sistemas de dominación ............... 33

5.2.3.5 La perspectiva de Castoriadis sobre las instituciones .................................................. 35

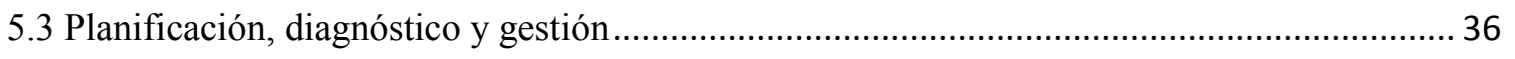

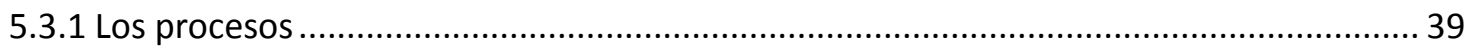

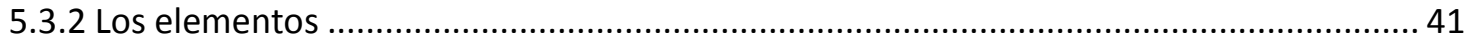

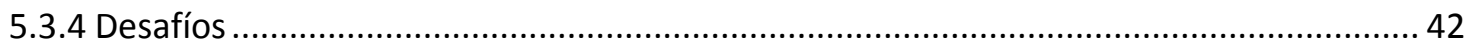




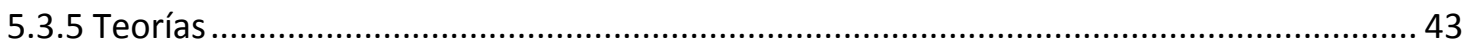

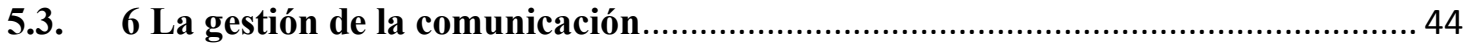

5.3.7 Importancia del diagnóstico comunicacional dentro de un escenario universitario........ 50

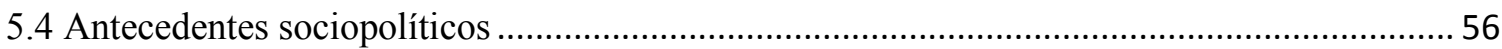

5.4.1 Concepto de Estado y sus implicaciones fundamentales en la sociedad........................ 62

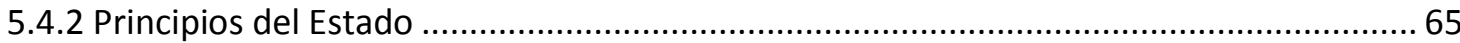

5.4.3 Papel de distintas instituciones que fomentan políticas públicas en la materia en

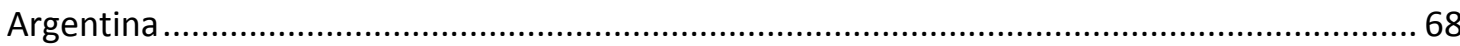

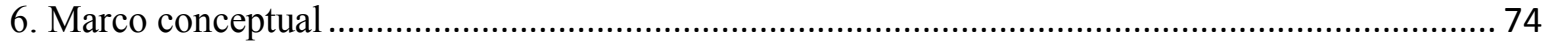

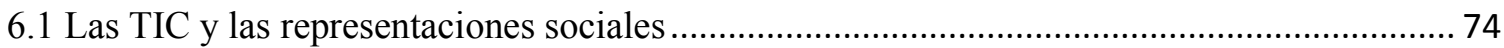

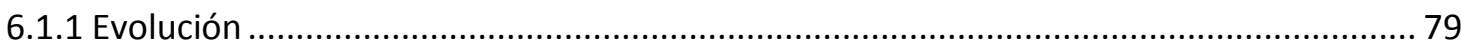

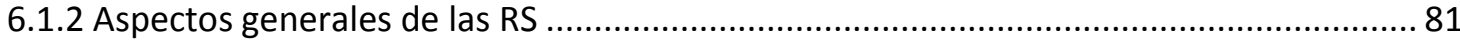

6.1.3 Proceso de formación de las representaciones sociales.............................................. 84

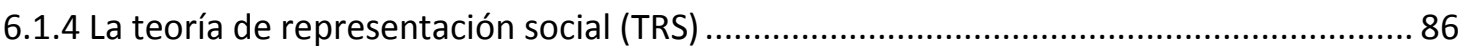

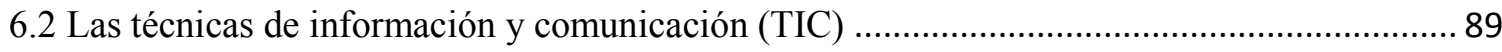

6.3 Las TIC aplicado en la comunicación corporativa ........................................................... 92

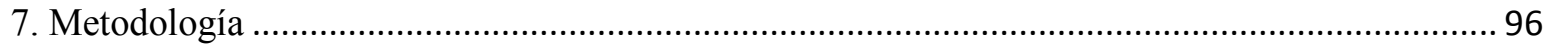

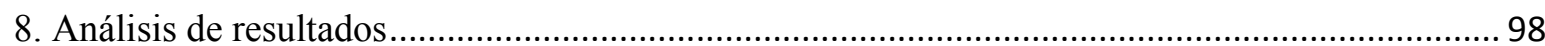

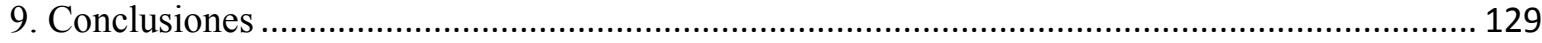

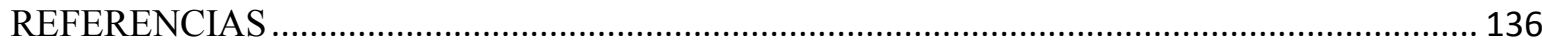

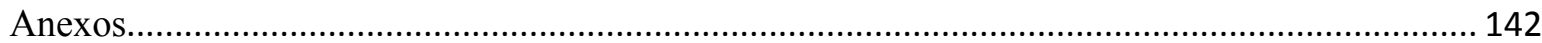

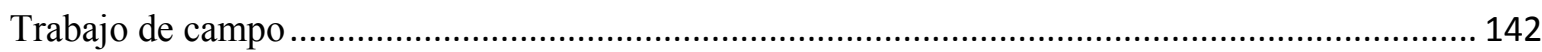




\section{Introducción}

En La Argentina el 12.9\% de la población cuenta con algún tipo de discapacidad, según el último censo realizado por INDEC en el 2010. Cifra para tener en cuenta, especialmente a la hora de diseñar e implementar políticas públicas para la población en situación de discapacidad, que muchas veces son mayormente atendidos por organizaciones sin ánimo de lucro, fundaciones o iniciativas como la UNITEC, que buscan mejorar la calidad de vida de una minoría; y en esa medida ningún esfuerzo está de más.

En el año 2013 tuve la oportunidad de vincularme a la realización de la campaña 'Sos vos soy yo' con el mismo derecho a ser diferentes, realizada por la Fundación MEDIHOME en el Pasaje Dardo Rocha de la ciudad de La Plata, provincia de Buenos Aires. En dicho escenario pude conocer de cerca las dinámicas que se manejan al interior de la población en situación de discapacidad, sus aisladas formas de relacionarse, organizarse y poca visibilidad en la sociedad platense.

Motivada por conocer en detalle sobre esta temática, me plantee varios interrogantes que quise responder inicialmente a la ligera, sin embargo me percaté de la complejidad del asunto y de mi responsabilidad como maestranda extranjera, primero por conocer de cerca la realidad del país donde me instalaba, y segundo porque el tema por sí solo me apasiona, pues mi vinculación con la campaña fue ajena a cualquier cuestión académica, fue un gusto social.

En la versión 2014, me vinculé de nuevo a la campaña, pero esta vez tuve la oportunidad de conocer la UNITEC (Unidad de Investigación y Desarrollo para la Calidad de la Educación en Ingeniería) que hace parte de la Facultad de Ingeniería de la Universidad Nacional de La Plata (UNLP). Con un novedoso stand, la UNITEC participó en la campaña, enseñando a los asistentes cómo desde sus laboratorios creaban, reparaban o diseñaban nuevas tecnologías para ser adaptadas al servicio de las personas en situación de discapacidad.

Desde el primer momento la idea me cautivó, pero sobre manera llamó mi atención el hecho de que un trabajo tan loable no contara con mayor reconocimiento, limitando así el número de población en situación de discapacidad a la cual pueden beneficiar y los apoyos o convenios interinstitucionales que podrían celebrar.

Por primera vez, después de pensar muchas veces la dirección correcta por donde debía avanzar mi investigación, sentí que no tenía dudas. Pero sobre todo, que la mía, podría ser 
una investigación que además de servir en mi objetivo de culminar la maestría, transformara un proceso, en este caso una organización como la UNITEC; sentí que la comunicación me daba el poder de transformación social.

En concordancia con la concepción PLANGESCO, considero que abordar los procesos sociales desde la comunicación implica situar su estudio en el terreno de la cultura. Para González (1994), "la cultura es un modo de organizar el movimiento constante de la vida concreta, mundana y cotidiana. La cultura es un principio organizador de la experiencia, mediante ella ordenamos y "estructuramos" nuestro presente a partir del sitio que ocupamos en las redes sociales. Es, en rigor, nuestro sentido práctico de la vida”. (p.34).

Mi investigación se sitúa desde el territorio de los actores, la organización, conocer el sujeto expresado desde su cultura, en su vida cotidiana, en su realidad, donde son atravesados por dimensiones contextuales culturales, históricas, económicas, sociales y jurídicas.

De acuerdo con el Plan Pedagógico de la maestría PLANGESCO, "la importancia de abordar el estudio de las prácticas sociales desde la cultura reside en que ella encarna la ligazón con el tiempo y el espacio. Lejos de constituirse en un mero organizador de la experiencia presente, la cultura nos habla también de los sueños y la fantasía, de las utopías; también es ligadura y raíz con nuestro pasado, recuerdo de los sucesos y acciones que nos fueron constituyendo a lo largo de la historia. Solo desde esta perspectiva es factible pensar en los sujetos inmersos en procesos comunicacionales; que se desarrollan en su contexto más cercano, de los mitos y ritos que los constituyen, de los discursos en los que la cultura cobra materialidad, cualquiera sea su soporte".

En el mismo documento, se retoma el concepto expuesto por Berger y Luckmann (S/F) en su libro 'La construcción social de la realidad' donde se concibe que los sujetos se constituyen individual y colectivamente enmarcados en un determinado universo simbólico ,"una trama discursiva en la que ciertos sentidos institucionalizados aparecen operando en la forma del ser y actuar social. Por tanto, se hace preciso adoptar una concepción del sujeto en relación con los discursos que lo construyen: un sujeto sujetado en el lenguaje.

Y específicamente ahí es a donde pretendo llegar; transitando un camino que me permita responder los cuestionamientos iniciales y los que surjan durante el proceso de investigación;¿Cuál es la situación inicial de la UNITEC?; ¿Cuál es la situación deseada al interior de la UNITEC?, ¿Cuáles son las prácticas comunicacionales que se desarrollan en la 
organización?, ¿Cuáles son las formas de organizarse?, de relacionarse como institución?, cuál es ese mirada que tienen del 'otro’ y cómo esa mirada los construye como organización?; y por supuesto;¿cómo se relacionan con la población en situación de discapacidad?; entre otras.

\section{Justificación}

Este proyecto propone en el marco de la maestría PLANGESCO, diagnosticar los procesos comunicacionales al interior de la Unidad de Investigación y Desarrollo para la Calidad de la Educación en Ingeniería (UNITEC), adscrita a la Facultad de Ingeniería de la Universidad Nacional de La Plata (UNLP), para diseñar y planificar estrategias comunicativas, a partir de los problemas detectados a lo largo de la investigación, tendientes a transformar la situación inicial de la organización por la deseada.

Desde el inicio de sus actividades formales, en el año 2007, la UNITEC marcó gran influencia en el área de extensión de la Facultad, creando gradualmente múltiples laboratorios que orientan su campo de acción a la utilización de las TICS. Según el documento fundacional, los objetivos generales son:

1. Impulsar la aplicación de Normas de Calidad en la Educación en áreas tecnológicas y promover la Gestión de la Calidad Educativa, y

2. Abordar cuestiones sobre la posible aplicación actual de las TICS para mejorar la calidad de la actividad docente, su complementación con los medios didácticos tradicionales, no sólo para un mayor aprovechamiento del tiempo, sino para una mejora integral de la enseñanza, que contribuya a formar profesionales eficientes y con alto sentido de la responsabilidad.

Para ellos, la metodología propuesta para el desarrollo de los objetivos de UNITEC es:

1. Llevar adelante tareas de investigación en el área de innovación y mejoramiento de la Calidad en la Educación y entrenamiento en Ingeniería (Educación basada en competencias, evaluación de aprendizajes, barreras al aprendizaje, etc), incorporándolas herramientas de las Tecnologías de la Información y la Comunicación (TICS).

2. Promover desarrollos tecnológicos y asesoramientos a requerimiento de terceros e impulsar tareas de investigación, extensión, asesoramiento y capacitación, basados en los objetivos propuestos. 
3. Promover y realizar estudios sobre indicadores para el mejoramiento continuo de la Educación en Ingeniería.

4. Fomentar actividades de transferencia de conocimientos, a través de la capacitación y formación de los miembros de la UID en temas relacionados con las TICS aplicadas a la Educación, otras Tecnologías y al Aseguramiento de la Calidad.

\section{Objetivos}

\subsection{Objetivo General}

Identificar, describir y analizar los procesos comunicacionales generados en y por la UNITEC, a través de la etapa de diagnóstico de los procesos de gestión que adelanta la organización.

\subsection{Objetivos específicos}

1. Diseñar un diagnóstico comunicacional sobre la situación inicial de la UNITEC.

2. Identificar y describir los procesos comunicacionales necesarios a considerar en el diseño de programas y estrategias para alcanzar la situación futura.

3. Analizar los procesos de gestión y comunicación generados en la UNITEC.

4. Plantear opciones de estrategias comunicativas para el desarrollo, a partir de las conclusiones del diagnóstico comunicacional.

5. Comenzar a co-construir redes de trabajo y líneas de acción que permitan el cumplimiento y potencialización de los objetivos de la UNITEC.

\section{Planteamiento del problema}

La UNITEC cuenta con un plantel de profesionales de diferentes disciplinas: Ingeniería y varias de sus ramas, Ciencias Exactas, Humanidades, Ciencias de la Educación, Pedagogía, Especialistas en Educación Especial, Psicología, Trabajo Social ,Derecho, Ciencias Económicas, Bellas Artes, Entre otras. Actualmente coexiste el trabajo de aproximadamente 50 personas.

Las actividades desarrolladas en la UNITEC se proyectan a la sociedad, a través de jóvenes talentosos, desinteresados y creativos, formados en la necesidad de volcar sus conocimientos para mejorar la calidad de vida, en principio, de los alumnos de las Escuelas de Educación Especial de la zona de La Plata. El ejemplo más destacable está representado 
por el hecho que estas actividades han trascendido la región y hoy se atienden escuelas de la Provincia de Buenos Aires (Verónica, Brandsen, Necochea, Lobos, Magdalena, etc), de Santiago del Estero (Añatuya), de Misiones (Puerto Piray), de Formosa (Clorinda) y a través de esta última escuelas de la zona aledaña a la República de Paraguay. Es en esta área donde la actividad multidisciplinaria e interdisciplinaria resulta invalorable.

Sin embargo, y a pesar de la excelente acogida de los proyectos y logros gestados al interior de la Unidad, sus coordinadores e integrantes han detectado la necesidad de contar con estrategias comunicativas que contribuyan a la planificación de sus actividades, en pro de alcanzar satisfactoriamente el que se ha convertido en uno de sus objetivos principales, el mejoramiento de la calidad de vida e inclusión de la población en situación de discapacidad.

Reconocer las dimensiones comunicacionales en los problemas del desarrollo es el primer paso para situar el análisis de la realidad comunicacional. La posibilidad de mirar comunicacionalmente un escenario, nos facilita la definición de canales y actores de la comunicación, los códigos, los modos, los contextos. Esta mirada nos "permite proponer nuevas formas de comunicación, desde la producción de mensajes y la promoción de redes que contribuyan a la solución de los problemas”. (Ceraso, 2007, p.45)

Para la presente investigación tomaré como guía elemental el manual 'Sembrando mi tierra de futuro`, que propone al diagnóstico como un momento del proceso de planificación de proyectos de comunicación. Es una herramienta que nos permite analizar la realidad comunicacional, priorizar los aspectos de la comunicación para conocer no solo las problemáticas de una comunidad, sino también sus formas de organización.

Entendiendo la comunicación como un proceso que significa relacionarse, encontrarse, acercarse, enredarse. Cuando nos comunicamos nos ponemos en juego, abandonamos ese lugar tan seguro de lo que pensamos y sentimos en nuestro interior para construir con otros, para construirnos en seres sociales.

En ese orden de ideas, luego de cuestionarme desde diferentes perspectivas, mi investigación partirá desde la pregunta: ¿Cómo la comunicación, la planificación y la gestión pueden transformar la realidad de la UNITEC para potencializar su desarrollo hacia la situación deseada? 


\section{Marco teórico}

\subsection{Antecedentes comunicacionales}

Hoy por hoy, hablar de comunicación es hablar de procesos que nos llevan a conocernos, sentirnos, relacionarnos, encontrarnos, enredarnos, acercarnos; construir una mirada de nosotros mismos con la mirada del otro, interpretar nuestro mundo, a los demás, a conjugarnos, a apropiarnos.

Al respecto, la doctora Cecilia Ceraso (2014) en su manual, 'Sembrando mi tierra de futuro' afirma que cuando comunicamos nos ponemos en juego, abandonamos ese lugar tan seguro de lo que pensamos y sentimos en nuestro interior para construir con otros, para constituirnos en seres en relación.

Para efectos de la presente investigación, esta premisa será la utilizada cuando se hable de procesos comunicacionales, pues cuando decimos que la comunicación es un proceso, hacemos referencia a la permanente dinámica existente en las relaciones, lo cual hace que se transformen constantemente; de manera individual y colectiva; influyendo a su vez, uno sobre otro de manera recíproca.

Para llegar a este concepto, el recorrido teórico y metodológico transitado a través de los años fue bastante arduo. Citaré entonces el recuento realizado por Ceraso (2014) sobre los sucesos teóricos/comunicativos más importantes a través de la historia; donde la Magister toma como punto de partida la 'Teoría Matemática de la Comunicación', planteada por los ingenieros Shannon y Weber, para buscar el por qué en la actualidad la comunicación, muchas veces, sigue siendo enseñada como un proceso de transmisión de mensajes de un emisor a un receptor utilizando un canal.

Esta mirada puede ser explicada desde el modelo matemático originado en la década de 1940 en Estados Unidos, en el que la eficacia de la comunicación se mide a través de la fidelidad de la recepción, es decir, cuando el destinatario recibe exactamente lo que la fuente ha originado como mensaje a transmitir. Para que la transmisión de la información de un punto a otro sea exitosa, es necesario que no exista 'ruido' que afecte la circulación del mensaje.

Ceraso (2014) hace énfasis al aclarar y entender la formación de Shannon y Weber como ingenieros, quienes al formular su teoría estaban sistematizando un modelo de comunicación telefónica y su objetivo era optimizar la comunicación desde una perspectiva tecnológica. 
"Desde este modelo informacional inicial hasta hoy se dieron conceptualizaciones, aportes y reformulaciones en diferentes momentos del proceso y desde diferentes disciplinas".

Sin embargo, Armand Mattelart (1997) en su libro "Historia de las teorías de la comunicación', establece su punto de partida un poco más atrás, al reconocer a la escuela de Chicago como una pionera de los estudios comunicacionales. "La escuela de Chicago centra su enfoque microsociológico de los modos de comunicación en la organización de la comunidad, lo cual armoniza con una reflexión sobre la función del instrumento científico en la resolución de los grandes desequilibrios sociales".

Por su parte, Ceraso (2014) resalta y retoma desde el terreno de la lingüística estructural, el aporte de otra dimensión hecho por Román Jacobson al análisis al modelo matemático cuando incorporó el concepto de 'contexto' en el momento en que se produce la transmisión de los mensajes, así como las diferentes funciones que puede cumplir el lenguaje.

Es aquí donde se evidencia el aporte de la Escuela Funcionalista y su detenimiento en observar la influencia de los medios de comunicación en la sociedad; pues cuestionamientos como qué función cumple el 'contexto' en los mensajes emitidos, ¿quién dice?, ¿por qué canal?, ¿a quién? y ¿con qué?; cada vez se toman un papel más relevante. En este punto, Mattelart y Ceraso convergen durante su recorrido teórico/comunicativo.

Frente a la Teoría Crítica, Ceraso (2014) afirma que aportará su perspectiva desde una conceptualización del poder y la sociedad de masas, donde los medios de comunicación se integran a las fuentes de poder y a las autoridades para construir y ejercer hegemonía. Desde esta línea teórica se ponen de manifiesto la ideología y la manipulación en los procesos de comunicación.

En un momento el papel del receptor, como subsidiario del esquema de comunicación (que solo parece modificarse cuando ocupa el lugar del emisor), lleva a éste proceso de conocimiento a realizar nuevas proposiciones con las perspectivas de diferentes disciplinas como la semiótica, la teoría literaria y algunas miradas sociológicas como las representadas por los estudios culturales ingleses, que permiten la superación de esta mirada pasiva acerca del receptor y lineal sobre la comunicación.

Frente a esto, Mata (S/F) sostiene que los emisores ya no transmiten unos mensajes significados elaborados en virtud de un instrumento neutro. "Tanto en la esfera de la emisión como en la de la recepción existe producción de sentido y no mera transferencia de los 
primeros a los segundos, aún cuando ella sea desigual, no simétrica... De aquí que podamos recuperar para la comunicación la idea de contrato o negociación, donde ambas partes emisores y receptores- son activas, permaneciendo diferenciados en sus roles y su capacidad de operar".

Prosigue Mata (S/F) al insistir en que reconociendo el indiscutible poder del emisor debemos advertir en su discurso la presencia activa de los receptores porque ellos están presentes como término de su producción como el otro que habla en lo que yo digo. Las perspectivas que vamos encontrando en el proceso histórico de la comunicación, como dominio de saber, llevan implícita una forma de ver el mundo y se corresponden con un modo conceptual o teórico de ver a la sociedad y sus relaciones. Estas miradas guardan relación profunda con el contexto político en que surgieron y con las características de los procesos de comunicación que describen.

Es esta la noción que los comunicadores debemos tener presente la hora de desarrollar procesos de planificación; al concebir al otro como un ser capaz de producir sentidos frente a lo que se quiere comunicar, capaz de responder y analizar desde su contexto y con su mirada, cultura, saber y perspectiva, lo que se quiere comunicar, para que desde allí aporte al proceso y lo asuman como suyo para alcanzar la situación deseada de la organización o comunidad.

Es precisamente con la llegada de estas nociones y conceptos al campo de la comunicación, que se empieza a dejar de lado el afán por medir y cuantificar la comunicación, cambiando definitivamente el rumbo de las investigaciones en comunicación. El eco de la teoría crítica empieza a surgir efecto y su rebote llega a América Latina para reforzar y acompañar los movimientos sociales que se venían gestando desde los años 40 y que promovían férreas ideas de cambio social y desarrollo.

Misma época en que se desarrollaron las primeras experiencias comunicativas que generarían valiosa recordación y se constituiría como punto de partida para los años venideros; es el caso de las radios mineras en Bolivia y Radio Zutatenza en Colombia. Es preciso citar entonces lo que Melo (1998), llamaría Escuela Latinoamericana para la Comunicación, con la cual se empiezan a gestar teorías, investigaciones y trabajos académicos propios de la región, acordes con nuestro contexto, cultura e idiosincrasia. 
Según el autor, citado por Arroyo $(\mathrm{S} / \mathrm{F}))$ en su texto, 'Escuela Latinoamericana de Comunicación y el pensamiento crítico de Antonio Pasqualli', la constitución de dicha escuela debe considerar dos contextos, uno internacional y otro regional: En el ámbito internacional, el tema que marcó el campo económico, social, político y académico fue el desarrollo de los países "tercermundistas" rango en el que entraban los países latinoamericanos. Este tema movilizó recursos y organismos internacionales, que desde perspectivas particulares buscaban una salida al problema del subdesarrollo.

Y agrega: "Una de estas instituciones fue la Unesco, que apostó por la comunicación como el mecanismo para generar procesos de desarrollo (educación, salud, etc.). Con esta finalidad, Unesco facilitó la integración entre los medios productivos y la Universidad, para potenciar la capacitación y la investigación en este campo. La prueba palpable de esta situación fue el decisivo apoyo que brindó para la constitución de la International Association of Mass Communication Research (IAMCR) y la creación del Centro Internacional de Estudios Superiores de Comunicación para América Latina (Ciespal).

Arroyo Goncalves afirma que de esta manera, la Escuela Latinoamericana de Comunicación es producto de la confluencia de por lo menos dos matrices foráneas de la comunicación: la norteamericana y la europea (sobre todo francesa). Cada una de ellas, correspondientes a contextos diferentes, presenta formas particulares de pensar un mismo fenómeno.

La línea norteamericana, que adoptó para sí el concepto comunicación, estuvo motivada desde un inicio por el desarrollo tecnológico de la comunicación y su impacto en la sociedad. Sus primeros trabajos en el campo tuvieron influencia de la sociología y la psicología. La línea europea, que empleó el concepto de la información, se preocupó más por el contenido y tuvieron en sus estudios una marcada presencia de las Teorías Sociales.

Sin embargo, Latinoamérica sumida en su realidad, mestizaje teórico, hibridismo metodológico, pluralidad y procesos culturales, no tardaría mucho en emerger los verdaderos cauces de pensamientos que se gestaron durante años. Uno de los pioneros a la hora de consolidar lo que hoy en día se conoce de estudios e investigaciones de comunicación en América Latina fue Antonio Pascuali, a quien Ceraso también tomó como punto de referencia en el marco de su investigación.

De acuerdo con Pasquialli (S/F) La filosofía ha rechazado siempre un saber incomunicable, o ha determinado desde su comienzo que lo incomunicable es lo incognoscible, y lo 
incognoscible no es, pues supone que lo inexpresable es alógico y lo alógico una 'agnóia' o no saber. Por lo tanto, el grado y modo de su comunicabilidad define pues, a un saber cómo éste define a su plexo social; de lo cual puede inferirse directamente en perspectiva sociológica, una mutua inherencia dialéctica entre los medios de comunicación del saber y su correspondiente grupo social. Sólo hay sociedad o estar-uno-con-otro donde hay un consaber y sólo hay con-saber donde existen formas de comunicación.

Precisamente es ese ‘con-saber` propuesto por Pascuali, el que la presente investigación propone describir. Es necesario que en el momento de conocer la realidad de sus prácticas sociales, la Unitec piense a sus actores como sujetos de conocimiento; pues los espacios de comunicación y reflexión donde éstos diálogos de saberes ocurran, darán los argumentos necesarios que serán insumo para la toma de decisiones y consolidación de estrategias comunicativas en pro de alcanzar la situación deseada, de la que habla Ceraso (2014) en el manual Sembrado mi tierra de futuro.

$Y$ es que no podemos seguir concibiendo la comunicación de forma vertical o lineal como en un principio lo hicieron Shannon y Weber, por el contrario debe ser entendida en torno a un bagaje socio-cultural que integra a cada uno de los sujetos de conocimiento.

Coincidiendo con lo expuesto por Ceraso (2014), "cada individuo conlleva un saber que le permite relacionarse en sociedad. El saber parte de la experiencia concreta. De la trama de relaciones dentro de la cual los seres humanos nos movemos. Por esto, todo saber es social". (p.45). Y retomando a Pascualli (S/F) menciona "Sólo es pues, auténtica comunicación la que se asienta en un esquema de relaciones simétricas, en una paridad de condiciones entre transmisor y receptor y en la posibilidad de oír uno a otro o prestarse oídos (Heiddeger), como mutua voluntad de entenderse" (p.50).

Me propongo en la presente investigación, generar diálogos de saberes entre la Unitec universidad y sociedad, diálogos donde se encuentra la problematización del propio conocimiento. Este conocimiento no puede ni debe estar fuera del marco de la realidad, para poder comprenderla, explicarla y transformarla.

Dicho conocimiento es al que se refiere Ceraso al citar a Freire, conocer no es el acto a través del cual un sujeto transformado en objeto, recibe, dócil y pasivamente, los contenidos que otro le da o le impone... En el proceso de aprendizaje, sólo aprende verdaderamente aquel que se apropia de lo aprendido, transformándolo en aprehendido, con lo que puede, por eso 
mismo, reinventarlo; aquel que es capaz de aplicar lo aprendido/aprehendido a las situaciones existenciales concretas. Por el contrario, aquel que es 'llenado' por otro de contenidos cuya inteligencia no percibe, de contenidos que contradicen su propia forma de estar en su mundo, sin que sea desafiado, no aprende.

Y complementa Ceraso (2014) es aquí donde se da la integración entre comunicadoreducador en la práctica social, donde se aprehende la realidad. Es aquí desde donde comienza un proceso de diálogo, desde donde nos reconocemos como sujetos capaces de transformar dicha realidad. La educación, dice Freire, es comunicación, es diálogo, en la medida en que no es la transferencia de saber, sino un encuentro de sujetos interlocutores que buscan significaciones. La comunicación implica una reciprocidad que no puede romperse. No es posible comprender el pensamiento fuera de su doble función: cognitiva y comunicativa. No hay pensamiento aislado así como no hay hombre aislado.

La metodología PLANGESCO adopta y desarrolla estas nociones de comunicación para la transformación y propone la aplicación de dicha perspectiva en los procesos que incluyan comunicaciones dentro de su devenir; la misma será desarrollada más adelante en un apartado.

Considero necesario incluir igualmente la mirada comunicacional aportada por Jesús Martín Barbero, en su libro De los medios a las mediaciones, donde principalmente plantea

que la cultura es la gran mediadora de todo proceso comunicativo, y propone el concepto de mediación, desde donde se otorga sentido al proceso. Barbero plantea que los mensajes, canales, emisor y receptor son parte de lo cultural, desaparecen entonces como entidades separadas y deben estudiarse inmersos en las prácticas cotidianas.

\subsection{Teoría de las organizaciones y las instituciones}

En relación a este concepto, es importante expresar que se trata de una estructura establecida para promover un conjunto de funciones, llevadas a cabo por un colectivo de trabajadores vinculados a relaciones sociales y económicas específicas, que permiten cambios sociales y el desarrollo del Estado en sí mismo. De igual manera, es entendido como un grupo de personas que poseen propósitos comunes, como lo pueden ser los actores sociales: familia, las instituciones educaciones, el gobierno, las instituciones religiosas y el ejército. Se trata entonces, de un sistema integrado en otro de mayor nivel, la cual puede ser 
reconocida como la sociedad en donde se establece. A este respecto, Carreón y Campos (2008) han establecido que las organizaciones se basan en un sistema social integrado por sujetos y equipos laborales que contestan a una estructura específica, dentro de un ambiente controlado por estos de manera parcial, donde se llevan a cabo tareas y ejecuciones de recursos dirigidos a cumplir con objetivos comunes. Tal y como es expresado por Carreón y Campos (2008) en relación a las concepciones de la organización por parte del filósofo Foucault:

La sociedad es -como ya es bien sabido- una sociedad con preeminencia organizacional; ya que por lo general, nacemos dentro de una organización (hospital), consumimos una buena parte de nuestra existencia preparándonos en organizaciones (escuelas), nos ganamos la vida en organizaciones (trabajo), proveemos nuestros distintos bienes y servicios de organizaciones (mercados, tiendas, comercios, etcétera), nos distraemos, divertimos y practicamos la recreación en organizaciones (cines, teatros, deportivos, espectáculos, etcétera) y concluimos, en términos generales, nuestra existencia en una organización (panteón). (Carreón y Campos, 2008, p. 145146).

Como se evidencia en la cita que los autores realizan al respecto de la definición de las organizaciones, se denota que todas instituciones que hacen en vida en la sociedad, constituyen en sí mismas una organización, ya que todas son promovidas con el objetivo de servir al ser humano en el alcance de sus propósitos personales y colectivos, contando además, con una estructura específica que permite el trabajo de los sujetos y su desarrollo. Según Carreón y Campos (2008), estas serían las dimensiones que permiten que las organizaciones transciendan en su quehacer con la gente y para ellos. Ante lo expuesto anteriormente, también es preciso recalcar que las organizaciones pueden pertenecer a un nivel inferior, en donde se ubica la familia como principal representante, hasta los niveles macro, en donde se ubicarían las estructuras con las que cuenta todo Estado, desde los hospitales, escuelas, empresas, hasta constituirlo en toda la extensión del territorio.

Por otra parte, cabe destacar que el objetivo de toda organización es promover la formulación de un ambiente favorable para el desarrollo del ser humano. Por tanto, esta debe concebirse como una herramienta administrativa, en donde los documentos establecidos deben planificarse considerando las aptitudes y destrezas de las personas que laboran en esta. De igual manera, tiene como objetivo principal brindar ayuda para conseguir que los propósitos tengan sentido, así como promover la eficacia de la institución. De esta manera, 
se puede considerar que el objetivo de toda organización está en dividir de manera efectiva el trabajo entre las personas mediante la presencia de una coordinación o ente de regimiento que lidere tal función (Aguilar, 2009).

Ante lo expuesto, Carreón y Campos (2008) señalan que pueden establecerse tres tipos de concepciones acerca de las organizaciones: la primera se denomina 'clásica', debido a que establece la investigación de las tareas que se deben llevar a cabo para alcanzar los propósitos; la segunda, se encuentra relacionada con las función en las asociaciones entre sujetos, en donde la investigación se enfoca en aquello que motiva al ser humano, así como en su comportamiento en el ámbito laboral y social; por último, se encuentra una concepción de la organización basada en términos de sistema, en donde la focalización de la atención va dirigida en las decisiones que pueden ser llevadas a cabo para conseguir los propósitos establecidos (Aguilar, 2009).

\subsubsection{Argumentos políticos}

En cuanto a este punto, es preciso aseverar que el concepto que se maneja de la organización se encuentra vinculada a la idea de que esta propone un bien para todos y de manera equitativa. Por tanto, esta goza de una estatus de tipo simbólico y legal, debido a que la organización suele llevar a cabo los propósitos particulares en el ambiente de la eficacia. El tema principal de las organizaciones ha mutado con el pasar del tiempo, al mismo tiempo que las categorías del mundo actual entre un punto de vista tríadico, ante la heteronomía, así como un punto de vista didáctica, que remonta a la época contemporánea que coloca enfrente a la persona y a la organización. La principal referencia a la organización lleva a hacer énfasis sobre las acepciones de jerarquía, trabajo en equipo, integración y coordinación, en un contexto jurídico, en donde se pretende formular un marco institucional (Pesqueux, 2009).

Por otro lado, Pesqueux (2009) remonta hacia las consideraciones epistemológicas relacionas con el carácter primaria que se otorga a la organización. Comenta que el estudio de las organizaciones promueve la divinización del orden en un punto de vista contrario al desarrollado a través de la historia, que reduce el carácter formal, político e institucional de esta. El hecho de formular organizaciones como entes objetivos, encuentra sus cimientos en el pensamiento de limitarlas a las compañías o de concebirlas como referentes sin importar la pluralidad de sus maneras. Por esta razón, no es sencillo hallar un punto en común entre las micro compañías, las medianas y las grandes, y mucho menos las trasnacionales. 
En otro sentido, aunque es otorgado el término de organizaciones trasnacionales, no se ha formulado una relación, al menos no parcialmente, entre aquellas denominadas Organización de las Naciones Unidas, por ejemplo. Estas constituyen en la contemporaneidad el eje principal del carácter institucional de las organizaciones, como lo es, por ejemplo, las pautas de la Unión Europa o de las sugerencias promovidas por el Banco Mundial (Pesqueux, 2009).

\subsubsection{Argumentos teóricos}

En este sentido, en referencia a los principales autores que hacen referencia a la teoría de las organizaciones, se encuentra en el área de la economía la integración de diversos modelos convencionales, como lo son el modelo de Commons, el cual establece una restitución acerca del concepto de la organización como una actividad integral que maneja el gravamen sobre los activos y pasivos para sí mismo y para el resto. Del mismo modo, se halla dentro de las teorías sociológicas, el análisis de las organizaciones propuestas por Durkheim y Weber (Pesqueux, 2009).Este autor, Durkheim, había establecido su asociación al área de la sociología en donde comienza a fundar una teoría de las instituciones, las cuales actualmente son referencias a las prácticas que se llevan a cabo en áreas como la psicología, pedagogía, psiquiatría, entre otros. En referencia a estas instituciones, se constituyen sobre aspectos estructurales como la rutina, los ritmo de las escuelas, entre otros, las métodos institucionales, de trabajo en equipo, los consejos de educación, todos estos, clasificados como "internos", mientras que, por otro lado, se dispone un sistema de instituciones “externo", los cuales está basado en la constitución de enlaces de intermediación, acompañado de una burocracia interna (Pesqueux, 2009).

Por parte de las teorías contemporáneas de las organizaciones, estas provienen, en gran parte, de los Estados Unidos, a partir de la década de los años 70, en donde se integran una diversidad de corrientes relacionadas con los significados, campos y formas organizacionales desde de un punto de vista institucional. En este sentido, por parte del área económica, se denotan argumentos basados en teorías de las instituciones, vinculadas con los costos, derechos de propiedad, agentes y evolución, desarrollada por autores como Coase, Nelson y Willamson, entre otros. Por otro lado, por parte del área sociológica, se hallan una serie de trabajos de investigación vinculados a los pensamientos provenientes de la sociología 
cognitiva, las investigaciones culturales, la etnometodología, entre otros. Estos estudios enfatizan en los pensamientos más que en las normas, centrando la mayor parte de su atención en los sistemas de creencias en el ambiente de las organizaciones. Entre alguno de los investigadores vinculados con este paradigma, se encuentran: Garfinkel, DiMaggio y Powell, Luckman, entre otros. Para los últimos mencionados, indican que la realidad es una construcción social, netamente humana, y que permite la vida en sociedad entre personas. A raíz de estas posturas, comienza a darse mayor importancia a las cogniciones humanas en la comprensión del surgimiento de las instituciones sociales. Para estos autores, las instituciones serían un conjunto de tipificaciones de actores que a través de sus comportamientos, ejercen funciones importantes en la vida en sociedad. Estos argumentos teóricos se encuentran en la actualidad en oposición a la metodología individualista de la economía, haciendo énfasis en los niveles de la sociedad. A su vez, recalca la importancia de los elementos tanto simbólicos, del pensamiento, como en las representaciones propias de la dimensión normativa, en referencia de la dimensión funcionales de la organización (Pesqueux, 2009).

Desde otro punto de vista de las teorías contemporáneas de las organizaciones, las posturas se centran en el énfasis por el diálogo de la eficacia económica y en la importancia de los sistemas sociales más extensos. Ante esto, los autores Zukin y DiMaggio (2000), comienzan haciendo una distinción entre el ajuste político y cultural, cognitivo y estructural. Las organizaciones estarían entonces con el propósito de generar un desarrollo sostenible, promovido a través de las empresas, así como también proveería de la suficiente sostenibilidad para garantizar el funcionamiento de las instituciones dentro del sistema social. Estos autores afirman que las reglas de las instituciones serían tomadas en cuenta como mitos, y a su vez, serían equivalentes a realidades socialmente establecidas. Son las mismas organizaciones quienes ponen en funcionamiento a las instituciones dentro su propia acepción, entendiendo que estas, se organizan y esquematizan su funcionamiento como una institución, en este sentido las organizaciones garantizan que re perpetúen las organizaciones dentro de una sociedad, generando una especie de simbiosis donde una subsiste dentro de la otra, generando de esta manera, diferentes dinámicas dentro de las mismas, es así como las instituciones logran mantenerse vigentes al pasar del tiempo, son las organizaciones quienes 
se encargan de seguir con el funcionamiento de las anteriores, generando el buen funcionamiento y dándole dinamismo a la sociedad de un país (Pesqueux, 2009).

En este sentido, las instituciones y organizaciones conforman los diferentes entes que ponen el funcionamiento diferentes entidades y aparatos dentro del sector social, en el ámbito económico y hasta político, sabiendo que las diferentes organizaciones que ponen en funcionamiento las instituciones y viceversa, conforman un todo en el haber económico de un nación, generando un entorno propicio o negativo para su desarrollo y crecimiento, a la par con el desarrollo socioeconómico de una sociedad.

A medida que las diferentes entidades en cuanto a organizaciones e instituciones respectan, van creciendo en un sistema dinámico en lo que concierne a lo económico y político mayormente, van interactuando con el mismo, siendo partícipes ambas de la dinámica de este contexto, donde las decisiones tomadas por las instituciones del estado, y su funcionamiento, inciden directamente en las dinámicas y procesos de las organizaciones y viceversa, generando diferentes situaciones, contextos y escenarios dentro de una misma sociedad (Pesqueux, 2009).

\subsubsection{Contextualización de las organizaciones}

En este sentido, es de saber que toda organización funciona en medio de una serie de situaciones y escenarios que pueden resultar beneficiosos o perjudiciales para su crecimiento o desarrollo, todo esto, es el cúmulo de situaciones y contratiempos que se puedan suscitar en un determinado contexto o panorama político, social y económico, el cual, puede determinar, inclusive la existencia y posterior permanencia de una determinada organización, dependiendo de las condiciones dadas en el ambiente directo e indirecto que rodea una determinada entidad social, como lo es una organización (Carreón y Campos, 2008).

Se entiende entonces que existen en cada sociedad, diferentes factores que componen el total que representa el contexto que se desenvuelve de una región o comunidades, sin importar las dimensiones de la misma, entendiéndolo por una determinada zona, región o país, algunos de estos factores corresponden a situaciones más generales, que se encuentran en instancias de incumbencia a nivel naciones o que comprende áreas más extensas que el contexto cercano y directo de la organización. 
En este sentido puede hablarse de dos tipos de contexto, uno que conforman entidades más generales como la economía, la situación sociopolítica de la nación, factores de tipo culturales, comportamentales e inclusive factores religiosos, y de creencias espirituales, también con sistemas legales y normativas en el ámbito legislativo las cuales, representan el entorno de manera generalizada dentro del contexto en el que se encuentra una determinada organización, afectándola de manera externa, es decir, los antes mencionados son factores externos que se encuentran en el entorno indirecto y lejano de una organización (Carreón y Campos, 2008).

Por otra parte, el mimo contexto directo en el cual se desenvuelve una organización presenta ciertas características y factores que implica repercusiones directas y cercanas a la organización, empezando por quienes representan la fuente de materia prima ara las organizaciones, entiéndase por materia prima a cualquier insumo que puede originar el mejoramiento y mantener la producción de una organización que represente un préstamo de bienes, productos y servicios en una determinada comunidad o sociedad. Así como también potenciales clientes o usuarios de sus servicios, del mismo modo existen en su radio de acción más directo otros competidores que ofrecen los mismos bienes, productos y servicios de una organización, y que, en conjunto con los factores mencionados anteriormente conforma el contexto directo de una organización, y componiendo el total de factores que intervienen e influyen en el regular funcionamiento de la misma (Carreón y Campos, 2008).

El contexto de esta investigación se circunscribe en la UNITEC, Desde el inicio de sus actividades formales, en el año 2007, la UNITEC marcó gran influencia en el área de extensión de la Facultad, creando gradualmente múltiples laboratorios que orientan su campo de acción a la utilización de las TICS. Según el documento fundacional, los objetivos generales son:

-Impulsar la aplicación de Normas de Calidad en la Educación en áreas tecnológicas y promover la Gestión de la Calidad Educativa, y

-Abordar cuestiones sobre la posible aplicación actual de las TICS para mejorar la calidad de la actividad docente, su complementación con los medios didácticos tradicionales, no sólo para un mayor aprovechamiento del tiempo, sino para una mejora integral de la enseñanza, que contribuya a formar profesionales eficientes y con alto sentido de la responsabilidad. 
Para ellos, la metodología propuesta para el desarrollo de los objetivos de UNITEC es:

-Llevar adelante tareas de investigación en el área de innovación y mejoramiento de la Calidad en la Educación y entrenamiento en Ingeniería (Educación basada en competencias, evaluación de aprendizajes, barreras al aprendizaje, etc.), incorporándolas herramientas de las Tecnologías de la Información y la Comunicación (TICS).

-Promover desarrollos tecnológicos y asesoramientos a requerimiento de terceros e impulsar tareas de investigación, extensión, asesoramiento y capacitación, basados en los objetivos propuestos.

-Promover y realizar estudios sobre indicadores para el mejoramiento continuo de la Educación en Ingeniería.

-Fomentar actividades de transferencia de conocimientos, a través de la capacitación y formación de los miembros de la UID en temas relacionados con las TICS aplicadas a la Educación, otras Tecnologías y al Aseguramiento de la Calidad.

Para el logro de sus objetivos, la UNITEC cuenta con un plantel de profesionales de diferentes disciplinas: Ingeniería y varias de sus ramas, Ciencias Exactas, Humanidades, Ciencias de la Educación, Pedagogía, Especialistas en Educación Especial, Psicología, Trabajo Social, Derecho, Ciencias Económicas, Bellas Artes, Entre otras. Actualmente coexiste el trabajo de aproximadamente 50 personas.

\subsubsection{Tipos}

Existen, en este sentido, diferentes tipos de organizaciones dependiendo de los niveles de actividad que se manejen en el entorno tanto directo como indirecto que contemple el contexto en el cual se desarrolla, funciona y labora una organización, el cual puede presentarse igualmente de dos maneras, de las cuales, cada una determinará ciertas características de una organización, dependiendo en qué contexto se encuentre y la dinámica de su funcionamiento, $\mathrm{y}$ el de sus diferentes instituciones $\mathrm{y}$ principales organismos (Pesqueux, 2009). 
Es así como existen dos tipos de organizaciones, en dos tipos de entornos diferentes, calificándolos, como se explicó anteriormente basándose en la dinámica del sistema y el contexto directo y universal donde se encuentre en funcionamiento una determinada organización; la primera se conoce por ser más estable, donde se maneja un modelo de estructura siendo relacionada con muchos con la burocracia propia de estos sistemas, presentando características más estables. Por otra parte, se presenta otro tipo más dinámico, donde se proponen nuevas estructuran en cuanto al modelo y sistema organizacional, se presentan estructuras más horizontales y participativas (Pesqueux, 2009).

\subsubsection{Enfoques}

En referencia a este punto, cabe destacar la presencia de un conjunto de enfoques que en la teoría de las organizaciones se han desarrollado. El primero de estos, es el denominado enfoque sistémico, en el cual se ven implicados fenómenos y objetos que no pueden ser separados, sino que deben observarse como parte de una unidad. Por tanto, no se encuentra representada por la suma de los elementos, sino como la integración de estos que se hallan en constante relación, de manera conjunta, que genera nuevas características distintas, cuyo producto es superior al de los elementos que lo constituyen. Desde la filosofía, este enfoque se fundamenta en la categoría de lo macro y lo micro, es decir, del todo y de los elementos que lo constituyen, y se halla sustentado teóricamente en las acepciones acerca de la unidad material. En este punto, es importante definir lo que significa un sistema, considerado como un conjunto de unidades vinculadas entre sí, que trabajan de manera coordinada y esquematizada en pro de conseguir un objetivo preestablecido. (Zukin y DiMaggio, 2000).

Por otra parte se muestra la teoría de las relaciones humanas, las cuales responden a las necesidades de los individuos que componen a una organización y los diferentes grupos en los cuales esta se subdivide. Del mismo modo se encuentre el enfoque relacionado con la teoría burocrática descrita anteriormente sobre, las estructuras verticales y organizadas donde se basan en un sistema de subordinación de diferentes puestos y cargos los cuales desempeñan labores específicas bajo una dirección jerárquica. Otro enfoque, más de tipo funcional, propone una manera estratégica de funcionamiento, donde cada uno de los miembros forma parte de una planificación específica para cada función o cargo específico. Por otro lado, se presenta un enfoque científico que se refiere al crecimiento y desarrollo 
intelectual e investigativo del personal de una organización, generando nuevo conocimiento y estrategias organizacionales (Zukin y DiMaggio, 2000).

\subsubsection{Aplicabilidad en la Sociedad}

Al entender el funcionamiento de las organizaciones se puede inferir sobre su aplicabilidad en las sociedades, ya que son las mismas quienes ponen en funcionamiento la vida social, económica, política y cultural de un país, siendo la misma sociedad organizada quien manifieste su institucionalidad a través de sus distintas organizaciones, así como también en los productos, bienes y servicios que las mismas ofrecen como parte de su aporte al desarrollo y crecimiento de la sociedad de una nación.

\subsubsection{Institución y organización}

Existen en la sociedad, entes organizados que rigen ciertas actividades, costumbres, normativas y estructuras sociales a través de las cuales, la sociedad puede funcionar como un organismo sistematizado, coherente y estructurado, teniendo como base o hilo conector estas entidades $\mathrm{u}$ organizaciones que se encargan de establecer de manera coordinada las pautas a seguir por algún sistema social, desde el aspecto cultural, religioso, político, económico, social, educativo, entre otros, cada uno de estos aspectos de la sociedad, es regido o representado por una institución que regula y organiza sus funciones de acuerdo a los objetivos que se buscan dentro de cada uno de los factores antes mencionados.

Esto, tiene relación con lo expuesto por Gómez y Castillo (2004), con respecto a la acepción social que se tiene sobre el concepto de institución, donde se reflejan las diferentes ideas y acepciones con las cuales se relaciona comúnmente este término, en lo expuesto por estos autores se puede evidenciar como, al momento de consultar con el ciudadano común sobre el concepto de institución, el mismo hará referencia a ámbitos sociales como el Estado, la educación, las religiones, e inclusive el matrimonio, entendiendo el sistema, muchas veces percibido como político y relacionado con la burocracia, que rige una sociedad.

En este sentido, otros autores llevan la definición de institución a una acepción inclusive mucho más amplia que lo común, refiriéndose no solo a las organizaciones sociales, sino que se convierten en pautas sociales, impuestas, adquiridas o manifestadas de forma natural y espontánea dentro de una sociedad, de esta manera, se entiende como institución a 
"sistemas de reglas sociales establecidas y extendidas que estructuran las interacciones sociales. El idioma, el dinero, la ley, los sistemas de pesos y medidas, los modales en la mesa, las empresas (y otras organizaciones) son todas instituciones" (Hodgson, 2011, p. 22).

\subsubsection{Procesos dentro de las instituciones y organizaciones}

Es así como puede observarse la relevancia social que tienen las instituciones; éstas, están arraigadas en los más profundo de la sociedad, en sus costumbres y modales, factores que son resultantes de su cultura e idiosincrasia, que determinan inclusive su comportamiento y la forma de dirigirse unos a otros. Las instituciones son entonces un referente dentro de una determinada sociedad que se considere estructurada desde sus cimientos. En este sentido, sería necesario entender los procesos y sistemas internos de una institución, ya que, a través de la misma se puede inferir sobre ciertos patrones de una sociedad, entendiéndolas como estos sistemas que yacen en los orígenes de la misma, y que, de cierta forma, estos procesos pueden describir estos mismos sistemas sociales, su cultura y la forma en cómo funciona una determinada sociedad.

Otros autores se remontan al origen de las instituciones, entendiendo que las mismas surgen de las ideologías; como se explicó anteriormente, las instituciones se encuentran en distintos ámbitos de una sociedad, inclusive en modales, costumbres sociales y demás componentes arraigados en la sociedad, por lo tanto, los mismos están asociados a ideologías, o formas de pensar de una determinada sociedad y su población. Del mismo modo puede observarse como otros autores, explican la institucionalización y su relación con las organizaciones, las cuales tienen su punto de vinculación donde se encuentra la institucionalización de las organizaciones, ya que el proceso tiene que ver con arraigar una cultura e ideología organizacional mientras se genera una institución con sus propias creencias, convicciones y fundamentos, así como en lo social, las instituciones yacen en las costumbres y la cultura de una sociedad.

Es necesario aclarar que comúnmente se hace referencia a las instituciones como organizaciones, sin embargo, si bien se tienen a relacionar estos dos conceptos, los mismos resultan diferentes y en ciertos puntos, contrastantes, ya que, si se entiende una institución como un conjunto de pautas, normativas y estatutos que hayan surgido de manera natural, 
impuesta o adquirida, las organizaciones resultan ser entidades estructuradas, donde cada parte que la compone desempeña una función, funcionando con un objetivo determinado, bien sea impuesto o que surja de las diferentes partes que la componen.

En relación con lo anteriormente expuesto, las organizaciones funcionan gracias a los esfuerzos y diferentes actividades que realizan los individuos que la componen dentro de la misma organización, estos esfuerzos y actividades resultan en el logro de los objetivos de las mismas, que terminan estando intrínsecamente ligados al beneficio de las comunidades, de la sociedad en general, y aportan al desarrollo y funcionamiento de un país o región.

Así mismo, se puede observar como diferentes organizaciones funcionan en una sociedad, entendiéndose como un grupo de individuos con un mismo fin, la iglesia, las escuelas, familias, el gobierno, entre otros, son organizaciones; individuos que, de manera coordinada y estructurada trabajan con un mismo fin, generando un impacto en la sociedad a la cual pertenecen, respondiendo e interactuando con la misma. De esta manera, las organizaciones terminan siendo un ente participativo, que interactúa en su entorno social, respondiendo a su contexto social, político, económico y cultural, influenciando en el mismo y siendo influenciado por este, ya que sus condiciones, repercuten en el comportamiento organizacional de sus miembros, oportunidades y amenazas para su funcionamiento, desarrollo y crecimiento.

\subsubsection{Diferencias y semejanzas}

En este sentido, se pueden encontrar diferencias y semejanzas entre los conceptos de institución y organización, e inclusive, se puede hace referencia a puntos de encuentro en estas dos, ya que de manera conjunta se complementan una a la otra en ciertos aspectos inherentes a la estructura y al funcionamiento de cada una, dado que en la organización puede existir la institucionalización, y en la institución se requiere organización, se entiende así como puede existir confusión al momento de pensar que ambas, son lo mismo, sin embargo, debe entender a las instituciones y organizaciones como entes individuales aunque una yace en el intrínseca en la otra.

Es así como, existen aspectos de la institución necesarios en la organización, la segunda, necesita pautas, normativas, estructura, planificación e inclusive una cultura e identidad institucional para su funcionamiento; es así como se habla de institucionalización 
de las organizaciones, y como la primera, aporta desde su naturaleza cultural y social, una serie de pautas, estatutos y esquemas en distintos ámbitos que le dan orden y estructura a las organizaciones, las cuales, terminan siendo un grupo de individuos que comparte un fin, sin embargo, con la contemplación de la institucionalización, las organizaciones pueden trabajar de manera coordinada, más precisa y sistemática, respondiendo a sus intereses, objetivos propios y a objetivos sociales que se haya trazado.

Por otra parte las instituciones, entendiéndolas por su naturaleza social y cultural, no irían más allá sin un grupo de individuos organizados que se unan en pro de objetivos en común, nutriéndola y desarrollándola como un ente organizado y estructurado que funciona gracias a la participación de diferentes miembros que hacen posible su desarrollo y crecimiento; de esta manera, si las instituciones no contemplan un sentido más organizacional de sí mimas, pueden no dejar de existir, sin embargo su crecimiento y establecimiento de manera social no sería tan compleja como para erguirse de manera prolongada y su impacto en la sociedad podría verse limitado por la falta de adeptos y miembros que pongan en marcha su funcionamiento

Se entiende entonces, como ambas provienen de una naturaleza de origen cultural y social, sin importar si sus intereses son económicos, religiosos, políticos, educacionales, entre otros, de igual manera la institucionalización aporta cultura, identidad y estructura a las organizaciones; y las organizaciones aportan el capital humano, y participativo a las instituciones, teniendo siempre en cuenta que no deben entenderse como la misma idea, ya que la diferencia estará en el origen de su concepción y formación, en sus objetivos y en la forma en cómo, la interacción con su entorno social, haya incidido en la noción de sus comienzos.

Es así como, ambas, instituciones y organizaciones, afectan directamente en el funcionamiento de una sociedad, ya que, ambas, provienen de la misma y responden a diferentes aspectos culturales y al contexto político, social, cultural y económico de la misma, así mismo, se suma el hecho de que, ambas pueden participar en el intercambio de bienes y servicios, entrando en el aparato económico del país, produciendo tanto beneficios a nivel social, como traduciendo esto en ingresos económicos para sus diferentes miembros; esto dependerá de la naturaleza y los servicios y objetivos de las mismas, entendiendo que pueden 
ser concebidas también como empresas, de origen económico y que basen sus funciones en la obtención de beneficios materiales o inmateriales para sí mismas y para la sociedad.

Existen, del mismo modo, diferencias entre estas dos, instituciones y organizaciones, sin embargo las mismas tienen relación con lo referente a los proceso tanto de producción como de funcionamiento, mientras unas presentan funciones y actividades más esquematizadas, las otras son más abiertas a funcionar de diferentes formas, permiten la interacción y el trabajo en conjunto de manera horizontal, entendiendo el sistema organizacional como un trabajo en equipo y participativo, donde los miembros representante de cada una de las áreas que componen una organización realiza un aporte significativo tanto en la dinámica de trabajo como en la toma de decisiones.

En este sentido, las instituciones son aquellas que muestran una estructura más esquematizada, en su mayoría, proponen organigramas verticales y se basan en un sistema de jerarquías de mando, tales como la iglesia, o las fuerzas armadas de un país, donde existen rangos superiores y un sistema de jerarquías inferiores que se despliegan de la misma, estableciendo cadenas de mando, sistematizando su funcionamiento de manera estructurada donde los miembros que la componen tienen poca o ninguna participación en la toma de decisiones.

Por otra parte, las organizaciones, al ser conformadas por un grupo de miembros, que establecen un equipo, muchas veces multidisciplinario, se ven nutridas por cada una de sus partes, donde existen sistemas de funcionamiento más horizontales, ya que, si bien puede existir una jerarquía de cargos, la participación de todos sus miembros es crucial para la toma de decisiones de la organización, por ejemplo; existen organizaciones sin fines de lucro, en las cuales, los diferentes miembros que la componen, muchas veces en calidad de voluntarios, participan activamente y emprenden proyectos sociales dentro de las mismas organizaciones, basados en sus experiencias y preparación académica; es necesario enfatizar que no se hace referencia a la carencia de una estructura en las organizaciones ya que, si existe tal estructura en estos grupos, sin embargo lo resaltante yace en sus procesos y la forma en como estos hacen funcionar la misma de manera más abierta, horizontal y participativa.

Puede entonces apreciarse como las instituciones y las organizaciones poseen cosas en común, ya que, la naturaleza de las mismas es de origen social, teniendo su punto de partida unas, en pautas, costumbres y normas sociales, nacidas de forma espontánea o adquirida, las 
mismas pueden ser una influencia directa al momento de formar una organización, ya que sus miembros se pueden ver directamente afectados por estas mismas pautas y normas sociales para organizarse como un grupo o equipo de trabajo con un objetivo. Del mismo modo, ambas poseen objetivos sociales, siendo la meta de todas, el aportar bienes y servicios a la sociedad, ayudando al desarrollo económico, social, cultural e inclusive en cuanto a la mejora de los niveles de calidad de vida de las comunidades dependiendo de los objetivos específicos de la institución u organización, ambas, si bien pueden no tener objetivos específicos en el ámbito social, aportarán con su trabajo a la dinámica económica y al funcionamiento del país, ya que son estas mismas, instituciones y organizaciones quienes hacen funcionar estas dinámicas, entendiendo que son quienes hacen vida en pro al desarrollo, funcionamiento y crecimiento del mismo de diferentes ámbitos.

\subsubsection{Instituciones Sociales y Organizaciones}

Si bien, hasta el momento, se ha explicado a las instituciones como un conjunto de normas, y pautas a seguir, sebe tomarse en cuenta no son sólo éstas pautas las únicas necesarias para que se establezca una institución como tal. Es así como éste término se puede extender aún más en su acepción, entendiendo que una institución, más allá de su normativa y pautas de comportamiento, es su estructura y sus estatutos, se compone también del equipo de personas que forman parte de ella, quedando esto establecido de manera permanente, a través de instancias sociales. Su identidad y cultura institucional, al quedar estipuladas de manera perenne, son las que dan, en conjunto con lo antes mencionado, existencia a una institución. Es así como, se da garantía de la existencia de las instituciones aún sin las personas que las componen, y más allá de su funcionamiento activo, por ejemplo instituciones estadales, o empresas de naturaleza meramente económica, entidades de préstamo e intercambio de bienes y servicios, u otras instituciones más complejas en su estructura y comportamiento institucional, los gobiernos monárquicos y en general, en este sentido

Definir las instituciones como un comportamiento nos llevaría al error de presuponer que las instituciones no existirían si los comportamientos asociados a ellas se interrumpieran. ¿A caso la monarquía británica deja de existir cuando los miembros de la familia real están dormidos y no ocurre ninguna ceremonia real? Por supuesto que no: las prerrogativas y los poderes reales continúan, incluso cuando no están siendo ejercidos. Estos poderes, y no los comportamientos, son los que significan que la institución existe (Gómez y Castillo, 2004, p.23) 
De esta manera se entiende a la institución social, más allá de sus normativas y funcionamiento, de su comportamiento y cultura organizacional, en este orden de ideas, se puede asumir una acepción mucho más amplia del concepto de institución, llevándola a niveles más extensos y generales; se puede asumir entonces que una sociedad es una institución, o bien se puede entender a una institución como una especie de estructura social, tal como lo explica Wells (1970), muchos otros autores coinciden con este postulado.

Por otro lado, las organizaciones, como grupo estructurado también pueden relacionar su significado con el de la sociedad, ya que, su población puede verse como cada uno de los integrantes que la componen, unidos por un mismo objetivo que responde a interesas particulares de cada una de las partes del grupo como bien, puede responder a beneficios comunes, como el desarrollo social, el crecimiento económico y cultural y hasta la mejoría de la calidad de vida de cada uno de los sectores que compongan esa sociedad u organización.

Se puede evidenciar, en este sentido las diferencias y relaciones que existen entre instituciones y organizaciones, teniendo en cuenta la naturaleza de las mismas, y entendiendo sus estructuras y comportamiento, así como también los diferentes procesos a través de los cuales se logra el funcionamiento de cada una, así mismo, se puede evidenciar como cada una de las antes mencionadas, forman parte de la vida diaria de una sociedad, y de un país, sabiendo que éstas son de origen social y que responden a las circunstancias de un entorno que interactúa constantemente con éstas, de momentos, nutriéndolas y ofreciéndoles un panorama propicio para su crecimiento y desarrollo o presentando condiciones adversas que perjudiquen el funcionamiento de ambas.

Es vital que se entienda la importancia y relevancia que tienen las instituciones y organizaciones dentro de una sociedad o país; ambas, son un reflejo del comportamiento y las características intrínsecas de esa misma sociedad de la cual provienen y que propicia la creación de ambas; el conocimiento de las características de su funcionamiento permite comprender como éstas pueden contribuir al desarrollo y crecimiento de una sociedad desde diferentes puntos de vista, en diferentes aspectos, generando soluciones a las problemáticas sociales, o bien contribuyendo con el desarrollo socioeconómico del país a través del intercambio de bienes, productos y servicios. 


\subsubsection{Concepciones teóricas acerca de organizaciones e instituciones}

\subsubsection{Las organizaciones como objeto de estudio}

El entendimiento de las organizaciones como objeto de estudio y de los administradores como sujeto, es aún poco profundo en los países subdesarrollados. El estudio epistemológico de las organizaciones resulta fundamental como aporte teórico-práctico para los individuos de cualquier sociedad, debido a que en la modernidad el contacto con las instituciones y organizaciones es un hecho inevitable y necesario para poder desenvolverse adecuadamente en el contexto globalizado de hoy en día. (Carreón y Campos, 2008)

En tal sentido, los individuos no pueden escapar de la influencia de las organizaciones y sus respectivas acciones, estos entes con sus características de mayor o menor burocracia, autoridad, distribución de poder y modelos para alcanzar la eficacia, tienen resultados que impactan directamente el contexto en el que se desenvuelven tanto en el aspecto ambiental, social e inclusive político de los países.

Actualmente, las personas deben interactuar de forma directa o indirecta con organizaciones de distinta índole; religiosas tales como la iglesia; políticas, que incluyen los diferentes partidos que hacen vida en la sociedad y, económicas que incluyen todas aquellas compañías orientadas al lucro a través de la producción de bienes y servicios orientados a satisfacer las necesidades humanas innatas o creadas. Además existen organizaciones que solapan diferentes índoles o intereses, de tal forma que se evidencian las de tipo sociopolítico, como el Estado y las socio-económicas que incluyen emprendimientos sociales que buscan satisfacer necesidades o carencias optimizando costos para ofrecer precios que beneficien a la sociedad y satisfagan sus necesidades de lucro. (Carreón y Campos, 2008)

En cuanto a la dinámica y estructuras inherentes a las organizaciones y estudiada desde una perspectiva epistemológica, Chanlat (1994) afirma que estos sistemas sociotécnicos están conformados por elementos innatos que se relacionan al conflicto y las tensiones derivadas de la contraposición de intereses de los diferentes actores que tienen vida dentro de las mismas. Dicho de otra forma, dentro de las organizaciones existe una puja constante y continua de diferentes fuerzas que buscan imponer sus objetivos y agendas. Sin embargo, existen otros aportes que sugieren lo contrario, es decir, que las organizaciones son sistemas en los cuales se busca la homeostasis, el equilibrio y por tanto, el conflicto es solo tomado en cuanta cuando incluye problemas que pueden ser resueltos. 
De hecho, siguiendo a Carreón y Campos (2008) existen otras corrientes neopositivistas que plantean a las organizaciones desde una perspectiva reduccionista y simplista a través de la cual se proponen recetas constituidas de un conjunto de pasos que permiten gerenciar las organizaciones desde la excelencia. Estas teorías por lo general colocan el estudio de las organizaciones desde una perspectiva trivial, por medio de la cual no se lleva a cabo un verdadero análisis de las mismas y de su inherente complejidad, y por el contrario se proponen fórmulas que no plantean el conflicto y las contradicciones como parte de la ecuación.

\subsubsection{El poder y la dominación dentro de las organizaciones}

Entendiendo la complejidad previamente planteada, por medio de la cual se propone que las organizaciones son sistemas sociales y técnicos de inherente conflicto y tensión, resulta válida mencionar la visión de Max Weber de las mismas. Weber entendía la dominación y el poder como elementos necesarios para gestionar el conflicto y la complejidad a lo interno de las organizaciones. En tal sentido, el poder se instaura dentro de ellas y posteriormente se implanta la dominación la cual es legitimada y aceptada por todos los miembros de la misma de forma racional, es así que se vuelve tarea del cuadro administrativo gestionar los elementos weberianos propuestos. (Weber, 1997)

En tal sentido, es tarea de la administración promover todas las acciones de gestión organizacional para que los procesos fluyan de una manera efectiva. Sin embargo, la realidad es que la administración en general cumple un rol ambiguo en cuanto a la dominación, ya que ha faltado mayor sincronización de esfuerzos y voluntad política para la toma de decisiones gerenciales en diversas instancias.

\subsubsection{El poder y la dominación de acuerdo a Michel Foucault}

Los conceptos de poder y dominación han sido acaparados desde un punto de vista teórico por la teoría Marxista. En tal sentido, el marxismo es la corriente ideológica y política que ha atraído mayor atención hacia tales conceptos en el marco de la sociedad industrial y capitalista; este enfoque propone que la mayoría de los procesos de trabajo están sometido a fuerzas y actores que se caracterizan por ser unos los dominantes y otros los dominados. La clase dominante hace referencia al grupo que tiene control sobre los medios de producción y 
que gracias a su poder económico puede ejercer también influencia y control sobre la clase proletaria (los dominados) que deben vender su fuerza de trabajo a los capitalistas). (Poster, 1991)

Sin embargo, pese al evidente acaparamiento de la teoría marxista de las concepciones de poder y de dominación, también han surgido otros enfoques que no se centran únicamente en el análisis del poder desde el proceso de trabajo teniendo como punto focal las tecnologías de poder predominantes, por el contrario surgen autores como Michel Foucault quienes proponen dichos conceptos desde un punto de vista más crítico y haciendo referencia a otras prácticas distintas a las ya mencionadas por Marx (en el contexto de la sociedad industrial).

En tal sentido Foucault plantea que existen otras formas de dominación y de subyugación que se presentan en el marco de las relaciones sociales a través de distintas prácticas que abarcan ámbitos de la vida humana como la sexualidad y el castigo dentro de las prácticas de parenting. Aunque también, el autor plantea sus conceptos de dominación y subyugación dentro de las relaciones laborales en el marco de las sociedades capitalistas e industrializadas. (Foucault, 1980)

El análisis de Foucault del poder también se relaciona con las estructuras relativas a la diseminación y transmisión de conocimiento. El autor plantea que el sistema escolar surgidos en el siglo XIX no son más que una forma a través de la cual el Estado identificó y diseño una estructura de poder y dominación sobre los jóvenes estudiantes quienes deben someterse a un conjunto de normas y de disciplina en general que funciona como corset de control de los niños y jóvenes de las sociedades. Es decir, que la educación se creó no solo con la finalidad de satisfacer una demanda social por parte del Estado, sino también para gestionar los procesos y prácticas disciplinarias de control y dominación. (Foucault, 1980)

En términos más específicos Foucault define el poder como una forma de represión. Represión en el sentido de que se frenan o moderan a diferentes niveles, pudiendo ejercerse poder sobre los animales, la naturaleza y por su puesto a los individuos, bien sea a través de una clase social determinada o a la persona per se. El poder entonces se manifiesta dentro de las relaciones de todo tipo, sin embargo Foucault propone superar la visión reduccionista a través de la cual se concibe al poder únicamente dentro de las relaciones laborales, de explotación y alienación capitalista. 
El término poder además de la represión se centra también en una continuación de la guerra de forma pacífica o silenciosa a través de la cual se presenta una lucha de fuerzas entre actores con una relación asimétrica tanto de intereses como de medios para satisfacerlos. El poder busca entonces fortalecer las sutilezas de las fuerzas desiguales que intervienen en los distintos aspectos de la sociedad incluyendo el ámbito organizacional. (Ceballos, 1994).

Empleando el aporte teórico de Foucault al ámbito organizacional se puede llevar a cabo el análisis del concepto de poder disciplinario. La implantación del poder disciplinario a lo interno de las empresas lleva a que los empleados cumplan con una serie de funciones y obligaciones que permitan evitar amonestaciones o refuerzos negativos dentro del ámbito laboral. De tal forma que dentro de las organizaciones se da un tipo de poder disciplinario que generalmente está implícito y que es inherente a la naturaleza más o menos burocrática que puede tener la organización.

En tal sentido, Foucault propone que dentro del marco de la sociedad capitalista existe un sistema de dominación que a micronivel plantea nuevas formas de organización del trabajo o de especialización del mismo que promueve el poder disciplinario en el marco de la productividad y la eficiencia de los trabajadores. El poder y la dominación se evidencian en un sistema en el que los colaboradores desarrollen una mentalidad orientada al cumplimiento de las normas y al logro de la eficiencia dentro de lo establecido en la estructura organizativa. (Ceballos, 1994)

En síntesis se puede comprender la teoría foucaultiana entendiéndola como un aporte que observa al poder desde diferentes aristas y como un elemento transversal que se encuentra presenta en todas las relaciones sociales en diferentes ámbitos incluyendo el estatal, laboral y educativo. El poder se presenta a través del uso de un conjunto de estrategias y técnicas orientadas a buscar controlar a las personas en diferentes ámbitos, en tal sentido, el rol de los administradores consiste en el uso de esas estrategias para lograr legitimidad en el poder organizativo. (Carreón y Campos, 2008)

\subsubsection{El enfoque de Bourdieu y su entendimiento de los sistemas de dominación}

De acuerdo con el enfoque de Bourdieu la dominación dentro de las sociedades se mantiene gracias a la transmisión de los valores culturales a cada una de las clases sociales existentes. Uno de los medios a través de los cuales se garantiza la transmisión y perpetuación del sistema de dominación es gracias a la educación, ya que en la escuela se transmiten una 
serie de acciones orientadas a inculcar la cultura dominante y las diferentes relaciones de poder, lo que por ende contribuye a perpetuarlas. (Castillo, 2012)

De tal forma que a través de las distintas estrategias pedagógicas utilizadas por los educadores se transmite la cultura dominante como si esta se tratara de un sistema inmutable de valores y de relaciones de poder, lo que a su vez contribuye a la alienación en términos marxistas y a un proceso de socialización que promueve el poder y la dominación de una clase sobre otra. (Castillo, 2012)

Dentro de la educación y de la estructura organizativa de los centros educativos que cumplen tales fines se refleja una conformación estructural para la dominación y el control social de los individuos sometidos a la misma. En tal sentido, los agentes de socialización conformados por organizaciones como el Estado y la escuela, aunque también la familia, contribuyen a enmarcar las conductas dentro de una serie de reglamentaciones, normas y códigos que las restringen y reprimen en base a los establecido. (Apple, 1987)

Es así que dentro de los sistemas y organizaciones y particularmente con aquellas organizaciones de corte educativa, diferentes grupos sociales intentaran imponer sus intereses a través de una serie de reglamentaciones implícitas o explicitas que garanticen la reproducción de valores de una cultura en la que un grupo social prevalece sobre otro.

Además, Bourdieu (2009) plantea que las instituciones educativas de la modernidad reproducen una serie de relaciones de dominación dentro de la sociedad. En tal sentido, las instituciones educativas se transforman, de acuerdo con este autor en espacios donde se presenta la pugna de intereses de diferentes grupos sociales y su diferenciación de acuerdo a sus niveles de poder y autoridad que reflejan la sociedad en cuestión.

La escuela es entonces un espacio que imita o reproduce la conformación social moderna en términos de relaciones de poder de tipo simbólico que tienen como principal fin mantener y conservar el orden establecido. Dentro de los centros educativos se presentan a micronivel una serie de procesos que ponen de manifiesto la complejidad de las relaciones sociales y la búsqueda de conservación de la autoridad por parte de unos grupos, mientras que otros desarrollan simultáneamente una conciencia de clase o de grupo en términos marxistas. (Bourdieu, 1996) 


\subsubsection{La perspectiva de Castoriadis sobre las instituciones}

Castoriadis propone en su análisis sobre las sociedades que estas se construyen y se alteran a sí mismas. Es decir, no se presenta el ensamblado de elementos que son prefabricados sino que cada uno de los elementos son definidos y creados por la sociedad en cuestión, y a su vez, se debe comprender que la sociedad es entonces una institución autónomamente construida por sus miembros en un proceso bidireccional que contribuye a las características y valores de sus individuos y a los elementos propios de tal sociedad. (Castoriadis, 2007)

El análisis socio-histórico propuesto por el autor facilita la comprensión de que las sociedades y las instituciones que hacen parte de ellas, no son inalterables o inmutables, por el contrario atraviesan un proceso de constante auto-alteración que se da con una velocidad tal que permite que este sea casi imperceptible para los individuos que la conforman.

En tal sentido, las instituciones son creadas en el imaginario social por el anónimo colectivo a través de las cuales se conforman una serie de elementos y significaciones específicas que permiten dar sentido y propósito a las mismas y ser aceptadas por los miembros que hacen vida dentro de la sociedad. Para la creación de dichas instituciones y organizaciones sociales hacen falta dos elementos fundamentales a los que debe atenderse; en primer lugar, las restricciones externas, que se refieren a las condiciones biológicas inherentes a los individuos y a la naturaleza misma que imponen restricciones si se pueden llamar triviales a la conformación de estructuras e instituciones dentro de la sociedad. (Pérez, 2011)

También se presentan dentro de las restricciones externas, las condiciones históricas, y esto se debe tomar en cuenta ya que ninguna sociedad emerge de la nada; es decir, en general existen una serie de elementos históricos que condicionan la conformación de las organizaciones sociales y de las instituciones que se erigen en una sociedad en cuestión. Esta interpretación y reconstrucción del pasado forma parte de la conciencia colectiva de tales sociedades y permite la conformación de una serie de instituciones características en función de su tradición particular.

De igual forma, se presentan también las condiciones o restricciones intrínsecas, que se consideran menos triviales y más interesantes de analizar. En tal sentido, las instituciones sociales deben contar con coherencia, es decir, debe existir una relación de conformidad entre 
los individuos debidamente socializados, las actuaciones de la sociedad en su conjunto y de las instituciones que en ella tienen lugar. En pocas palabras, dichas acciones deben estar basadas en una autoridad legítima bien sea gracias a la religión o a las leyes, pero que en términos finales promueva la conformación y aceptación de los miembros de la sociedad de tales acciones. (Pérez, 2011)

Es importante resaltar como apunte final que, la coherencia de dichas sociedades, no implica que en ellas no se presenten luchas internas o situaciones de conflicto o tensión. De hecho, de acuerdo a Castoriadis las sociedades feudales o esclavistas pueden ser consideradas coherentes pese a la lucha de poderes que allí se presenta y la distinción de clases de dominantes y dominados.

\subsection{Planificación, diagnóstico y gestión}

De acuerdo con la Unidad de prácticas y producción de conocimientos (2008) destaca que cuando se planifica no solo se deben identificar problemas y potencialidades que permitan diagnosticar una realidad a intervenir sino que se debe visualizar un lugar a futuro al cual se debe llegar con esfuerzo y dedicación. Se deben trazar las líneas necesarias para poder transformar la situación problema y lograr el camino correcto que permita el cumplimiento de los objetivos establecidos.

Según la Unidad de prácticas y producción de conocimientos (2008) en su módulo de planificación señala que no todo el tiempo los problemas de los proyectos se logran desde una perspectiva económica, pues muchas veces se pueden disponer de todos los fondos necesarios pero no se logra articular una organización perfecta que genere resultados definitivos. Es por ello que se hace muy necesario analizar los problemas desde una perspectiva holística, amplia y generalizada, no desde un solo punto de vista, pues hay diferentes posiciones y alternativas de solución que se deben analizar simultáneamente para conseguir la solución y demostrar la viabilidad de la propuesta.

De tal manera, que la Unidad de prácticas y producción de conocimientos (2008) establece que se deben considerar las siguientes viabilidades para la puesta en práctica de un proyecto de planificación.

-La factibilidad económica. Este apartado se refiere a la planificación financiera del proyecto, buscar las vías de financiamiento, la administración eficiente de los recursos 
disponibles, la articulación de los esfuerzos del capital humano, la organización de los recursos materiales para su optimización, entre otros.

-Viabilidad política. Esto tiene que ver con la capacidad organizativita, las relaciones interinstitucionales, la capacidad de gestión, de liderazgo organizacional y llevar a cabo lo planificado con su respectiva supervisión y control, es decir la habilidad parta tomar decisiones racionales en un momento determinado.

-Viabilidad social y cultural. Esto se relaciona con el apoyo que pueda existir en la comunidad o la sociedad en general. Es decir, si el proyecto beneficia a un colectivo, mientras más apoyo exista por parte de diferentes actores, mayor es la viabilidad social y cultural lo que permitirá mayores probabilidades de ejecutarse con éxito.

Es necesario que el equipo de planificación logre articular y trabajar de forma mancomunada buscando la manera de hacer viable el proyecto desde todas las aristas. Para ello es importante el proceso de comunicación organizacional, el liderazgo, la visión prospectiva y la evaluación constante de las decisiones generadas sobre la base del consenso.

De esta manera toma relevancia el concepto de gestión. De acuerdo con la Unidad de prácticas y producción de conocimientos (2008) la gestión se centra en la generación de criterios para la toma de decisiones racionales en un momento determinado. Se busca que con esas decisiones se logre articular la organización y se fomenten trasformaciones profundas en el estado de cosas. De acuerdo a dicho manual la gestión se refiere a la forma en la que se generan objetivos, se organizan las actividades, se fomenta la articulación de los esfuerzos y se proyectan los recursos disponibles, ya sean técnicos, financieros y humanos en el logro de los objetivos. La gestión se refiere a la toma de decisiones en el camino, paso a paso, analizando el contexto en tiempo real.

Para la Unidad de prácticas y producción de conocimientos (2008) la gestión se enmarca en el proceso de desarrollo del proyecto, se inicia con la conformación del equipo de trabajo, su articulación, la formulación de los objetivos, el análisis de los recursos disponibles, su ejecución, supervisión y evaluación en el proceso a fin de tomar las acciones correctivas necesarias.

Es por ello que el manual citado establece que el proceso de gestión no está aislado del proceso de planificación, incluso de ninguno de los momentos del proceso administrativo, puyes en todas las fases se deben generar estrategias para la consecución de los objetivos. Es 
necesario resaltar que la gestión es parte resultante del proceso de diagnóstico y de la planificación del proyecto de ahí que la gestión se enmarca en la forma que se le debe dar al proyecto en formación.

Así que, en el proceso de planificación se deben generar las estrategias, objetivos, procedimientos, normas, actividades y tareas, y en la gestión se ejecuta operativamente todo lo planificado articulando los esfuerzos para lograr lo planteado, supervisando, evaluando, corrigiendo en el proceso y generado trasformaciones. La gestión es una acción, es darle vida al proyecto en la vida real, paso a paso hasta lograr todo lo formulado y decidido en la fase de diagnóstico y planificación.

Los procesos de planificación, gestión y diagnóstico de la comunicación han resurgido ante la necesidad de evaluar todas las estrategias y sistemas dentro de las instituciones educacionales como las universidades, para así colaborar a la efectividad de sus actividades, el cumplimiento de sus objetivos y la mejora continua en sus calidades e inclusiones a la población universitaria, sobre todo aquellos con discapacidades o inferioridades ante los demás.

La comunicación es el medio de transmisión de información más importante para los seres humanos, pues a través de él se ejecutan acciones como la persuasión, interpretación, información e inclusive la enseñanza y educación. Es todo un conjunto de procesos donde conocimientos e informaciones pueden ser impartidas a otras personas para el manejo, aprendizaje y ejecución de tales interpretaciones ingeridas, y a través del cual, se mantienen los lazos o relaciones entre ellos. Por involucrar dentro de la comunicación una importancia de gran magnitud, y esencial para situaciones y procesos en los cuales la productividad se puede ver afectada, resulta urgente para las personas una correcta planificación de la comunicación para prevenir y mejorar circunstancias donde todos puedan verse beneficiados o perjudicados.

La planificación, en palabras resumidas, se refiere a un conjunto de acciones llevadas a cabo con la finalidad de establecer cuáles serán los métodos y técnicas aplicables para obtener los resultados esperados. Los tipos de planificaciones que se pueden llevar a cabo en el entorno de la comunicación son variables entre sí, de acuerdo a sus objetivos y finalidades primordiales. Hay situaciones en las cuales, incluso se ha utilizado a la comunicación como 
un medio por el cual obtener un desarrollo sustentable para las naciones afectadas desde la segunda guerra mundial, pues a través de esta, se mejoraban situaciones en la sociedad, en los sistemas del Estado y en las telecomunicaciones. A partir de esas circunstancias, se inició un fomento de la ideología de elaborar una planificación de comunicación adecuada que genere beneficios considerables al desarrollo, a los avances tecnológicos que día a día van surgiendo y a los cambios drásticos de sistemas junto a un desarrollo de los Estados interesados.

Ahora bien, aplicando estos conocimientos de planificación de la comunicación que se vienen desarrollando desde hace años a las instituciones educacionales, más a profundidad a las universitarias, resulta necesario un estudio analítico donde se evalúe la necesidad, la importancia, los procesos aplicados o por aplicar, la naturaleza de la comunicación en estos entornos y los métodos de planificación internalizados. Las instituciones educacionales, sobre todo aquellas de educación superior como las universidades, requieren de un procedimiento de planificación de la comunicación esencial y necesaria, ya que se está tomando en circunspección la relación de interpretación entre una totalidad considerable de personas, que se dedican a impartir y adquirir conocimientos e informaciones necesarias para las diversas profesiones y materias especializadas.

\subsubsection{Los procesos}

Para las universidades, la planificación de la comunicación resulta un elemento necesario en cuanto a la organización de todos aquellos sistemas y procesos estructurales de la institución, además de la profundización y materialización de la identidad personal jurídica que se pretende vislumbrar ante la sociedad. Los procesos de planificación evaluados de acuerdo con Middleton (1981) se dividen en dos grandes ramas, las cuales se pueden determinar primeramente sobre el uso de las teorías dentro de las planificaciones, y en un segundo punto están todos los procesos en sí como métodos adecuados para lograr la planificación.

Con respecto a la primera fase de los procesos de planificación, en cuanto a las teorías aplicadas, se proceden en estudio y análisis cuatro fundamentales, las cuales son: teoría del desarrollo, teoría sociológica, teoría de la planificación y teoría de la comunicación. Tomando como base fundamental de su estudio el uso de éstas en la comunicación, el "como" 
y el "por qué". Así mismo, las instituciones universitarias basan su elaboración y planificación en las teorías predominantes que más se adapten a las necesidades primordiales que requieran solventar.

Los procesos aplicados para constituir una correcta planificación de la comunicación dentro del ámbito educativo resultan sumamente importantes, ya que, al momento de su ejecución, hay circunstancias que se sobreponen por otras, las cuales a mediados del proceso, constituyen una decaída de la organización planificada llevada hasta el momento. Así, diversos estudios han dado resultados sobre las evaluaciones realizadas a instituciones donde se percibe que las comunicaciones no logran efectivamente la agilidad, el acceso y la difusión adecuada de la información, siendo esto un obstáculo considerable para llegar a los niveles de comunicación necesarios en la educación.

Para ilustrar mejor dicha opinión, Rivera, Rojas, Ramírez, y Fernández, (2005) expresan que cuando no hay un plan comunicacional debidamente constituido, evidentemente que tampoco se puede hablar de la existencia de una transmisión de la información adecuada, pues tal ausencia indica la falta de comprensión entre las personas involucradas en la institución universitaria. Así mismo, expresan que para poder hacer goce y disfrute de una organización exitosa, es necesario que se cuente con una comunicación igualmente exitosa, y para lograr tal hecho, es necesaria la planificación adecuada de la organización a través de todos los elementos involucrados en la comunicación y transmisión de información como medios de relación directa.

Hay que mencionar, además, que de acuerdo con León (2006), en América Latina y el Caribe la planificación de la comunicación se desarrolla en tres partes donde la primera etapa está constituida por todos los procesos determinados por los principios y doctrinas en el asunto. Ahora bien, dicha etapa está conformada por una serie de factores esenciales para su producción adecuada, las cuales son las políticas de comunicación que son en sí los principios, reglamentos y objetivos establecidos que se buscan lograr a través de la comunicación, las estrategias de comunicación que son aquellas acciones y/o procedimientos a ejecutar para llevar a cabo los propósitos o fines ya establecidos anteriormente, y por último los planes de comunicación que son aquel conjunto de actividades donde se pondrán a 
ejecución los objetivos y las estrategias ejecutadas en el asunto para lograr la efectiva comunicación.

Como bien se da a entender, la primera etapa consta de una serie de estrategias y planificaciones teóricas en cuanto a los procedimientos a ejecutar, y si este tipo de elementos teóricos se llevan a cabo en el ámbito educacional, sobre todo en el asunto relacionado con las universidades, resulta sumamente necesario en temas de organización estructural, debido a que la educación se basa en la comunicación efectiva a través de la transmisión eficiente de la información.

En cuanto a la segunda etapa, se basa generalmente en la trayectoria que conllevará la planificación de la comunicación a su práctica, puesto que no siempre resulta de la manera en la cual se planificó todos aquellos procesos y estrategias comunicacionales que se buscaba implantar en la institución, bien sea por cuestión de eficacia en la ejecución de metas, acciones o planes, como de igual modo ocurre cuando el funcionamiento de los objetivos planteados no se efectúan de acuerdo al proceso y la planificación establecida.

La elaboración y ejecución de una fase no puede sobreponerse ni limitarse frente a la otra, sino más bien, estas actúan en conjunto con la tercera etapa que es el análisis entre las doctrinas aplicadas, así como las teorías y estrategias planteadas, fundamentadas en la ejecución y resultado de todas estas acciones tomadas en la comunicación dentro de las instituciones. Todo esto, constituye uno de los procesos que se puede ejecutar para la planificación de la comunicación.

\subsubsection{Los elementos}

En la era tecnológica que se vive actualmente, es inevitable su interferencia en los medios de comunicación, pues es a través de tales mecanismos donde se han aportado una serie de beneficios y avances en cuanto a la facilidad de comunicación actual, inclusive a escalas fronterizas. En materia tecnológica, los elementos esenciales se van constituyendo a raíz de las señales de comunicación, las cuales se dividen en analógicas y las señales digitales. Las primeras señales se caracterizan por involucrar en ella sondas eléctricas, como por ejemplo el uso de micrófonos o altavoces, las cámaras de televisión y todos aquellos aparatos electrónicos que se ven involucrados con los medios digitales y con la frecuencia medida en 
"Hertz". Las señales digitales en cambio de las anteriores, se diferencian por la identificación a través de "Bits".

La transmisión y distribución de la información a través de los medios de comunicación, son otros de los elementos necesarios en la planificación, pues es a través de ellos, donde se determinará con exactitud y detalle cuáles serán los métodos y el canal aplicado para transmitir las señales o informaciones necesarias. Estos mecanismos pueden ejecutarse de manera directa, a través de radiaciones electromagnéticas, o de forma indirecta, por medio de grabaciones. Las redes de comunicación son otros de los elementos en cuanto a la tecnología que se manejan a través de las redes en estrella y de malla.

\subsubsection{Desafíos}

Para poder prevenir la planificación de comunicación sin aquellas dificultades que se pueden presentar en los asuntos estructurados, sin la debida identificación de las necesidades esenciales en cada institución planteada, se establecen una serie de desafíos en los cuales cada institución debe evaluar y examinar sus procesos comunicacionales con el fin de que estos puedan ser ejecutados de la forma más efectiva. Primeramente, se debe tomar en consideración la planificación de la comunicación basado en las mediaciones, donde se hace referencia a las conexiones que existen entre las personas y su entorno, al modo en el que tienen que mediar para poder transmitir información.

De ese modo, todas las comunicaciones planteadas a través de la mediación de igual modo se tienen que tomar en consideración con la construcción de organizaciones comunicacionales, fomentadas a través de las necesidades, las demandas y las propuestas que la sociedad involucrada pueda disponer. Así como la planificación de las comunicaciones es un medio directo por el cual se ven perjudicados o beneficiados la sociedad involucrada, entonces se puede considerar como un modo de intervención en las prácticas sociales por el cual se ven directamente las opiniones y necesidades de los seres humanos en sí.

Siguiendo con el orden de ideas, también resulta necesario comentar sobre la importancia de una planificación de comunicación, siendo este un acercamiento directo a las construcciones sociales con aquellos entornos relacionados, dependiendo de la institución u organización involucrada en el asunto. Así también, está el diseño de los modelos 
organizacionales de la comunicación, todos enfocados en el derecho a la información que tienen todos los seres humanos en los diferentes Estados partidarios.

Por otra parte, hay que recordar que todas estas planificaciones tienen como finalidad el aporte a las culturas en las que se ven intervenidas y en las cuales se propugna el dialogo, así como se trabajan todas las estrategias de la comunicación, y se busca involucrar en las planificaciones la incertidumbre y las utopías, es decir, basar las planificaciones no solo en aquellas acciones que se tiene conocimiento seguro de su ejecución, sino también de aquellas presunciones o hipótesis que se puedan presentar en el asunto.

\subsubsection{Teorías}

La teoría en la planificación, también conocida como teoría sustantiva, se refiere a los problemas y sus causas en sí que todos aquellos planificadores de comunicación intentan modificar y mejorar, es decir, a todas aquellas circunstancias en las cuales la planificación se ve enfocada directamente a mejorar ciertos aspectos que el sujeto planificador toma en consideración y por donde se ve enfocada la comunicación directamente. Este tipo de teoría fundamenta y colabora la ideología de modificar las situaciones deficientes a través de la evaluación de circunstancias, y de la presunción de los resultados que se puedan obtener de ellos.

La teoría del desarrollo se ve enfocada a lo que su nombre se refiere, al desarrollo de las sociedades involucradas. Esta teoría se basa en la planificación de la comunicación, que busca como objetivo principal la mejora y avance del desarrollo en sí de todas aquellas personas relacionadas en el asunto de la manera más equilibrada y estable posible. De acuerdo con Middleton (1981), la comunicación, de acuerdo con esta teoría, se veía íntimamente involucrada con la economía y el desarrollo de los Estados desde periodos antiguos, siendo prescindible para su estabilidad la buena comunicación entre las sociedades involucradas.

La teoría sociológica, se concentra en la planificación de la comunicación enfocada directamente a generar cambios drásticos y mejorías considerables en la sociedad en sí mismo, es decir, en generar mejoras basadas en las necesidades de la sociedad, en sus modos de pensar, en sobre cómo es actualmente la cultura social y como debería llegar a ser. Se 
manejan en este asunto diversos campos relacionados con el área en los cuales se busca predeterminarse en tres grandes ramas, las cuales son la sociedad como estructura integrada, la sociedad en conflicto y la sociedad como individuos y grupos.

La teoría de la comunicación, es aquella que se encarga del estudio de la comunicación como un ente general que abarca todos los nexos y relaciones entre la sociedad y el entorno que los rodea. Se caracteriza, de acuerdo a los autores desarrolladores de esta teoría, como aquella fuente principal de todos los aspectos y acciones que se ejecutan en la sociedad, pues la comunicación se fundamenta como el primer paso para la correcta interacción entre personas y la transmisión de la información debidamente ejecutada, para así cumplir con los cometidos planteados. Surge entonces ante la necesidad de estudio y análisis, un determinado proceso el cual se fundamente en las teorías que más acorde estén a las instituciones o necesidades que se presenten.

Con todo lo anteriormente expresado, se puede dar finalidad en el asunto con la opinión de que la planificación de la comunicación organizacional, se adapta como un procedimiento que se fundamenta no solo en estrategias aplicadas para su correcta elaboración y ejecución, sino de igual manera, abarca una serie de tácticas que integran y complementan su finalidad, sus objetivos y colaboran para la obtención de los resultados esperados.

\subsubsection{La gestión de la comunicación}

La gestión de la comunicación es aquella acción en la cual se emplean una serie de actos, instrucciones y técnicas que resultan significativas para las personas, pues al momento de ser usadas de manera correcta, permiten la existencia de una excelente comunicación en la labor de las organizaciones. Se puede mencionar que tiene una serie de funciones, en las cuales destaca como forma principal, que sirve para que los miembros de la organización puedan relacionarse de una forma adecuada, cumpliendo con todos los procesos y reglas que este mismo conlleva.

Otra de las funciones que esto genera, es que de igual modo es útil para que aquellos integrantes de la organización puedan tener relaciones personales, es decir, para que puedan integrarse de una mejor manera, no solo personal, sino también de forma institucional. Del mismo modo, este sistema de gestión de la comunicación, permite que existan menos problemas íntimos entre los miembros, y ayuda a que las relaciones que se vayan 
estableciendo sean beneficiosas para todos, para que así pueda existir un ambiente agradable entre ellos, pero sobre todo, que sus lazos se vayan fortaleciendo cada vez más.

Este es un asunto que se tiene que tomar con suma importancia, por el hecho de que una de sus funciones es que sirve de gran ayuda al momento de que las personas involucradas pueden ser de gran utilidad para favorecer la formación de aquellos espacios de investigaciones, intervenciones y opiniones, los cuales funcionan para que los participantes sientan que son tomados en cuenta en las áreas de contribución, donde las metas que se plantean son ejecutadas en conjunto, y los sistemas y estrategias son creados por medio de una buena gestión de la comunicación.

Del mismo modo, esto también tiene que estar seriamente atendido, ya que es de vital practica para que las metas que ya fueron expresadas puedan ser realmente proactivas, que logren llegar al objetivo usando esos métodos. Se toma bastante en cuenta estas gestiones comunicativas en este sentido, ya que las personas que dirigen una organización en específico, pueden conseguir entre su público y miembros nuevas técnicas para la comunicación, para que esas actividades puedan lograr favorecer a la organización en sí, y puedan cumplir con los planes trazados.

Para que se logre alcanzar el éxito en la gestión de la comunicación, tienen que ser variados los sistemas que se utilicen, como por ejemplo, pueden ser por medio de videos, correos electrónicos, redes sociales, anuncios, periódicos, entre muchas otras opciones que pueden servir de ayuda, con el fin de que las ideas que ya fueron mencionadas sean cumplidas y alcanzadas de manera satisfactoria, y claro está, en conjunto y en unión, ya que si existe la comunicación en estos casos se alcanzan las metas propuestas, y así sería consolidada de la forma más cómoda para los integrantes.

Por otra parte, se puede decir que estas gestiones se consideran una fuente bastante positiva al momento de que exista una comunicación entre las personas que están dentro de la organización, por el hecho de que puede estar un mejor apoyo, y al mismo instante, la producción que se va generando con el transcurso del tiempo será más beneficiosa, ya que para el momento debe existir un compromiso entre los integrantes, y en conjunto una visión entre los objetivos, para que de esta manera la calidad de lo que se vaya creando sea cada vez más beneficioso con la información necesaria para generar mayor conocimiento. 
Hay que mencionar además, que debe existir un buen ambiente para la aplicación de estos sistemas de comunicación, de modo que así pueda ser realmente efectivo, ya que por ende, se tiene que entender que las personas proponen más ideas cuando el ambiente en donde están es agradable para ellos, y de la misma forma, no solo exponer ideas, sino también tener el derecho de decir que es aquello que les incomoda, que cosa les gustaría cambiar si no están de acuerdo con algunas decisiones, y por último, decir que les gustaría mantener.

Cabe destacar que, en estas gestiones de comunicación, se recomienda hacer esta transformación de ambiente, ya que también eso le hace saber a los integrantes que se le van generando sentido de pertenencia en el lugar, para que así puedan estar más cómodos al momento de comunicarse y al instante de accionar. Por consiguiente, en esta misma clasificación de recomendaciones que se establecen, se puede mencionar que esto, de igual modo, puede instituir una mayor participación de la comunidad, y que así se pueda generar una mayor colaboración en las actividades de la institución.

Todas estas observaciones se relacionan también con la creación de nuevos métodos de comunicaciones internas. En este ámbito interno, se menciona sobre que es buena idea fortificar aquellas técnicas que ya fueron creadas, y que, por ende, las más comunes suelen ser la televisión, la radio, carteleras, redes sociales, etc., y esta idea sirve de igual modo para que la gestión de la comunicación sea conocida por todas las personas a través de los medios, ya que, en la actualidad, la sociedad está acostumbrada y adaptada a los medios tecnológicos para un aprendizaje más desarrollado.

Se debe agregar también, que en este ámbito interno existen varias fases que son realmente grandes e importantes y que son de suma ayuda, ya que sirven como una sistematización para que pueda existir una mejor organización, agregando que los intereses de las personas están en un constante cambio, y por eso es que se ve la necesidad de que haya una sustitución de información en aquellos programas electrónicos, ya que si existe una mayor fuerza en estos programas, las personas van a tener un mayor interés en saber sobre estas gestiones comunicativas.

La gestión de la comunicación interna viene siendo un punto realmente estratégico, por el hecho de que al mismo instante genera una clase de compromisos, ya que crea motivación en las personas y con eso, se va generando una clase de objetivos, y se ven en la necesidad de cumplirlas, por eso es que distingue este sistema como algo que si produce beneficios en 
el entorno. Hoy en día la gestión de esta comunicación se ha visto como una metodología eficaz, porque, al momento de aplicarla en las organizaciones, la administración de la misma suele ser bastante positiva en el área de la comunicación.

Ahora bien, se hablará sobre las ventajas que esta gestión establece, y una de ellas es que genera de forma igualitaria información para todas las personas que deseen ingresar en este programa independientemente de donde se encuentre el usuario. En las áreas estudiantiles, pueden cambiar información por medio de las redes sociales o el sistema que ellos deseen, y así también pueden compartir las experiencias que han tenido, brindándole a los demás sus conocimientos y que de esa forma su eficiencia y productividad pueda ser más avanzada.

Al mismo tiempo, los que brindan la información estarían incitando a los espectadores sobre hacer un sistema igualitario o simplemente más reforzado, para que así más personas puedan obtener la información, siendo allí donde se ve la parte de su participación y colaboración para el sistema de investigación, de manera que así también puedan existir más opiniones y creaciones de ideas, para que ese método sea mejorado cada vez más, y así más personas puedan tener un conocimiento breve que pueda generar interés sobre estas gestiones comunicativas.

Por consiguiente, Gómez (2007) establece algunas características que esta gestión conlleva, y una de las principales es cuando habla sobre que estas gestiones tienen que tener forma completamente descendente, y del mismo modo, de forma ascendente. La forma descendente quiere decir, que la persona que posea más información debe comunicársela a aquellos que aún se les vea necesario esa capacitación, y cuando se habla sobre la forma ascendente, trata sobre las personas que no tienen casi conocimiento al respecto, ellos tienen la capacidad de poder comunicar aquellos reclamos, sugerencias, opiniones, debates de ideas, planes, etc., a la persona superior.

Igualmente, se menciona sobre la característica de comunicación horizontal, que se refiere a la gestión comunicacional basada completamente entre las personas que se encuentran en la misma jerarquía, o sea, que se mantengan en un equilibrio igualitario. Esta comunicación se produce de una manera formal, que se basa en un modo más organizativo, y también se puede presentar de una forma informal, que se confecciona por los temas de conversación personal que las personas mantienen entre sí. Todas estas características se ven 
realmente afectadas, por el hecho de que las personas al momento de comunicarse no siempre quieren el bien de su compañero.

En cuanto a los principios de la gestión comunicacional, se conoce más que todo sobre aquellas ideas iniciales que luego se ejecutan en las planificaciones, y por consiguiente se pueda llegar a una conclusión efectiva que realmente pueda ser desarrollada de manera positiva. Estos principios son de verdad tentativos, ya que esas planificaciones en su mayoría tienen como función poder hacer propuestas, para que se pueda tomar una decisión que resuelva algún problema, sea por audio, imágenes, entre otros.

Existe varios principios, y uno de ellos es el de congruencia, que se trata sobre que toda gestión de comunicación debe poseer el debido análisis, ya que esto es de gran ayuda al momento de que se presenten ideas y llegue el tiempo de que sean expresadas para que puedan ser de buena utilidad, y es por eso que se le hace énfasis a este principio, debido a que también surge porque debe disponer de una debida adaptación en las planificaciones, y por ende, cabe destacar que en este caso, la persona tiene que tener completamente en claro de que requiere conocimientos de unos conceptos de la comunicación, para tener su desarrollo eficaz de los objetivos que se quieren lograr.

El siguiente principio se trata sobre los valores, que se basan sobre su aplicación en la comunicación, que tiene mucho que ver cuando se desarrolla un objetivo, y que este mismo tiene que buscar las maneras de cómo desarrollarlo y de cómo puede lograr esta meta. Las personas que se han propuesto estos ámbitos comunicacionales, tienen bastante concordancia al vincularse sobre ellos mismos, ya que pueden buscar en sus propios valores una clase de afirmación para que su postura en los sistemas de comunicación sea cada vez mejor desarrollada, y que las decisiones que tome puedan ser seguras.

Por consiguiente, se hablará sobre el principio de la certeza. Se trata de cuando un grupo de personas tienen una serie objetivos en mente, pero solamente lo ven a futuro, no piensan en su presente, en lo que les rodea, y en este instante, no se imaginan lo importante que es la comunicación en estos casos, ya que las personas que si toman en cuenta la comunicación en su actualidad, tienen la completa certeza de lo que piensan en su presente para su futuro, ellos van creando planes en su actual tiempo para poder lograr sus objetivos próximos, teniendo en cuenta los valores que tienen y los procesos de la comunicación que este conlleva. 
Ellos están completamente abiertos a los sistemas de aprendizaje, quieren saber qué hay de nuevo en los sistemas de comunicación, qué nuevos métodos han sido inventados, y hasta algunas personas tienen como objetivo divulgar todos los conocimientos que han llevado por medio de sistemas comunicativos, de todos los estilos, para que las personas que tienen alguna discapacidad no se sientan rechazados ni discriminados, por eso es que, de igual modo, se crean más métodos día a día. Esta variedad de entornos son los que hacen que las técnicas de comunicación vayan en un constante cambio, y así también que sean actualizados, ya que existen diferentes desarrollos comunicativos.

Los que planifiquen estos sistemas, de igual modo tienen que tener la completa certeza de las acciones que están llevando a cabo, y así también estar completamente seguros de sus pensamientos, en conjunto con lo que quieren hacer, si existe algún problema, sea en sus datos o en los pensamientos de la planificación que se van creando. Por eso es que este principio es tan importante para las personas, pues deben disponer de completa seguridad en las situaciones que se presenten, por el hecho de que se debe actuar con sumo cuidado, tanto la persona que lo planifica, y así también del modo que lo va a emplear.

Por último, se hablará sobre el principio de aprendizaje, que es cuando se hace referencia sobre la aplicación de las teorías, esto quiere decir, que existen una serie de personas que buscan la manera de que sus conocimientos se amplíen más, o si tienen algún problema, lo comunican y buscan la forma de resolverlo, sea investigando o yendo a sistemas comunicativos sobre el tema que deseen resolver. Este principio también es bastante importante, ya que los planificadores comúnmente no están muy seguros de su conocimiento, entonces es allí donde ellos aplican el sistema de aprendizaje por medio de experiencias, pues ellos necesitan que sus metas tengan calidad y que sean realmente positivo para ellos, y del mismo modo, que se busque una forma de comunicación que pueda mejorar a la sociedad en conjunto.

La gestión de la comunicación se aplica así también en instituciones educativas, y donde hace más énfasis es en las universidades. Esto quiere decir que la alta gerencia ha creado sistemas de comunicación para poder agilizar un mejor aprendizaje, y de la misma manera para que puedan crearse más métodos entre ellos mismos, y puedan generar una clase de opiniones para que con el tiempo, el área universitaria pueda ir mejorando más en este ámbito comunicacional, ya que por ende se ve en la vida cotidiana con bastante frecuencia. 
En relación con lo anterior, también tiene mucho que ver cuando las personas que formen parte de la comunidad universitaria, quieran formar una relación personal y no solo académica, ya que día a día se van estableciendo nuevos grupos sociales, en donde existe una comunicación entre ellos. Por lo mismo, es que en esta área también es de gran valor para los involucrados, porque con la comunicación se van formando vínculos en donde se intercambian informaciones, experiencias de vida, ideas, metas, entre otros.

Además, se puede decir que esto también imparte mucho al momento de hablar sobre las metas que quieren ser alcanzadas, ya que por ende, la comunicación porta un muy importante papel en estas gestiones, pues ellos en esta etapa se enfocan más que todo en el futuro que desean construir, y es muy significativo decir que la planificación de lo mismo, conlleva a que la utilización de los principios sea de manera eficaz y positiva, para que se puedan cumplir los objetivos propuestos, y que del mismo modo pueda ser de una forma organizada.

\subsubsection{Importancia del diagnóstico comunicacional dentro de un escenario universitario.}

Un diagnóstico de la comunicación se refiere generalmente al estudio y análisis de aquellos resultados obtenidos a través de las planificaciones ejecutadas, por medio del cual, se determinaran los cambios y/o modificaciones que sean pertinentes realizar para que la organización en cuestión tenga la posibilidad de disfrutar de la transmisión de información y de lazos directos de manera proactiva y eficiente. A través de la realización de un diagnostico se puede determinar con exactitud todas las situaciones presentadas dentro de una organización, y de esa manera, poder evaluar correctamente cuales son los puntos o áreas que ameritan de más esfuerzo y dedicación para su mejoría y cuales están lo suficientemente estables.

Es necesario dejar claro, que el diagnostico comunicacional se produce a partir de la aplicación de una serie de habilidades de preparación, para la elaboración de conocimientos, con el objetivo de que se pueda especificar la realidad y la particularidad. De esa forma la transformación de dicha situación se puede lograr de manera voluntaria y consiente. Asimismo, este diagnóstico tiene como finalidad inspeccionar y regenerar, los métodos y prácticas de información de manera interna y externa, dentro de la formación en todas las áreas pertinentes. En efecto, se deben inspeccionar todos los productos de comunicación que 
se utilizan dentro de la organización, para evitar la eventualidad de murmullos que se producen del orden de poder de la misma.

Así mismo, el análisis de la información se toma también como instrumento, ya que es el que permite inspeccionar y comprender, de modo consecuente, las habilidades sociales y sus métodos específicos, con el fin de establecer el primer paso de la programación de técnicas comunicacionales. Además, se describe que la vida cotidiana y la manera de como los representantes colectivos o individuales, se organizan en ese argumento.

De ese modo se establece un concepto bastante claro y acertado en cuanto a lo que se reconoce por diagnostico comunicacional. Bruno (s/f), habla sobre este diagnóstico, mencionándolo como una forma útil para que se pueda observar como esta expresa la realidad, todo por medio de unos sistemas de comunicación y de conocimientos que estén debidamente orientados, para que esa realidad sea cambiada de forma consiente, y que así también se puedan generar y agregar aquellos factores que la sociedad implementa.

Haciendo énfasis en lo anteriormente expuesto, se instituye la importancia que el diagnóstico comunicacional radica, por el hecho de que en el transcurso de los cambios que se establecen en la iniciación de un acontecimiento, que ha sido efectuada dentro de una determinada organización, a través de los objetivos planteados se pueda valorar el sistema de comunicación, que en los momentos está siendo desarrollado dentro de una institución, con una organización adecuada y eficaz.

El diagnóstico ha sido considerado en primer lugar, una actuación de diferencia de los mecanismos de una establecida situación, que a su vez, accede a plantear las disyuntivas primordiales, para así descubrir el motivo de fondo, para que de esa forma se pueda procurar constituir caminos de ejercicio para irlos solucionando. En relación a esto se puede recalcar, que la organización diagnosticada es la influencia de un transcurso de cambio, en el que se toma en consideración la conspiración principal del análisis, de sus impulsos y, además, de las debilidades que se efectúan de los problemas, por los que se fundamentan objetivos de proyección.

Asimismo, se planteará la manera en la cual se lleva a cabo el desarrollo de dicho diagnóstico, y la forma de realizarlo es, primeramente, a través del reconocimiento en un 
escenario dentro de un grupo determinado, para que, de acuerdo a esa situación, se proceda a establecer las opciones y medidas de acción que conlleva a la planificación, que reconoce el cambio de la realidad para una organizada y analizada institución, sin que haya errores en los estudios que se estén realizando.

Con lo anteriormente mencionado, se trata sobre las organizaciones que se efectúan en el correspondiente análisis que se está planteando, en cuanto a las recomendaciones de información interior. De tal forma, que se deberá establecer la manera adecuada del diagnóstico que se quiere realizar, ante cualquier circunstancia determinada que lo amerite, en donde se debe tomar en consideración distintos aspectos, primeramente se tiene que identificar a los individuos involucrados dentro de una institución por medio de la comunicación, seguidamente se debe realizar un análisis del conocimiento de la actividad, además de la imagen en representación y del discernimiento de otros individuos de la misma jerarquía, en tercer lugar se debe tomar en cuenta la identificación de las amistades entre diferentes grupos.

Continuando con el orden de ideas, primero se deberá realizar un análisis y posteriormente una evaluación, con respecto a los escenarios de comunicación en cuanto a los instantes y áreas comunicacionales. En ese sentido, es importante analizar la comunicación recogida que se origina del organismo de acuerdo al carácter y contenido, por último, se tomará en cuenta la investigación de los flujos y recursos informativos de la organización, mediante el método de la comunicación que más acorde esté en la situación, de acuerdo con los receptores.

Estos planteamientos aplicados en el campo educacional presentan una importancia para la estabilidad comunicacional y para la correcta aplicación y ejecución de los objetivos o visiones involucrados. En el caso de las universidades e instituciones de educación, sus primordiales funciones se relacionan directamente con la comunicación, pues para la educación es necesaria una transmisión de información no solo de los profesores a los alumnos, sino también para toda el área estructural de la institución de manera que se desarrollen eficientemente todos los objetivos establecidos.

Todos los procesos se ejecutan con el propósito de generar algún tipo de cambio dentro del sistema u organización a aplicar, y es allí donde toma personalidad el diagnostico, pues es a través de él dónde se determinará el reconocimiento de la situación actual de la 
organización o ente en estudio. Lo anteriormente mencionado se ve íntimamente relacionado con el objetivo general que desarrolla el diagnostico en sí mismo, el cual es generar una serie de evaluaciones y recomendaciones en el ámbito estudiado, más específicamente, en el área de la comunicación organizacional.

De acuerdo a diversas instituciones y a su modo de implementación de las medidas comunicacionales esenciales, se pueden iniciar, según su planificación de comunicación interna, desde los resultados obtenidos de los diagnósticos practicados dentro de las áreas pertinentes, para de ese modo, adaptar los diseños de los procesos de acción de acuerdo a las necesidades encontradas en dichos resultados y así poder establecer una correcta elección de métodos y mensajes a transmitir.

Sin embargo, a pesar de lo mencionado, Bernal (2011) establece que el diagnostico no es el único paso de suma importancia en el asunto, sino que se constituye como el primero que se debe realizar para así después poder efectuar las consideraciones y acciones necesarias, así, por ejemplo, seguidamente del diagnóstico respectivo, se procede al estudio y elaboración de la planificación necesaria para poder satisfacer las necesidades junto con los objetivos planteados. De igual manera, el mismo autor expresa que la acción de diagnosticar radica mucho en las opiniones de los involucrados dentro de la institución u organización en cuestión, y si se lleva esta opinión al ámbito educacional, se puede decir que en las instituciones universitarias la opinión de todos los participantes, es decir, alumnos, profesorado, inclusive personal administrativo, resultan primordiales para poder obtener un buen diagnóstico de resultados tanto inicial, como final para evaluar los avances que la planificación comunicacional han logrado conseguir.

\subsection{Forma de diagnosticar}

Todas las áreas y asuntos involucrados en las instituciones en estudio pueden ser diagnosticadas, sin embargo, diversos autores como, por ejemplo, Bernal (2011) recomiendan que todos los procesos de evaluación y diagnóstico se ejecuten a determinadas áreas y asuntos en particular, ya que aplicar un proceso de evaluación a la institución en su totalidad generaría una confusión y provocaría un conflicto sobre cuáles son las áreas que requieren de primordial atención frente a las demás. Así, por ejemplo, determinan que como no hay una forma estándar de medición y diagnóstico, la principal circunstancia que se debe precisar es la necesidad de atención de las áreas en desequilibrio de comunicación, así como 
todos aquellos asuntos que impidan la eficacia en la realización de los objetivos planteados por la institución.

En el caso de las universidades, a opinión crítica, se puede determinar que una de las áreas con mayor relevancia en cuanto a la comunicación, resulta de la transmisión de información de profesores a los alumnos, pues ese nexo directo resulta el esencial que la institución busca generar y, por ende, recae en ella una importancia considerable frente a las demás. Asimismo, le siguen todos aquellos nexos comunicacionales entre el personal administrativo, entre otros.

Ahora bien, resulta necesario recalcar que, de acuerdo a diversos autores, se establece que el diagnóstico de comunicaciones puede presentarse enfocado en tres distintas perspectivas, en las cuales, de acuerdo a las necesidades básicas de cada institución, se van a emplear acorde a sus propósitos evolutivos. Así, se menciona la perspectiva funcionalista, la interpretativa y la crítica. La ejecución del diagnóstico a través de la perspectiva funcionalista, radica en la corrección de aquellas prácticas de la comunicación que impiden o perjudican la eficacia de la organización o institución en estudio, es decir, que se enfoca directamente en la evaluación de las funciones que impiden una correcta comunicación en el entorno.

Ahora bien, la perspectiva interpretativa se fundamenta en la evaluación del entorno a través de las prácticas y consideraciones sociales, es decir, interfieren mucho en el diagnostico todos aquellos valores, creencias, opiniones y objetivos plasmados por la sociedad involucrada en la institución u organización. Como último, está la perspectiva crítica, que se enfoca directamente en aquellas relaciones comunicacionales que se guían específicamente para aquellos que tienen o desean obtener el poder interno de la organización en cuestión, de esa manera, se busca crear un diagnostico que genere una correcta distribución y manejo de la comunicación para todos los entes involucrados y que no solo una pequeña parte de la población se vea beneficiada por ello.

Alguno de los métodos o técnicas recomendados que se pueden ejecutar para el debido diagnostico suelen ser las entrevistas a las personas involucradas, los cuestionarios que pueden realizarse de manera separada o en conjunto con las entrevistas, el análisis de todas aquellas redes comunicacionales que permiten evaluar de igual manera todos los obstáculos o difusión de la información errónea y los contenidos que se desarrollan en ello, las 
entrevistas grupales, las observaciones directas que generan un acercamiento más profundo en los asuntos estudiados y permite la familiarización con el entorno y el personal involucrado, y por último el análisis de las producciones comunicacionales.

Un diagnostico eficientemente ejecutado constituye una de las acciones primordiales a efectuarse con frecuencia dentro de las universidades, pues si de por sí, para todas las instituciones y organizaciones en general, la comunicación desempeña un papel primordial e importante en el asunto, para las universidades la necesidad resulta doble cuando se habla de instituciones que se basan en el desarrollo de profesionales a través de la transmisión de la información y los conocimientos. Estas instituciones en cuestión, requieren de una eficiente comunicación para la ejecución de sus objetivos en cuanto a exigencia de los usuarios intervinientes, y también para cumplir con aquellos estándares que la sociedad le imponen.

De este modo, un buen diagnóstico generaría para las universidades una buena ejecución de medidas preventivas y correctivas en cuanto a sus planificaciones de comunicación efectuadas y por efectuar, de igual modo, mejoraría considerablemente la eficiencia sobre sus medios informativos y sobre sus objetivos planteados y, así mismo, el cumplimiento de sus metas, visiones y misiones se generarían con mayor facilidad. La planificación y el diagnóstico forman parte de la dinámica de cualquier institución, puesto a que son elementos fundamentales para lograr el desarrollo continuo, uno en el cual cada meta alcanzada se torne al mismo tiempo en un punto de partida para otra meta. Haciendo énfasis en el diagnostico como acción primordial al momento de realizar una planificación, se debe tener en cuenta que el objetivo de la misma es permitir un conocimiento extenso y profundo sobre el tópico a tratar, y de esta manera permitir que la planificación incorpore todos los elementos necesarios para asegurar la eficiencia del mismo, es por esto que Bruno (s/f) expresa que el diagnóstico es una herramienta tanto teórica como metodológica.

Es necesario también determinar las diferentes perspectivas posibles que se puedan presentar a la hora de analizar la situación en cuestión, debido a que son las diferentes perspectivas las que permitirán enfocar de una manera amplia y globalizada los posibles elementos que intervienen en el tema, permitiendo a su vez que el diagnóstico sea más eficiente y por consecuente una planificación más exitosa. De la misma forma, el diagnóstico de la comunicación hace referencia al análisis de los diferentes factores y entes que forman 
parte de una situación social, teniendo en cuenta la variedad de contextos pertenecientes a cada uno de los individuos en conjunto a sus historias individuales y al marco cultural donde se desenvuelven.

Dicho diagnóstico por consecuente, debe comprender y abarcar los aspectos individuales y grupales desde un enfoque masivo, es decir, que el diagnóstico comunicacional debe contemplar todos los aspectos que relacionan de una manera $\mathrm{u}$ otra a cada uno de los individuos que forman parte de la relación, tanto individualmente como siendo parte de un colectivo. Es necesario recalcar que, como las problemáticas presentadas poseen sus propias características, obliga a que sea abordada desde una perspectiva diferente y que su acercamiento al aspecto comunicacional deba ser realizado de una forma renovada, por lo consecuente el diagnóstico debe ser enfocado a cada problemática en sí para que estén

presentes las condiciones necesarias para evaluar dicha problemática de manera amplia y eficiente, tomando en cuenta siempre los aspectos presentados por cada persona o grupo en función a la organización.

Teniendo en cuenta los diferentes aspectos mencionados y conociendo el alcance del diagnóstico como paso primordial para realizar una planificación efectiva, se puede denotar que en el área de la educación es este un elemento que puede significar un paso de suma relevancia para lograr que cada uno de los estudiantes, profesores y cada persona dentro de las instituciones en general, puedan interactuar de forma eficiente, puesto a que es la comunicación uno de los principales factores que favorecen a la consolidación de un vínculo estable entre los participantes.

De esta manera aplicar un diagnóstico comunicacional en las instituciones ayudará de manera considerable las relaciones interpersonales de cada uno de los miembros de dicha institución, generando así que la información facilitada dentro de la misma pueda impartirse a mayor velocidad, debido a que el entendimiento es más rápido y a su vez permitirá que se propague en una codificación entendible por cada una de las personas.

\subsection{Antecedentes sociopolíticos}

En el ámbito social, la educación constituye uno de los procesos fundamentales en cuanto a la estructura y caracterización de conductas, valores y conocimientos que los seres 
humanos ejecutan en su vida diaria. Todos aquellos aspectos de conocimiento y formación se van adquiriendo desde el nacimiento del ser humano, a través de las instrucciones e indicaciones que los padres van planteando poco a poco en la mente de los niños, sin embargo, ésta no es una tarea que solo le corresponda al entorno familiar, sino que se requiere para una buena educación y formación, la participación activa de todos los ciudadanos como entes guiados por un mismo fin o con los mismos valores en práctica, y por un Estado en su totalidad, enfocado directamente a generar en sus particulares una estructura pacifica, productiva y desarrollada con una serie de consideraciones y aspectos positivos a su alrededor.

Debido a la necesidad del Estado como principal ente responsable de la educación de sus ciudadanos, se lleva a cabo la estructuración y construcción de instituciones encargadas de propiciar una completa y eficiente educación en cuanto a conocimientos básicos generales hasta aquellos profesionalismos en las materias y áreas determinadas. En cuanto al territorio argentino, a través de una serie de estudios de amplia trayectoria, se ha buscado profundizar en el asunto de la educación superior, y en cómo sus evoluciones y transformaciones han ocasionado una serie de eventualidades y superioridades frente a otros Estados sobre la formación académica profesional que se tiene para su población.

Un ejemplo de tales estudios mencionados, Fernández (2003), establece en su investigación detallada, todo sobre la educación superior en Argentina, en el cual, sus propósitos en concreto es profundizar en cuanto a la información, la documentación y la elaboración de análisis exhaustivos sobre todos aquellos entes y organismos dedicados a la regulación y control de la educación superior, así como también se buscan expandir los conocimientos acerca de la educación en Argentina y sus avances generados por la intervención del Estado.

Todos los acontecimientos sobre la evolución de la educación superior, el autor en cuestión los determina en diversos periodos, que, a su opinión personal, resultan más prácticos para su estudio y entendimiento la separación de estas circunstancias a través de diez periodos, iniciando con los sucesos de las universidades en la época colonial y los primeros años de independencia de Argentina. 
El sistema educativo dentro del territorio argentino inició a partir del año 1613, donde las provincias aún no estaban establecidas y todo el territorio en cuestión se veía dominado por los grupos jesuitas, quienes fueron los que propiciaron la creación de un colegio jesuítico. Seguidamente en el año 1622 se le concedió la denominación de universidad a dicho colegio, tratándose entonces de una de las primeras instituciones universitarias en Argentina, junto con otras 20 organizaciones igualmente establecidas por los jesuitas.

Por el periodo en el cual fue estructurada tales organizaciones, se plantearon ideologías religiosas que debían ser impartidas en todos los entes educacionales, con el propósito de instaurar consciencia en cuanto a las creencias religiosas y propiciar ideologías y valores que se vean considerablemente influenciados por tales sociedades. Sin embargo, en el asunto no se involucraron los aspectos jurídicos y legales como una materia fundamental, lo que generó que la mayoría de los particulares interesados se guiaran por aquellas organizaciones que ofrecían tales conocimientos.

Igualmente, se iba generando el control de las instituciones con órdenes directas del Estado como único ente regulador de la materia, puesto que los poderes en torno a la educación se siguen mantenimiento centralizados, independientemente de la transformación de aquellas sociedades y poblaciones involucradas, tales como los jesuitas que posteriormente a un cierto periodo de tiempo, fueron sucediendo a los franciscanos, concluyendo con las autoridades del reinado del Rio de la Plata, así llegando hasta lo que actualmente se conoce como la organización Estatal de la República de Argentina. La creación de la universidad que se constituyó como la institución nacional de educación superior argentina fue en el año 1821 y se denominó como la Universidad de Buenos Aires, siendo la principal entidad educacional del territorio y el instrumento superior de educación y formación de los particulares interesados en la materia.

En conclusiones, el primer periodo se caracteriza por una serie de acontecimientos como la existencia de las universidades de Buenos Aires y Córdoba para ese momento, donde la universidad de Córdoba se enfocó directamente como una institución de religión eclesiástica, y se crearon otras instituciones de carácter superior, y por lo cual, se establecieron instituciones de educación media para cada una de las universidades nacionales establecidas, entre otros aspectos. 
Ahora bien, posterior a todo lo mencionado, se inicia el periodo de la universidad en las organizaciones nacionales y constitucionales, que marcan el hito en la historia argentina sobre la elaboración e implantación de la carta magna del territorio, y en el cual se veía reflejado todo lo referente a la educación superior, a las instituciones y a su reglamentación. A partir de allí, se dicta la mencionada constitución en el año 1853, donde se especificaba de manera muy superficial en el entonces artículo 67 inciso 16 (artículo 75 inciso 18 actualmente) todo lo referente a la educación.

En el mencionado artículo, se establece la responsabilidad que acarrea para el congreso de fomentar y estructurar todas las regulaciones legales que sean pertinentes para las instituciones que imparten educación superior, así como también se determina su responsabilidad en cuanto a la evaluación y control. Para cumplir con la regulación legal, se establecieron leyes como la Ley Avellaneda, y se modificaron otras como la Ley 1420 de Educación Común. En este periodo también ocurrieron una serie de modificaciones y mejoras en cuanto a las áreas y materias dictadas, se amplificaron los estudios jurídicos y se ejecutaron actividades y concursos para la aplicación de cátedras y materias nuevas.

Prosiguiendo en el orden cronológico, surge el periodo de las universidades oligarcas y liberales, que inicia a partir del año 1885 hasta 30 años después, en 1918, cuando se formalizaron las ideologías políticas y educativas del territorio argentino y se enfocaron ambas para un propósito común. Dentro de este lapso, se vieron muchas circunstancias en las cuales, profesionales de la materia ejecutan facultades como educador y educaban a los universitarios para proseguir directamente como ayuda en el área del educador asignado, es decir, aquellos profesionales enseñaban con la intención de utilizar esas mismas personas como apoyo en su área profesional.

Se llevaron a cabo acciones de establecimiento y creación de universidades nuevas, y así se constituyó la universidad de la Provincia de Santa Fé en el año 1889, la universidad de la Ciudad de Plata en 1890, la universidad de la Provincia de Tucumán en 1912 y la universidad Nacional de la Plata para el año 1905. De igual manera, surge necesario resaltar, que dentro de este periodo se percibieron los primeros indicios de la facultad de ciencias de la educación a raíz de un instituto de mujeres en el cual se preparaban mentalmente y se 
capacitaban a las alumnas para impartir todos sus conocimientos a través de enseñanzas sociales.

El siguiente periodo en estudio, es la reforma universitaria ocurrida a partir del año 1916, en el cual se inició el primer periodo presidencial de Hipólito Irigoyen el cual indudablemente que causo drásticos cambios políticos que perjudicaron todos los aspectos involucrados en la Nación, donde indiscutiblemente, se veía afectado igualmente la educación superior. Todo este cambio, sin embargo, resulto ser bastante beneficioso para las universidades, debido a que se incrementaron notables ajustes a las matrículas, se da un gran avance en cuanto a mejorías de las instituciones y la innovación de ellas, así como también se crearon nuevos centros e instituciones de educación con una diversidad de materias y áreas profesionales. De igual manera, para el año 1939 también se llevó la elaboración de la Universidad Nacional de Cuyo, con un perfil más conservador que las demás universidades ya estructuradas.

El siguiente periodo se determina por el peronismo y su conexión con las universidades, el cual inicio en el año 1945 con el nuevo presidente Juan Domingo Perón, el cual instauró en el territorio una nueva estructura de poder que relaciona casi todas las decisiones y acciones en el Estado con la Política. Aquí, indudablemente que las universidades se vieron afectadas, resistiendo a una serie de incontables sucesos donde se destacan incluso aquellas acciones de intervención ocasionadas al año siguiente en seis de las universidades principales. Del mismo modo, también se procede a la estructuración de la Ley 13.031 que determina con exactitud el régimen universitario y de toda su población involucrada bajo las áreas políticas del Estado, limitando considerablemente la autonomía que tanto les costó a las universidades obtener.

Posterior a este gobierno, se empezaron a implantar una serie de políticas que iban enfocadas directamente a garantizar la oportunidad de la educación a todas las clases sociales que hasta ese momento se veían completamente distanciadas y desligadas del asunto. Asimismo, se propició el ingreso libre y la gratuidad a todas las instituciones educativas, lo que generó indudablemente un incremento considerable sobre las matrículas escolares y universitarias. 
Ahora bien, posteriormente prosiguen ciertos periodos, como se pueden mencionar a la restauración reformista y su crisis, al gobierno de Perón en los años 70, la dictadura militar, las recuperaciones democráticas que causaron circunstancias en las universidades y los años 90 con su Ley de Educación Superior, dedicada exclusivamente a la materia en estudio.

Para el periodo de 1993 la educación (exceptuando la educación superior) se veía regulada directamente por las provincias y el gobierno en su totalidad, viéndose las facultades y obligaciones extensamente delimitadas y centralizadas en un solo poder, que en este caso sería el del Estado como ente regulador. Sin embargo, desde mediados del año 1980 hasta 1997 se logra precisar una serie de avances en cuanto a la cantidad de matrículas por año que se obtuvieron tanto en la educación inicial, como primaria, media y superior. En cuanto a la educación superior, las tasas de escolarización se mantuvieron en un proceso de 4,52\% aproximadamente para el mismo periodo mencionado, es decir, a partir de 1994 hasta 1998.

Las principales acciones por parte del Estado para la modificación y evolución de todo lo referente a la educación superior iniciaron a partir del establecimiento de legislaciones que regulan todo lo concerniente a la materia. Asimismo, se generó este avance a través de las leyes mencionadas. Fue a raíz de estas reglamentaciones implementadas en el Estado que se impartió la descentralización del poder en el área educativa, estableciendo los organismos pertinentes en la materia, para el control y resguardo de los derechos a la educación de las personas, y de los deberes que el Estado debe cumplir con estos.

De manera de evidenciar todos los avances y progresos que se generen en cuanto a la educación por parte de las actividades estatales, se procede a ejecutarse un Operativo evaluativo nacional donde se aplican una serie de pruebas a los estudiantes de Argentina de manera anual para analizar y establecer un límite o porcentaje de las mejorías resultantes. Hay circunstancias que indudablemente afectan todos estos avances que se puedan obtener, tales como la atención que se le otorgue al ámbito salarial de los docentes, así como las situaciones económicas, sociales y financieras del propio estado que generen dificultades a las instituciones en cuestión.

Así, por ejemplo, se puede mencionar al Consejo de Universidades, que está subordinado por el Ministerio de Educación y el cual se encuentra integrado por el Comité 
Ejecutivo del Consejo Interuniversitario Nacional, por la Comisión Directiva del CRUP (Consejo de Rectores de Universidades Privadas), por una serie de representantes de los Consejos Regionales de Planificación de la Educación Superior y del Consejo Federal de cultura y Educación. Todas estas, e inclusive muchas más que se determinarán posteriormente, son las instituciones encargadas en la regulación y control de la educación superior y de las universidades como entes partidarios de capacitación y conocimiento.

El Estado, en sus intensas y continuas acciones por lograr la mayor efectividad en cuanto a la educación, y no solo en ese aspecto, sino en todos aquellos que involucren y beneficien a su colectividad, generó durante un largo periodo de tiempo una incontable cantidad de actividades que crearan evoluciones en cuanto a la educación, a la tecnología, y a todos los aspectos sociales que sean de gran interés e importancia. De igual manera, se enfocó en la incorporación en todos los aspectos posibles (laboral, educativo, tecnológico, social) a todas aquellas personas que por cuestiones de discapacidades o diferencias suelen ser rechazados o distanciados de la sociedad por no cumplir con las actitudes o requisitos que la misma población impone.

Así, por ejemplo, ocurre con las leyes laborales en el territorio argentino, donde se ven actualmente modificadas y actualizadas de manera tal que se involucren todos los derechos de los ciudadanos en materia de trabajo para aquellas personas incapaces y que se resguarde la protección y se asegure el debido cumplimiento de la ley en torno a ello. De la misma manera ocurre con las leyes de educación, con la obtención y capacitación adaptada a las necesidades y circunstancias de cada individuo y asegurando por encima de todo, que cada uno logre ser un ciudadano productivo y eficiente por sí mismo a través de la protección que el Estado siempre debe garantizar por medio de las leyes.

\subsubsection{Concepto de Estado y sus implicaciones fundamentales en la sociedad}

Para dar inicio al siguiente análisis, de forma importante se hablará sobre el significado de Estado, y se empezará por su concepción. Tomando en cuenta la palabra "Estado", se puede decir que es considerado un área geográfica donde se establece una sociedad en específico, claro está, teniendo en cuenta las organizaciones políticas que este conlleva junto con un gobierno propio que ejecute tales acciones para el bienestar de la población, tomando el Estado como soberado y también que sea completamente independiente de políticas 
exteriores. Existe una gran cantidad de países en la cual son considerados los más cercano a ser lo ideal de un Estado, como, por ejemplo, los Estados de Europa occidental y también Estados Unidos.

Otro concepto que se ha establecido para el término de "Estado" es él ha creado Max Weber, donde habla sobre que es un ente completamente autónomo, que en su territorio tiene una jurisdicción sobre las acciones que se implementen bajo el mandato que se establezca en un momento determinado. Claro está, este concepto tiene una cierta cantidad de elementos que son adecuados para la situación, y que por ende, son tomados con suma importancia para este ámbito en específico, por el hecho de que son considerados en calidad física, que es el territorio en sí, y la población que se encuentre en esa área, ya que a ellos es a quienes se le aplica el poder coercitivo, pero también se establecen aquellos que no son físicos, como las leyes que se van creando y actualizando según la sociedad, creadas completamente por el gobierno y el ente autónomo.

Todavía cabe destacar otra definición de Estado que es tomada en cuenta de forma internacional, es donde John Hall dice que es una serie de instituciones completamente organizadas que se encuentran dentro de un área en específico, donde la institución es una parte importante ya que es la que controla aquellos indicios de violencia, y ahí es donde se establecen una serie de reglamentos a seguir por la población que se encuentre en el territorio. Podemos decir que a pesar de las definiciones que se han presentado en el presente análisis con referencia a el significado de Estado, existen muchas más en gran cantidad, pero las definiciones que más han llevado énfasis con el transcurso del tiempo, son las que se han presentado anteriormente, que en la mayoría se establece que en cada Estado se tienen que instaurar ciertos estudios en donde se debe establecer un orden adecuado a la sociedad, y que por ende, ellos tienen que tomar en cuenta las leyes que se presenten.

Han existido una gran cantidad de teorías que tienen como referencia el tema, y hay un montón de clasificaciones para estas hipótesis en específico, unas de ellas son las teorías objetivas y las teorías subjetivas, que se dividen de tal forma para que pueda existir un mejor orden de ideas en el presente análisis, y del mismo modo, que los enfoques estén establecidos de un modo más consecuente, y que aquellas teorías del Estado puedan comprenderse de una mejor forma en el ámbito sistemático. 
Las teorías objetivas son aquellas que, desde un punto de vista realmente objetivo, el Estado es considerado como un hecho, o sea, como algo real y que está plasmado fuera de nuestra mente, en donde se abandonan todos los semblantes psicológicos de aquellas acciones que el Estado genere. Otras de las teorías que se han establecido con referencia a las objetivas, es cuando constituyen que el Estado es considerado como una situación aparente, esto quiere decir que toman en cuenta la jerarquía que se mantenga en ese momento en conjunto con la sociedad.

A su vez, se puede decir que ayuda que las organizaciones tengan mayor énfasis en los sistemas que se comienzan a emplear para que las clases sociales puedan tener una mejor clasificación, y del mismo modo, se pueda observar que la riqueza del Estado es vista como un ámbito proveedor de los obreros y de la burguesía. Con respecto a los estudios que hacen referencia a las clases sociales del Estado, se puede destacar que aquellas relaciones son la que tiene más dominio en la sociedad y se desarrollan en el interior de las personas, y por ello, se habla de lo objetivo por las acciones que los pensamientos establecen.

Ahora se hablará sobre aquellas teorías subjetivas, que tratan de las identificaciones que le establecen al Estado, que tiene un completo énfasis en la sociedad y en el gobierno, también se toma en cuenta aquellos sucesos que ocurrieron en el pasado, o sea, la historia establecida del Estado en una temática de política, y por último también se le toma en consideración aquellas índoles jurídicas. La identificación que se le otorga al Estado tiene mucho que ver con la población, por el hecho de que hay en donde se encuentra el problema que ha pasado por alto, por el hecho de que ellos tienen la capacidad de organizarse de un modo que puedan velar completamente por su bien.

Hay que tener en cuenta que un grupo determinado de personas no conforman un Estado, y si no existe una cantidad de entes jurídicos, mucho menos puede ser creado, ya que deben de estar unos acuerdos judiciales que se encuentren en cuestión, por el hecho de que debe coexistir una organización en las relaciones que estos establezcan, y que se tiene que colocar una fuerza competente que pueda ser de gran voluntad al momento de impartir las ordenes en sí. Claro está, que el pueblo también es importante para el Estado, ya que por ende es gracias a ellos que le toman forma al asunto, pero ellos no son un Estado, también es importante aclarar en este sentido de que en dicha población se le tiene que declarar una autoridad competente y por supuesto, contar con cierta cantidad territorial. 
También se toma en cuenta que el Estado con uno de sus elementos que sería el gobierno es considerado su identificador, por ende, se toma en cuenta de que es un ente completamente con autoridad en sí. Si analizamos mejor el tema en cuestión, podemos decir que el gobierno no solamente tiene el poder del Estado, sino que también se le agrega que obtienen la esencia de la misma. Con lo anterior se quiere decir que las consideraciones que se toman en cuenta son las historias de nuestros antepasados, en donde el gobierno del Estado tiene la obligación de recalcar, y por eso es que se permite crear una serie de análisis que traten sobre aquellos hechos del pasado y de las percepciones que se establezcan, tanto de la sociedad y del gobierno.

\subsubsection{Principios del Estado}

Existe una serie de principios que se toman en cuenta en el ámbito social, y pueden estar completamente asociados a unos proyectos que se van estableciendo y que son prioridad para ello, se puede tomar como ejemplo los ámbitos económicos, militares, religiosos, entre otros, que también son considerados importantes de la misma magnitud. Estas son asociadas para que pueda haber una clase de diferencias en las relaciones que la población establezca, del mismo modo, ellos toman esto como una lucha de tales principios, ya que ellos quieren mantenerlos en pie y en un orden adecuado.

Se puede decir que hay una serie de principios de socialización que tienen una competencia entre sí, por el hecho de que están vinculados a varios sistemas principales, contando de que son de diferentes entidades como tal, también cabe destacar que en la población están establecidos varios valores de la sociedad civil, y en consecuencia de esto, cualquiera podría llegar a ser dominante, no todo un período, pero si una determinada cantidad de tiempo. Tales consideraciones pueden estar realmente vinculadas a los atrevimientos para poder mantener lo más mínimo de las integraciones institucionales, claro está, teniendo una completa cohesión social dentro de aquellos límites territoriales que se establezcan en el Estado.

Ahora bien, se comenzará a hablar sobre las políticas públicas, que tratan sobre aquellos proyectos que se van generando con el pasar del tiempo, y que, de la misma forma, el Estado va creando una serie de actividades que son gestionadas a través de un gobierno y por entes de una administración pública, en la cual tiene como fin poder compensar aquellas necesidades de la población. De la misma forma, se puede comprender como aquella serie 
de acciones que implementa leyes, reglamentos y medidas estratégicas para poder combatir con cualquier tipo de violencia que se presente, que son emitidas por una entidad gubernamental.

Esto ha sido sometido a una serie de estudios completamente concretos, y de la misma forma, Morata (1992) establece aquellas teorías que se llevan a cabo con más magnitud, así mismo, de la manera más organizada posible. Estos intereses que se fueron presentando se encuentran con una doble vista, una de ella trata del desarrollo de instrumentos que se emplean en este ámbito, para poder enfocarse en los estudios que se van estableciendo con el tiempo para que puedan ser sometidos a una serie de averiguaciones eficaces, del mismo modo, la siguiente trata sobre las intervenciones públicas que se hacen por medio de este sistema.

Aquí se toma en cuenta este asunto hasta el siglo XIX, donde se comenzaron a someter a una disminución de aquellos sectores que se fueron mezclados, como, por ejemplo, la policía, la seguridad interna y externa en esos casos, la defensa, entre muchas otras clasificaciones que se toman en consideración. Cabe destacar en este sentido, aquellas organizaciones se encargan de crear una serie de métodos que realmente funcionen para que al momento de ser ejecutados puedan ser realmente satisfactorios y de gran beneficio.

Aquellos análisis que fueron realizados de una forma económica, pueden decirse que tienen una completa relación con los aumentos que se implementen por parte del Estado en cuestión, y que los desarrollos socioeconómicos vienen vinculados de igual forma, ya que tienen que ser presentados por aquellos entes con mayor jerarquía. Los crecimientos en esta área tienen un completo origen del Estado protector, $\mathrm{y}$, además, de los efectos que se presentan en este ámbito, ya que siempre han querido generar una serie de cambios en los mecanismos que estos implementen.

El crecimiento de aquellas políticas sociales que se presenten, es tomado de suma importancia por el hecho de que forma parte de aquellos frutos de las transformaciones que se muestren en el sentido más constituido en el ámbito económico, cabe decir, que al mismo momento la violencia de sus contradicciones genera un afecto enorme en estas áreas. Este punto de vista se complementa en los economistas, de tal forma que las dimensiones serian suplementaria, y los progresos que se vayan generando en el Estado formarían parte de las expansiones de los sistemas de protección social. 
Este tema en general tiene una clasificación de enfoques, que se tratan sobre la forma de gobernación que se implementen en estas políticas, y por ende, se trata sobre las organizaciones que se estén efectuado, también tomando en cuenta las personas que se encarguen de estos métodos, ya que ellos son los que tomarían las decisiones respectivas, agregando los intereses de la población para que así puedan estar bien constituido, de igual forma, la población es lo que conforma esto de manera generalizada.

Claro está, cabe resaltar que aquellas integraciones e invenciones de sistemas que se encuentren establecidos tienen mucho que ver con esos enfoques ya que poseen una sistematización, así mismo, se puede resaltar que las personas que se encargan de este asunto de procedimientos, tienen que tener la completa certeza de las cosas que están sucediendo en el Estado, ya que ellos son los que formaran las propuestas que se generen para la ayuda de los estudios formativos para la sociedad.

Aquí también se toma en cuenta como enfoque las metodologías que se implementen, del mismo modo, tiene función para los estudios que ofrezcan sobre las políticas públicas. Aquel enfoque de la misma forma está completamente definido en los materiales que se utilizarían en estos ámbitos, ya que aquellas estructuras informativas tienen que estar completamente enfocadas en la gobernanza de los agentes sociales, para que así del mismo modo se puedan crear investigaciones de los fragmentos de la realidad, que pueden servir de suma ayuda al observar las experiencias realizadas.

Aquellos enfoques sobre la gobernabilidad han estado desde hace bastante tiempo, por el hecho de que las necesidades que se van presentando cada vez son mayores y tienen una mayor magnitud en el tema, y es por eso que se requiere una serie de orientaciones para las acciones que se vayan implementando sean cada vez mejores y así también que las tutelas digeridas sean de ayuda para las personas que no posean conocimientos de estos ámbitos de gobernabilidad. A pesar de que existan entes que no conozcan sobre el asunto, de igual modo deben ser tratadas e informadas sobres los acontecimientos que sucedan en el momento.

Aquellos elementos que forman parte de estas políticas públicas, son las que de manera principal se toma en cuenta las educaciones que se implementen, esto es tomado con suma importancia por el hecho de que los conocimientos del tema tienen que estar completamente aclarados, y la sociedad tiene que obtener tales preparaciones, claro está, para que las 
políticas públicas sean aplicadas de la mejor forma y que el gobierno pueda ser visto de una forma distinta dependiendo de las acciones que lleve a cabo.

Por consiguiente, se toma en cuenta la calidad del asunto en cuestión, ya que es de vital ayuda para que las acciones y las decisiones que se implementen sean completamente eficaces y puedan ser tomadas en cuenta de forma positiva. En este sentido, las metas que se han trazado tienen mucho énfasis, ya que sirven de guía para las especializaciones y para las operaciones que se vengan formando con el tiempo, tomando en cuenta la sociedad y las legislaciones que estén en completa vigencia.

Ahora bien, las gestiones de las mismas también son consideradas como elementos. Estas tienen que estar debidamente organizadas, con una serie de métodos, como, por ejemplo, talleres que se puedan utilizar como herramienta para sus funciones, teniendo en énfasis también a las personas que poseen discapacidades, ya que para ellos de igual forma se les he creado una serie de mecanismos a seguir para que su emprendimiento en las políticas públicas pueda ser realmente efectivo y que no obtengan dudas sobre eso.

Por último, la pertinencia también es tomada en consideración, ya que es considerada una de las más importantes en este ámbito, por el hecho de que es realmente efectiva en sus implicaciones. Tiene que haber un completo compromiso en estas cuestiones porque son temas sumamente delicados que no pueden ser tomados a la deriva y mucho menos por personas que no posean conocimientos adecuados de las políticas públicas, ya que estos temas son tratados para la sociedad, y las personas que lo traten tienen que tener conocimientos sobre el asunto, además de cómo puede ser expresado para la conveniencia.

\subsubsection{Papel de distintas instituciones que fomentan políticas públicas en la materia en Argentina}

Para lograr un abordaje a profundidad sobre la importancia de las instituciones en el Estado argentino que implementen políticas públicas en el asunto estudiado, resulta necesario primeramente especificar cuál es la importancia que recae en la implantación de tales políticas públicas anteriormente analizadas. Por ello, surge necesario, dar una breve apertura sobre a qué se hace referencia con "implementar" y porque resulta esencial dentro de todo el proceso estudiado. 
La implementación en el asunto de las políticas públicas se constituye como el último paso, pero no por ello se puede catalogar como el de menos importancia, sino todo lo contrario, en él radican todas aquellas actividades en cuanto a ejecución de los planes y acciones establecidas. Es a partir de todas aquellas negociaciones y establecimientos legales impartidos que se inicia la ejecución y aplicación inmediata dentro del territorio a través de la implementación de todas aquellas consideraciones.

Diversos autores, como, por ejemplo, Morata (1992), determinan para un correcto estudio y análisis de la implantación de las políticas públicas, una serie de estructuras que enfocan todas las cualidades que la fase ejecutiva aporta para estos procedimientos. Así, inicia el autor mencionado destacando como principal característica la primacía jerárquica de la autoridad, que en estos casos se ven involucrados la administración del estado como el ente capacitado y facultado para la ejecución de las medidas establecidas. También se destaca en el asunto como segunda característica a la distinción que se debe establecer entre el aspecto político y el aspecto administrativo. De igual modo, como ultima pero no menos importante características, se establece la búsqueda exhaustiva de la eficacia en los asuntos realizados por el Estado, donde este ente como principal responsable de todo el territorio argentino y de su población en general, tiene que estar enfocado siempre a lograr la eficacia y eficiencia en cuanto a todas sus acciones establecidas y ejecutadas para asegurar el resguardo, la protección, el control y las mejorías necesarias para todos los individuos en el territorio.

Implementar puede darse como sinónimo de actuar, aplicar, ejecutar, administrar y otra serie de conceptualizaciones que requiere de suma atención y dedicación porque todo lo anteriormente estructurado y evaluado no tendría la absoluta importancia si no existe una buena interpretación y aplicación en la vida cotidiana. De este modo, se puede resumir que la implementación de las políticas públicas busca surgir diferencias en cuanto a los responsables de designar las tareas necesarias para las acciones involucradas, la comunicación y ejecución eficiente de las políticas públicas en estudio junto con las interacciones y procedimientos necesarios, el ejecutor capacitado para asegurar la correcta aplicación y elaboración de las decisiones anteriormente planteadas.

En el aspecto del estudio, en la determinación y ejecución de diversas políticas públicas se tiende a generar la participación de diversas instituciones con el fin de que estas, según 
sea su área de trabajo, aporten de una manera u otra al desenvolvimiento de dichas políticas, cabe resaltar que estas instituciones son utilizadas también como herramientas de análisis de datos, lo cual permite que aporten no solo consejería basada en ideologías sino que están en la capacidad de ejercer un análisis que favorezca al desarrollo de la política, entre estas instituciones se puede nombrar al CONICET y el Ministerio de Educación en Argentina.

Si los objetivos primordiales de las políticas públicas es buscar la resolución de los problemas sociales planteados sobre un territorio determinado y definido políticamente, es netamente necesaria la intervención pública del Estado a través de la estructuración y ejecución adecuada para asegurar buenos resultados en solventar los inconvenientes. De allí, deriva la necesidad de que no sea solo el Estado el ente preocupado y encargado de asegurar las medidas para satisfacer las necesidades sociales y solucionar los problemas consolidados, sino también surge esencial que las distintas instituciones y organizaciones del país se vean íntimamente relacionados en el asunto, para de esta manera poder abocar ampliamente los conflictos sociales y asegurar que todas las medidas implementadas sean suficientes para su resguardo y protección.

Todas aquellas instituciones públicas o subordinadas al Estado se encuentran en la obligación de aplicar las políticas públicas que sean necesarias para esclarecer los acontecimientos que se presenten en el día a día, pero la responsabilidad no recae solamente en ellas, sino en aquellas que, a pesar de no depender netamente del Estado, tienen una obligación con la sociedad que los involucra directamente a relacionarse con el ente superior y así ejecutar las políticas que sean necesarias. Más allá de un tema gubernamental o político, esta necesidad surge para la protección de la sociedad en sí, y para el resguardo de los derechos y deberes constitucionales.

En materia educacional, el Ministerio de Educación, por ser una organización directa del Estado, se le hace estrictamente necesario aplicar todas aquellas políticas públicas que vayan surgiendo con el propósito de evolucionar o mejorar en torno a la educación en Argentina, ya que, de acuerdo a las legislaciones reguladoras y la propia carta magna, es este ente el encargado de todo lo relacionado con la materia en cuestión. Asimismo, diversas instituciones privadas se han tomado el atrevimiento de interferir en las situaciones de la Nación y ejecutar las políticas públicas que sean pertinentes para su buen desarrollo y su 
colaboración con el asunto, así, por ejemplo, ocurre con el Consejo Nacional de Investigaciones Científicas y Técnicas.

El Consejo Nacional de Investigaciones Científicas y Técnicas (CONICET), tiene como objetivo que los entes públicos puedan entender debidamente los temas que se les presenten, de igual modo, que puedan emplearlos de una manera eficaz y positiva, para que la evolución de los mismos sea cada vez más satisfactoria. Aquellos conocimientos que se fueron generando a partir de los procesos pueden ser ejecutados de una forma favorable, claro está, que dichos conocimientos estén basados en investigaciones que estén apropiadamente empleadas, y que se obtenga calidad en el asunto.

Lo anteriormente mencionado quiere decir que aquellas funciones que ellos llevan a cabo para las políticas, se generan de los conocimientos que se pueden ir complementando con el tiempo por medio de las investigaciones que se realicen. CONICET ayuda a que los proyectos establecidos del Estado tengan una completa cohesión, y de la misma forma, brindan el apoyo necesario a las actividades editoriales del Estado Argentino que traten sobre la ciencia y tecnología, agregándole así también que dichos asuntos sean expresados de una manera verbal o física, ya que ambos tendrían de igual modo una función positiva para los proyectos trazados o que estén por tratarse.

Cabe destacar que, en la actualidad, el uso masivo de las tecnologías es bastante elevado, ya que la sociedad se ha ido adaptando mucho más a ellas, y con lo mismo, la población busca la manera de investigar la mayor información posible para que sus curiosidades puedan ser satisfechas. De la misma manera, estas tecnologías fueron diseñadas para que el gobierno pueda presentar sus ideales por los medios digitales que a ellos en el momento les parezcan oportuno. Destacando esta parte del análisis, se puede decir que existen asuntos que van en conjunto con los propósitos políticos públicos, sean decisiones que deban tomarse, consideraciones u otras implicaciones que puedan presentarse por medio de las vías tecnológicas.

Teniendo en cuenta el interés que presentan diversas organizaciones y personas, para promover algún tipo de política en una sector en específico o a nivel nacional, se debe mencionar que el avance tecnológico debe ser, por lo consecuente, acelerado, en constante modificación y actualizarse continuamente según los indicadores internacionales para procurar mantenerse siempre a la vanguardia, puesto a que las diferentes áreas tecnológicas 
permitirán a las personas poder abarcar mayor área y poder establecer su idea de manera sólida frente a las comunidades a las que va dirigido.

Debido a esto, diversas autoridades tanto de instituciones de investigación como universitarias han aportado sus esfuerzos para permitir que estos medios tecnológicos se encuentren bajo ciertos estándares que permitan el uso de todos los argentinos, uno de los enfoques que se han tocado en los últimos años es el contenido de acceso público y abierto, puesto que existen librerías en línea que permiten a los usuarios tener acceso a diferentes documentos de manera libre y gratuita, uno de estas librerías es la Scientific Electronic Library Online o SciELO, la cual posee una selección de revistas seleccionadas bajo diversos entandares, lo cual asegura que los documentos presentes en su plataforma posean la veracidad necesaria para que sus usuarios puedan utilizar los mismos con la seguridad de que son documentos con contenido verdadero

Al mismo tiempo, estos sistemas informativos tienen que ser acordados con bastante compromiso, por el hecho de que se va generando una clase de presión entre los trabajadores de la producción de información científica, por ello, las capacidades que se vayan formando no deben ser modificadas en su totalidad, sino solamente que sean perfeccionadas. Esas acciones van presentando una serie de metas en cada trabajador que se refieren a la política, y del mismo modo los integrantes de la organización van observando hacia el horizonte, en otras palabras, hacia el futuro, y se puede decir que las formaciones que se han ido fundando son consideradas de igual forma como una serie de productos sociales que se van estableciendo con el tiempo, que tiene como función que la población y las implicaciones que este conlleva puedan ser completamente específicas.

En estos temas se puede decir, que las diferencias que se han ido generando son establecidas en las clasificaciones de jerarquía, y necesariamente no tienen que ser del mismo rango, sino simplemente que se encarguen de las mismas funciones pero que sus instituciones sean completamente distintas. Esto quiere decir, que las decisiones que se vayan ejecutando, van completamente dirigidas por las gerencias del CONICET y de igual modo de aquellas autoridades políticas que se vayan generando en los sistemas argentinos, tomando en cuenta también los entes que se encargan de formar los equipos para las investigaciones respectivas de los temas que se planteen. 
En esta área se le agrega una serie de consideraciones que se toman en cuenta para las técnicas que se vayan ejecutando. Desde 1974, CONICET es el completo responsable de las publicaciones que se les presenten, y de la misma forma, ellos se encargan de la organización de los mismos, y ellos también toman el completo encargo de aquellos recursos que se vayan generando, contando con aquellos que fueron editados dentro del país, refiriéndose en conjunto con los registros de los mismos, agregándole su base de datos para que sea tomado en cuenta de forma internacional.

Últimamente se han ido creando algunos organismos que tienen completamente centralizada la participación del Estado argentino, de allí se obtiene un enfoque en las revistas que poseen como tema principal las funciones científicas en un contexto completamente extenso sin restricción alguna, y también completamente gratuito, o sea, que cualquier persona que desee integrarse a estos sistemas puede hacerlo, sin ni siquiera tomar en cuenta el lugar donde se encuentren, ya que es tomado de una forma internacional, destacando que tampoco existirá discriminaciones. Teniendo en cuenta que los programas que ellos utilizan se encargan de crear nuevos métodos de aprendizaje, sobre los almacenamientos de información, y de igual forma, tomando en cuenta las evaluaciones de las publicaciones científicas que se encuentren en el soporte técnico, donde cada uno debe generar un completo impacto en la sociedad, y en la política de igual modo.

Todos estos sistemas son creados adaptándose al método educativo de cada persona, sean considerados principiantes, más expertos en el área, o que la persona no obtenga mucho conocimiento, pero tampoco posea demasiado. Estos procedimientos han sido creados tomando en cuenta la perspectiva de los usuarios, manteniendo de igual forma las variedades en los temas, y aquellos programas que tienen soporte para la sociedad política, tomando en cuenta los grupos que se vayan generando para que las conclusiones de los temas sean realmente efectivos, y agradables.

Este así también permite brindar apoyo a aquellos autores de las informaciones científicas y tecnológicas que se vendrían tratando en conjunto con la política pública, ya que las plataformas que se generan deben servir de tutela para el investigador, y que esa tutela trate sobre los antecedentes informativos que tuvieron en función de que fuera de una gran calidad, y que así pueda ser publicado de manera internacional sin que haya ningún tipo de inconveniente. Con eso también se propone al apoyo de las normas de los análisis 
documentales que estén en el momento, y también a los repositos especializados, tomando en cuenta la profundización de conocimiento.

Los servicios que este genera son para el apoyo a aquellos propósitos que se estén trazando, tomándose en cuenta el ámbito político. Así también otros servicios que este implementa es que los elementos sean debidamente expresados y que sean tomados en cuenta, que son los valores, el vocabulario que se esté utilizando.

Con relación a los diversos aspectos mencionados se denota la importancia que poseen las diferentes organizaciones en unión con el Estado para poder analizar y ejecutar políticas públicas que favorezcan el ámbito de la educación, implementando de igual manera dentro de dichas políticas elementos que permitan una integración de las diferentes personas que deseen formar parte de alguna institución educativa sin que se presenten problemáticas en el caso de que dicha persona posea alguna limitante o discapacidad, puesto que la educación no debe limitarse a ciertos sectores o personas con ciertas condiciones sino que debe ser integral

y todo individuo debe estar en la potestad de recibirla y el Estado debe asegurar que esto se cumpla por medio de sus políticas, siempre haciendo énfasis en la supervisión de las mismas para que se cerciore de que se cumplan de manera eficiente.

\section{Marco conceptual}

\subsection{Las TIC y las representaciones sociales}

La representación social partiendo desde un concepto básico trata de los distintos aspectos culturales con relación al hombre para ser investigado y analizado, a través de la interacción con otros participantes de su entorno social. El ser humano al ser una persona "social", interactúa y se relaciona con los otros para la construcción de una mejor sociedad. Principalmente esta busca la creación de teorías que respondan a los patrones de conducta de los individuos, tanto en solitarios como de manera grupal, analizando los estatutos y su relación con el sujeto. Estas parten de los seres humanos como principales productores de representaciones sociales, así lo encuentran los autores Emile Durkheim (1985) y Serge Moscovici (1969), dado a qué la relación con el entorno permite crear nuevos métodos de adaptación, generando patrones de conducta y creencias a las cuales se aferran (Ortiz, 2012). 
En el campo de las ciencias esta tiene lugar en la psicología generando sin embargo tema de discusión ya que puede emplearse de distintas maneras en materias que no se refiera a la psicología, explicando y conservando que esta es la representación del conocimiento, puede ser filosófico, lingüístico, matemático o psicológico. La definición de representación suele estar enfocada, partiendo de la perspectiva de autores como Ibarra (2000), a la sustitución, queriéndose referir a el acto en el que el sujeto sustituye un objeto y pasa a representarlo a de manera simbólica (Materán, 2008). Esa representación es vista como una forma de sustitución o adecuación de un objeto al cual se quiere copiar o representar, esta no solo implica la transformación de este proceso, sino que los sujetos tienen su propia interpretación de la realidad que los acontece, esta está basada en los criterios, valores, religión y necesidades que este pueda tener, además de otros aspectos que pueden afectarlo, demostrado así en los aspectos socioculturales.

Aquí se incluye el lenguaje y las prácticas sociales que presenta un grupo cultural específico, aplicando que las representaciones sociales se encuentran y demuestran en la cultura, sociedades y el mundo en sí mismo, dado a que las comunicaciones e información transmitida de manera interpersonal, usando los medios de comunicación para moldear y forjar la moral y el sentido del bienestar colectivo en las personas. Las categorías sociales como los valores, las creencias y las actitudes participan de manera principal como organizadores del objeto en materia social. La TRS es de gran interés ya que se encarga de seguir los procesos involucrados con lo educativo y el estudio de estos objetos.

La representación social vista desde otro ángulo más específico, tomándola como una conciencia colectiva que poco a poco se fue adaptando a los nuevos métodos y formas de legitimación de las sociedades en el mundo moderno, en el cual los grupos sociales están en la obligación de legitimar las bases del conocimiento que dan paso a nuevas ciencias y que actúan según el sentido común de las personas, en función de lo que es socialmente correcto en consenso (Materán, 2008). Las diferencias sociales son los que hacen surgir la representación social y van de la mano, no se puede hablar de una sin la otra ya que el capital cultural y las creencias que estos posean se vinculan directamente con el status que tengas en la sociedad, ya sea de mayor o menor rango. 
En el libro de la Aproximación al estudio de las representaciones sociales escrito por Elsa Ortiz (2012) se propone un ejemplo, sin embargo, es necesario agregar otro, como en el caso geográfico, el preceder del sujeto lo suele clasificar, como consecuencia, en una mayor o menor posición en la escala social. Si provienes de una zona rural, sin internet en esta sociedad "moderna" estas en los estratos más bajos ya que se supone que hasta allá no llega la información y por ende la gente es más iletrada, no es lo mismo a vivir en el centro de la ciudad y sin embargo estés sin internet, ya que de todos modos suelen llegar más las noticias y con mayor rapidez, por lo tanto se entiende que estas personas son colegiados profesionales (Castorina, Kaplan, 2003).

La sociedad suele clasificar a las personas, reafirmando un patrón tradicional y sociocultural. Esta forma de ver la realidad que nos acontece no viene aprendida, se enseña y se va forjando a través de las experiencias adquiridas, al principio es algo inconsciente pero poco a poco las personas van apropiándose de esos valores y conocimientos, representándolo de distintas formas, no solo en lo en lo individual, sino en lo social ya que mayormente esto es lo que busca, patrones de conducta en base al carácter social (Materán, 2008). Con el paso de los años, las interacciones de los seres humanos generan nuevas formas comunicarse, mediante la educación y los medios de comunicación que forman parte esencial de este aspecto. Estos le dan fuerza en torno a la construcción que tiene cada uno de la realidad que lo rodea y cómo la percibe, no solo como individuo, sino la forma en la que lo hacen las otras personas, generando nuevas perspectivas o aprobación e identificación entre los que comparten el mismo enfoque.

Los medios de comunicación influyen en la percepción de las personas, ya que cada uno proporciona una forma de ver la realidad, tus decisiones te darán una perspectiva distinta del que ve o utiliza otro medio. Estos suelen presentar una versión de los hechos y no todo el suceso, algunos medios si lo hacen, aquellos que actúan con imparcialidad, pero en su mayoría no presentan el caso completo o de la mejor manera, permitiendo que los usuarios decidan por si solos que les parece ese suceso, los mismos medios permiten el mantenimiento del estatus en la sociedad. Los objetos sociales como parte de la representación, ya que permiten clasificar, valorar, explicar por qué pasa y evaluarlo al mismo tiempo, permitiendo conocer la realidad de otras comunidades a través de la explicación de un fenómeno o suceso 
ocurrido en algún lugar, y que generalmente es cuestionado por medio de los procesos de comunicación y del pensamiento social (Materán, 2008).

Las RS permiten entender la dinámica de las interacciones personales y las habilidades sociales que la conforman, describiendo las representaciones, la estructuración de los discursos y las practicas que se van generando mutuamente por la interacción anteriormente mencionada. Los contenidos manifestados por las operaciones realizadas en los procesos se caracterizan por el sentido común que provee el conocimiento, este otorga un pensamiento dirigido hacia lo social y el bien colectivo, constituyendo formas de pensar y actuar orientados a la mejor comunicación, la comprensión y el dominio de la realidad que la rodea de manera ideal o material (Materán, 2008).

En todos los casos las representaciones sociales están formadas por procesos cognitivos conscientes e inconscientes, en donde se generan valores buenos o malos, creencias, normas, opiniones y estereotipos convencionales designados así por consenso y que actúan en función de los principios orientadores e interpretativos de las interacciones sociales. Las RS es la representación de algo (un objeto) y de alguien (el intérprete), ya que este último lo traduce mediante un proceso intelectual y es allí cuando entra en juego el objeto pasando a ser un símbolo. Entendiendo lo anterior se puede decir, partiendo de lo establecido por Jodelet (1984), que es un proceso de transformación en el que el algo pasa a ser un símbolo en la mente del alguien, caracterizándolo así en las mentes de todos a través de una elección previa y consensuada (Ortíz, 2012).

El ser humano suele tener este procedimiento para el entendimiento de las RS y reflexionar por el cómo fueron concebidas por ellos, dando paso a la legitimación o invalidez, aceptación o reconstrucción del mismo a través de la meditación. La teoría de las representaciones sociales cubren un espacio que había dejado libre el marxismo clásico, en donde las personas solo se dedicaban a observar lo que pasaba alrededor de manera pasiva, sin embargo lo que se plantea esta autora es que al llenar esta área los seres humanos no son seres pasivos, dispuestos a no hacer nada con respecto a las situaciones que los rodean, sino que es eso lo que motiva a querer reconstruir las bases sociales, pensando, criticando y comparando para avanzar y en algunos casos retroceder, mejorando y cambiado los acontecimientos (Ortiz, 2012). 
Como sujetos individuales los humanos son moldeados, al igual que nuestros pensamientos, por los medios de condicionamiento social que se convierten en formas subjetivas de ver los hechos, ya que de alguna manera eso ha sido afectado por las plantillas sociales que se impuesto a través de las distintas instituciones, llámese familia o sociedad en general, estos mismos pensamientos pasaran a las próximas generaciones. Este hecho está presente constantemente, aunque al tener derecho de libre pensamiento o ideología puede romper con algunos de esos patrones, aferrándose a la autonomía.

El querer reafirmar la capacidad de autonomía conlleva al rompimiento de la filosofía de vida que ha sido impuesta y aceptada de tal manera que lleguen a pensar que esa es su voluntad, empujados a cuestionar la institución llamada sociedad, que pone las reglas y límites de lo bueno y lo malo, y exponer a las instituciones que esta abarca, asumiendo que han sido ellos quienes les han dado el poder de dominar el mundo, pasando rápidamente por una transición en la que vuelven a darle la razón a la sociedad, porque sin ella no pueden vivir en paz con los demás, sin las instituciones y leyes habría anarquía, quien más que ellos son es capaces de cambiar a la sociedad y mantenerla de manera consciente Castoriadis (1997).

Moscovici (1961) explica que, a diferencia de Durkheim (1895), la sociedad no es algo externo, sino que esta la conforman cada uno de ellos de manera individual, formando así con las RS las construcciones sociales, esto reestructura a la palabra con un significado más libre y no como un hecho cultural que se impone lo cual lo hace legitimo para la humanidad. Esta posición se basa en lo constructivista que viene del conocimiento y no en el dualismo que existe entre el mundo y la imaginación, apoyado por la psicología del pensamiento y la mente.

Las RS son sumamente importantes para poder describir y explicar las prácticas sociales de los seres humanos, de manera clara y que pueda ser comprendida de manera sencilla. Los sujetos entendidos como seres sociales y entendidos como actores de la vida cotidiana dan paso a fenómenos y acontecimientos producto de las interacciones, que necesitan ser investigados para dar sentido a estos y a los que los realizan el porqué de lo que hacen, poniendo en perspectiva la vida y los objetos que forman parte de las culturas, tanto básicas como particulares (poco comunes). 
Lo valioso de esta teoría, aclarando que el cuestionar las áreas de nuestra vida, el conocer y descubrir lo que conforma el centro fundamental de una sociedad, del cual surgen la creencias e ideologías constituyen un proceso trascendental para el cambio de la representación y una mejora de las prácticas sociales (Materán, 2008). El reajuste de las creencias que se consideran impropias e inadecuadas, la revalorización de los saberes que proveen el importante sentido común y la ciencia vista como punto crítico de los sucesos que acontecen diariamente, hace un cambio en la interpretación de la vida.

Estas figuras proporcionan enfoques necesarios para una alteración en las representaciones sociales y la contribución de una mejoría social. Jodelet interpreta esto como la forma en la que los sujetos piensan, sienten, conocen e interpretan los fenómenos que ocurren a su alrededor y como ellos como sujetos forman parte esencial de estos para cambiarlos y reconstruir esas prácticas sociales en donde los sucesos de más alto impacto son aquellos que se apartan o destacan gracias a sus características que se salen de lo común o se forman de manera compleja, poniendo en marcha cada uno de los elementos que deben ser analizados y reintegrados mediante el aprendizaje de varios enfoques o mirado por varias perspectivas para lo cual es necesario y fundamental el trabajo en equipo.

\subsubsection{Evolución}

A comienzos del año 1961 se describió una teoría planteada por Moscovici (1961), llamada la teoría de las representaciones sociales, una teoría que tiene un amplio desarrollo y que ha sido causa de múltiples investigaciones en varios países, con el fin de descubrir nuevas ideas y aportes sobre la concepción del mismo y darle un uso mediante la ciencia, agregando el surgimiento de sus diversas disposiciones que permiten un aporte favorable para la comprensión de los fenómenos situacionales que puedan ocurrir o que ya ocurrieron en el mundo. Cabe destacar que en 1985 también existió una teoría acerca de esto, concebida por Durkheim (1985), que hablaba de la TRS, pero de una manera más colectiva.

La especificación de dichas orientaciones dicha por Moscovici (1961) pone en práctica cada una de las herramientas para las cuales se ha dotado de maneta metodológica adecuadamente, dando paso en este marco a los artículos en los cuales se esbozarán las características que conciernen a las TRS y sus diversos estudios. En cuanto a la investigación original llevada por Moscovici pone en práctica la teoría de psicoanalítica durante los años 
50e intenta dar un ejemplo de cómo se puede aplicar y cómo este puede ser útil para las TRS de manera metodológica y científica, en donde se pueden tomar como base las orientaciones ya existentes.

Moscovici (1969) explica el derrumbe de una investigación tradicional que pretendía cambiar los comportamientos de las personas o predecirlos para así poder contrarrestarlos. La relación sujeto y objeto formaría parte de esto mediante la exploración de la relación entre un estímulo y su respuesta, mejor dicho, la reacción de un sujeto al provocarle un estímulo, viendo así la reacción que podrían tener millones de personas ante un suceso antes de que este ocurra. Este experimento divide el mundo exterior del interior, colocando al sujeto y a el objeto (surgidos de un mismo modo, lo que los hace iguales), provocando la representación de un suceso de manera conjunta e indiferente, llamado estímulo y respuesta.

De lo anterior surgen nuevos espacios y diversas formas de analizar un hecho de manera sensible, objetiva y metódica, reconociendo un nuevo concepto de cultura, cotidiano, y subjetivo en donde las personas le dan un giro y significado de valorización distinto con la capacidad de antes de transformarse (Ortiz, 2012). Estos mismos aspectos que eran invisibles al ojo humano e incapaz de ser tratados objetivamente ponen en juego el paradigma positivista y reivindica el valor de primer orden, sin abandonar los métodos y criterios científicos.

Según hace referencia Ortiz (2012), Edgar Morín (1997) explica la complejidad que compone la esencia del ser humano y que no ha tenido resultados efectivos científicamente, demostrando que es necesario una posición crítica y evaluativa sobre el aumento de las flexibilización e interminable búsqueda de otros modelos de teorías rígidas y metódicas que hagan más fácil el hecho de comprender y explicar el estado humano en el que se encuentran actualmente, esto ayudaría a la mejor apreciación del concepto del saber que sin embargo está mucho más claro que la definición de conocimiento o del mismo pero tratado de manera científica. Luego de la aclaración anterior se puede hablar de las verdades compuestas de manera sumamente compleja y que lleva a cabo las claves del conocimiento (también del científico), pero también las herramientas y formas del saber.

Esta perspectiva comprende la complejidad del ser humano y los dogmas convencionales de la simplificación, el camino hacia el positivismo y las conductas 
socialmente aceptadas, para la reorganización tradicional de la orientación de todo y por supuesto en el ámbito educacional, en donde se les comparte a los jóvenes una forma de aprendizaje lineal, mecánico y que pasa de generación en generación, entendido como una simple causa y efecto proporcional, es decir, los niños aprenden algo, pueden ser conductas o hábitos buenos o malos representando la causa, que luego se convertirá en un hecho o sujeto bueno o malo.

\subsubsection{Aspectos generales de las RS}

Esta teoría vive en constante desarrollo y se ha vuelto tema de discusión desde la década de los 60 en Francia hasta la actualidad con lo cual han pasado más de 50 años desde su primera aparición en el mundo, esta sigue siendo tema de debate por su aplicación teórica y abarque en las investigaciones obtenidas a través de la experiencia y observación de los acontecimientos, además de la integración del orden interdisciplinario planteado a modo de evolución del mismo y estudio en la actualidad. Este modelo puede considerarse relativamente nuevo en el área de la psicología, ya que este propone un esquema metódico que no solo es dinámico y atrayente, sino que propone un análisis renovador dentro del llamado sentido común que permite tomar decisiones en la vida diaria y en la cotidianidad, valorándose como la perfecta explicación de la construcción social de la realidad.

Con el estudio de Moscovici (1961), aplicado al público francés obteniendo respuestas sobre como la representación social aplica también para el psicoanálisis, este autor explica en su libro llamado el psicoanálisis, su imagen y su público las TRS formalizando así un estudio que constituyó el descubrimiento de un terreno novedoso y de investigación no antes vista de la psicología social. El concepto de RS lo componen una serie de sistemas mentales llevados con lógica y lenguajes propios de cada uno, que no solo la caracterizan simples opiniones, actitudes e imágenes sobre algún objeto o símbolo, sino que estas teorías y materias de investigación conceptual abarcan otras áreas como el conocimiento y la organización de una perspectiva de la realidad.

Estos sistemas de valores, pensamientos y maniobras tienen una doble función, en este caso es establecer principalmente un orden que permita a cada uno de los sujetos por individual ubicarse en el mundo de forma material y social, dominando así estos temas, en segundo lugar está la comunicación entre los miembros de una comunidad específica y 
proveerlos de leyes o normas para regir el comportamiento y un código lingüístico único para nombrar y clasificar los diversos aspectos que los rodean, generando una historia individual (personal) y grupal como humanidad evolutiva. Las representaciones sociales no solo son generadas por la mente, sino que estas están más allá de lo que se cree, como construcciones simbólicas que se originan y reconstruyen mediante el avance de las interacciones sociales, comprendiendo que estas no son estáticas y no las definen por completo.

Estas pueden explicar de forma específica cuáles y cómo dar a conocer mediante un comunicado, la realidad e influencia determinadas por las respuestas dadas mediante la interacción de las personas con los sucesos (Rateau, 2013). El equivalente a estos (interacciones humanas), son la sociedad y los sistemas de creencias tradicionales, llegando a conocerse que estos representan la visión más contemporánea del sentido común. Las formas de pensar y de ver la realidad pertenecen a un grupo de elementos de propiedad simbólica y que permiten adquirir e imitar el conocimiento y el saber, sin esto las personas no tienen la capacidad de transferir el sentido de realidad social, con la única finalidad de modificar lo desconocido en algo natural reconocible, esto es para Moscovici un carácter que debe ser usado universalmente.

Las RS son caracterizadas como la manera más genérica de conceptualizar a las instituciones operativas, usada para el mejor entendimiento de la comunicación y la actuación en la vida diaria, estas actúan como un conjunto organizado e impreciso de creencias, imágenes y conocimiento que es necesario y con la que los humanos cuentan para actuar en las distintas situaciones que se presenten y así llevar a cabo un plan de acción (Rateau, 2013). Otra característica de esta es que se obtienen a través de la experiencia que se produce con el contacto con los demás en la vida cotidiana, adquiriendo el sentido común o el cómo actuar en las diferentes situaciones que acontecen, como las enfermedades, etapas de crecimiento, muerte de amigos o familia y muchas más, esta concepción de las RS la transforma en un conjunto que ha generado investigación de forma empírica en materia de las ciencias sociales.

Las funciones de las RS según León (2002), explica que estas tienen diversas funciones que se muestran cuando se conoce su verdadera naturaleza en el ámbito social, obteniendo de estas cuatro características funcionales. El convencionalismo es uno de ellos, los objetos, sujetos y fenómenos que suceden diariamente, concediéndole el hecho de una forma 
determinante, ubicándolo en una condición y establecerlo en un modelo distinguido y diferente tipo, compartido por una comunidad de personas, en el cual se convierte de una realidad desconocida a una acostumbrada y habitual.

Otra de esas funciones es propiciar la buena comunicación e interacción entre las personas, ya que el primer aspecto implica compartir distintas perspectivas de la realidad y diversos ámbitos. La número tres trata de patrocinar el pensamiento colectivo y la reflexión de los grupos sociales para generar una identidad social como requisito fundamental para pertenecer y conocer el grupo al cual se está denominado. Finalmente, el justificar las decisiones y comportamiento producto de la interacción sociales entre estos grupos.

Las RS son parte fundamental de la explicación de la interacción social y sus funciones por su carácter compartido, lo cual intercede directamente de varias maneras, por el ambiente en el cual las personas y grupos sociales están ubicados y la comunicación que crean entre ellos, mediante el conjunto de conocimientos el cual se les otorga previamente, como la cultura, los códigos lingüísticos, valores éticos e ideologías religiosas o no, que están directamente atados con su posición social o jerarquía especifica.

Las RS nacen gracias a determinadas circunstancias en la cuales las condiciones no son las ideales y se requieren de ideas claras, que puedan ser de provecho en una situación de conflicto o de crisis, según esto hay tres herramientas a ser usadas en estas situaciones. Entre los factores se encuentran la dispersión de la información en la cual esta nunca es suficiente y siempre esta desorganizada, ya que los datos con los que se cuenta son mayormente parte de las experiencias y respuestas a los estímulos de las personas, formando una idea u objeto preciso, que limita la investigación y que en algunos casos abunda. Luego está la focalización, en el cual las personas de una comunidad se enfocan en el proceso y se involucran en la interacción social, como parte de modificar los pensamientos y opiniones de estos.

La presión a la inferencia es cuando la sociedad reclama informes, actitudes y acciones con respecto a hechos que son de interés público necesarios para establecer una postura y tomar acción ante ellos. Esto se exige ya que en todo momento deben ser capaces de responder a una situación y tomar las medidas requeridas por los grupos sociales durante la vida cotidiana. Las exigencias de estos grupos son en base al querer conocer cómo debe de 
actuar en un momento determinado, en donde su vida cotidiana se ve afectada, con el propósito de no ser excluido en la comunicación de las conversaciones y poder realizar deducciones rápidas, opiniones sobre estas y construir un discurso elaborado de respuesta, constituyendo con lo dicho anteriormente un proceso de formación para los habitantes y estos a su vez estar prevenidos.

\subsubsection{Proceso de formación de las representaciones sociales}

A partir de aquí se dan dos procesos mediante los cuales se generan las RS, estos mecanismos sirven para la interpretación de los grupos sociales al mismo tiempo que van siendo guiados y controlar sus acciones, así mismo explora el hecho de cómo lo social se transforma en conocimiento que posteriormente pasa a ser representado y como este último logra transformar lo social. El primero de estos mecanismos es llamado objetivación que se refiere al objeto social en lo que respecta a la representación, es un procedimiento que inicia con la selección y luego con la descontextualización de los elementos que la conforman, también pueden ser ideas o conceptos que formaran un centro o núcleo que se transforma de conceptos abstractos a imágenes concretas (símbolos). Este proceso lleva a la realidad un bosquejo del desarrollo de una imagen a una estructura definida, mediante ese proceso se plasman el conjunto de significados, estableciendo un concepto relacionado con una imagen.

Moscovici (1969) plantea que la objetivación no es más que el recoger un exceso de conocimiento y significados que luego pasaran a ser plasmados, reconstruyendo lo que el objeto significa, volviéndolo familiar para la garantía de control de ese suceso. El autor finaliza con el análisis de este proceso, en el cual logra reconocer la relación que hay entre los valores, los pensamientos y lo parámetros que establecen la realidad social, poniendo en práctica la constitución de valores creada por la RS explicando los diferentes campos normativos por lo que se da. La objetivación es solo la explicación de un conocimiento científico de dominio público, siguiéndolo un segundo proceso llamado anclaje.

O mejor descrito, la representación en el contexto social, este se define como un marco de referencia en donde los grupos sociales son usados como herramientas para interpretar la realidad y poder actuar conforme a ella. Este permite que los sucesos y los símbolos de la realidad no se presenten como extraños, sino que se vayan incorporando poco a poco como parte de una agregación a la realidad social, a través de este proceso la sociedad modifica un 
objeto social por una herramienta mediante la cual se pueda disponer de este, colocándolo en un status de preferencia según las relaciones sociales previamente existentes. Este consiste en transformar lo que resulta desconocido a algo habitual en la cotidianidad, reconocer aquello que parece extraños en el día a día, así lo que lo diferencia de la objetivación es la cualidad de integración en una amplia trama de clases y significados.

El anclaje incluye la inclusión de conocimientos mediante la representación cognitiva del objeto dentro de un sistema existente formado por las ideas y sus respectivas mutaciones, tratándose de una inclusión en una organización del pensamiento previamente constituido. Jodelet (1999) declaraba que este mecanismo suele generar conclusiones rápidas sobre la aprobación de nueva información relacionado al modelo previamente acordado que proporciona una base ideológica para integrar a la representación simbólica y a las funciones que lo acompañan.

Para Moscovici (1969), ambos procesos, tanto la objetivación como el anclaje, limitan las normas de lo que se debe o no hacer, y así como el primero define los elementos que circulan en una sociedad, el segundo los hace comprensibles y naturales a modo de poder contribuir a la generación de relaciones sociales y su nueva forma de expresión. Las RS suelen aparecer en las sociedades modernas en las que circula un grado medio de conocimiento, dado por un modelo dinámico por las informaciones que allí se manejan y que demandan ser apreciadas como guías de uso para a vida diaria, diferenciándose de otras teorías, las representaciones sociales no tienen la viabilidad de convertirse en tradiciones ya que los medios de comunicación requieren de un cambio constante y variedad de conocimientos.

Tratando el tema de investigación este tiene un campo muy amplio, en donde desde el principio de su creación el número de análisis ha ido creciendo y multiplicándose, los estudios sobre este en materia psicoanalítica, agregado a eso el ambiente urbano, las enfermedades, la corporeidad, entre otras cualidades, son algunos de las razones por las cuales se debe aplicar un enfoque a este como una investigación empírica. Esta a pesar de ser una herramienta exquisita para investigar y analizar la realidad social, muchos otros la han criticado como un modelo poco preciso, refiriéndose a ella como una teoría que posee ambigüedad al momento de definir las representaciones, pero que al mismo tiempo 
Moscovici reconoce como perfecto para tener la posibilidad de crear e integrar nuevos elementos a esta teoría, sin precisar un proceso sistemático molesto.

Sin embargo, estas críticas se han convertido en un área de exploración importante, ya que lleva a la reflexión e indagación psicosocial, sin estas críticas no se hubiesen generado numerosas investigaciones que conducen a un debate teórico sobre las semejanzas y diferencias con otros enfoques y definiciones que puedan resultar a fin. Esta se enfoca en la reconstrucción social del saber, dentro del cual los estudios sobre la mente y su relación con la sociedad, se focalizan con una identidad caracterizada por lo psicológico social que cada vez más se aleja de lo psicológico, de lo cual se ha caracterizado desde hace mucho tiempo.

\subsubsection{La teoría de representación social (TRS)}

Esta es una propuesta que se hace en busca de un explicación teórica y metodológica de los distintos aspectos de los procesos educativos y así poder entender el por qué los profesores, estudiantes y personas en general traen sus valores y creencias aprendidas (prácticas sociales), a sus trabajos, su vida privada y otros ámbitos. Las RS son herramientas necesarias para poder darle significado a los diversos espacios en los que se vive o en los que alguien convive, el primero representado por una materia, una estrategia de marketing y el segundo por alumnos o un CEO respectivamente.

En la TRS se encuentra una subteoría llamada teoría del sentido común, en donde se pude observar a la psicología social como una materia que se dedica a la investigación de este y se especifica al hecho de que constantemente se dirigen a aprender conocimientos y facultades de poca confianza, lo que cual no logra explicar el mundo. Es necesario comprender y dominar el ambiente en el que están, volviéndolo previsible y encontrando estabilidad y coherencia en la realidad, si esto no funcionara de esta manera no podrían evolucionar y encontrarse en un limbo, estático en el que no pueden avanzar, sin coherencia o estabilidad no pueden alcanzar el puro significado de los sucesos y acontecimientos, no comprenden los comportamientos, las ideas o las interacciones que los mantienen en constante relación con los demás en una misma sociedad.

Las representaciones sociales se pueden considerar como un sistema que funciona a base de opiniones, saberes, conocimiento, creencias y valores, que son características de una cultura determinada y forman parte de un grupo social. Estas implican una pequeña distinción 
entre las nociones de las opiniones de los demás y sus creencias que muchas veces suelen ser antiguas. Las opiniones vienen del más sincero cuestionamiento sobre una situación y tomando una postura sobre eso, mientras que los conocimientos provienen del saber y de las experiencias que han tenido o de las de alguien más, también aprenden de sus creencias y convicciones, todo esto demuestra que pueden adquirir información de cualquier sitio. La observación constante de estos fenómenos, estos proveen de conocimientos valiosos, que al mismo tiempo genera una confusión entre lo que uno piensa, cree o sabe, lo que no deja del todo calificados para dar opiniones o información, concluyendo que las RS son un conjunto muy complejo de elementos almacenados en la mente y que son sobre objetos y símbolos que forman parte de una realidad.

Esta teoría tiene cuatro características fundamentales, la primera es que todo es organizado, refiriéndose a que no necesariamente todo está colocado de manera exacta, pero todos forman parte de una estructura que los mantiene unidos, estos elementos que interactúan entre sí, tienen conexiones independientes (Rateau, 2013). Esa correlación son el resultado de una visión múltiple de un suceso, estas pueden ser apreciadas como perspectivas distintas que dan un mejor enfoque, de forma que hay una equidad entre el manejo de términos, pero también aporta para los que son o no piensan de la misma forma, las opiniones pueden ser compatibles con ciertas creencias o al contrario ir en contraposición con ellas.

En segundo lugar, están los pensamientos compartidos por un mismo grupo social, este dicho consenso por parte de un grupo social puede ser relativo, ya que una vez puesto en práctica la dependencia y homogeneidad del grupo con respecto a un objeto puede romperse y de esta manera esta supuesta representación de las ideas de todos puede estar parcializado y con frecuencia estar limitado a unos pocos. La número tres tiene que ver con un complejo proceso comunicacional, producto de un consenso colectivo, que puesto en marcha el común de los elementos originarios forman parte de la RS y que como consecuencia está subordinado y obligado a ser compartido por los intercambios individuales y las comunicaciones internas y externas que se producen en el grupo (Rateau, 2013). La posibilidad de descubrir y adquirir nuevos conocimientos provenientes de otros informadores, que permiten ver la transformación y convergencia que estos puedan crear, surgiendo nuevos consensos y opiniones para tener un pensamiento, creencias y valores 
uniformes que logren representar a una misma comunidad y grupo social especifico de un ambiente determinado.

En último lugar se tiene que debe ser socialmente útil y aportar nuevos conocimientos, por una parte, las RS son constituidas por la lectura, su interpretación y posteriormente la comprensión de la realidad en la que viven diariamente, de esta manera son socialmente útiles y sirven de guía para afrontar el día a día con las constantes interacciones sociales que los rodean de un modo masivo a lo largo de la vida y que comparten con otros grupos. Esta teoría tiene como rasgo el proveerlos de criterios de evaluación que permiten definir, justificar o dar validez a algunas conductas y desaprobar otras, es aquí cuando pone en perspectiva cuan función se encarga de cumplir en cuanto a la orientación de los acontecimiento sociales y conjunto de sistemas que permiten un mejor desenvolvimiento y ajuste mental con relación al cuerpo, interviniendo en todos los casos por igual al hecho de constituir un sistema justificado de cada uno de nuestros comportamientos o los de los demás.

Cada una de los detalles anteriores comprende el por qué estas representaciones los llevan por el camino de las normas, la comprensión y el dominio sobre nuestra vida diaria, hecho que no está aislado del pasado y que ha pasado por muchos procesos para llegar hasta aquí, como consecuencia de las transformaciones que se han dado de forma evolutiva y que lleva una carga de implicaciones relacionadas con lo contemporáneo y el objeto de dicha investigación. Una definición fundamental para los hechos históricos, sería la utilizada por Michel-Louis Rouquette (1994), en la cual se comprende a estos como un desarrollo que modula mediante la transformación y decadencia del mismo, convirtiéndose en una especie de producto creado con conciencia. Este autor también habla sobre una representación que debe su resultado a un momento especifico de la historia de alguien y que luego pasa a ser legible para todos, con el dicho proceso de desglosar los significados que estos proveen.

A estas se le adjudican tres modelos de comprensión, el primero es el modelo sociogenético, descrito como una ambición de exponer de dónde y cómo se desarrollan las RS. Según Moscovici el acontecimiento de una nueva situación innovadora y que de manera eventual favorece a las representaciones sociales al darle un grado de emergencia para reaccionar y que debido a esta condición la respuesta debe ser lo mejor posible, hecha con la poca información obtenida por los diferentes grupos sociales que están involucrados. 
En el modelo estructural el proceso se basa en la percepción social y la formación de opiniones de las personas, en este se contribuye a esclarecer la lógica social y mental que sostiene a las organizaciones mediante la TRS. A este modelo lo atañen dos componentes pertenecientes a un estatus, tienen el sistema central que organiza cada uno de los elementos cognitivos que están relacionados con el objeto de estudio, este es el resultado de los acontecimientos de causas naturales, históricos, simbólicos o sociales determinados, en los que los patrones y peculiaridades están controlados por los grupos sociales. Este sistema tiene dos propiedades principales, la primera representa estabilidad y asegura la permanencia de la representación en sí misma, mientras que la segunda es el sitio donde se ponen de acuerdo llegando a un consenso en común, lo que permite ver a cada uno de los miembros todos los lados de un mismo objeto. La segunda propiedad es la de un núcleo central reconocido solo por su estabilidad sin importar el ambiente en donde se encuentre, este sistema tiene que ver con las emergencias surgidas en la cotidianidad, las cuales permiten una mejor adaptación por parte de sus habitantes, que la aprendieron mediante la representación en los contextos sociales.

Finalmente, en el modelo socio-dinámico están los procesos de anclaje o representación en el contexto social. Willem Doise (2001), explica que este modelo se va por la conciliación de estructurar las representaciones sociales y su integración en los diferentes ambientes culturales y con ideologías múltiples. Esta teoría que busca organizar y dejar un espacio fundamental para las relaciones grupales, mostrando como todos los estratos sociales es capaz de determinar y acordar diferentes principios, desde distintas perspectivas y representaciones de realidades de diferentes comunidades. Las TRS tienen una importante aplicación en los problemas sociales, este ha sido parte de aspectos como los de salud, economía, ecología y las nuevas tecnologías, a pesar de haber nombrado varios la lista de aplicaciones es interminable. Esta teoría ha demostrado ser flexible y adaptable a las múltiples circunstancias de la vida cotidiana, con sentido psicosocial del llamado sentido común y que procede de manera metódica sin importar el suceso.

\subsection{Las técnicas de información y comunicación (TIC)}

Las TIC han sido por muchos años la mejor manera de comunicar las cosas a un público en específico, este ha tenido muchos rumores y desaciertos como el hecho de que estas 
podrían cerrar la brecha existente entre rico y pobres, cosa que solo podría lograse mediante acuerdos y negociaciones de los gobiernos. La creencia de que las TIC provocarían el surgimiento de una nueva cultura uniforme, revelando que esto solo sería posible con el desarrollo de una cultura universal llena de otras subculturas (Martínez, 2011). Las Tic funcionan de manera distinta a como se hacía creer en lo anterior, estas generan avances de al impacto como la transformación del comportamiento, interacción y tradiciones de las comunidades previamente existentes, la disminución de requerimientos físicos para la interacción presencial entre los sujetos, con lo cual se da paso a las nuevas comunidades y generaciones que funcionan de manera virtual o electrónica, puramente encontrados en la red y no en su forma física.

La disminución de la necesidad de salir de la comodidad del hogar para comprar algo que pueden encontrar por internet, teniendo el producto al alcance de nuestras manos en pocas horas o días de encontrarse muy lejos. Las diferencias entre los diversos grupos sociales y su oportunidad para encontrar trabajo, generando nuevos medios que podrían generar igual de condiciones y oportunidades (Martínez, 2011). Estas facilitan las incorporaciones virtuales, asociaciones o alianzas temporales para la realización de un proyecto, cambios en el desarrollo de los sectores industriales o económicos y el acceso a la información que promueve el conocimiento y las oportunidades de una capacitación profesional, para obtener un determinado empleo.

Las TIC tienen un gran efecto en cuanto a la comunicación humana se refiere, esta se ha hecho compleja para quienes siempre han utilizado los medios convencionales como prensa, libro, tv y radio, porque claro estos fueron los primeros medios en ser usados para la comunicación masiva de alto alcance mientras que las nuevas tecnologías como la computadora solo era concebida como una calculadora, muy necesaria para los que se dedican a hacer cálculos constantemente, pero que para los comunicadores sociales no parecía nada atractivo (Carretero, 2010). Estas tecnologías fueron evolucionando poco a poco y dejaron de ser solamente para sacar cuentas, se empezaron a crear juegos interactivos, programas para escribir, guardar información, pintar y otras herramientas que existen hoy en día, reemplazando los costosos y molestos deberes, de esta manera simplificando la vida del ser humano, colocando todo en un solo lugar, dejando obsoletas las máquinas de escribir, los archivadores, el corte y pegado a manos en los periódicos. 
Las nuevas tecnologías llenaron de productos algunos innecesarios a las personas, pero produjeron un nuevo método de soporte, en donde la información esta digitalizada, almacenándola y difundiéndola en cuestión de minutos, la computadora pasó de ser un mecanismo monstruoso a generar comodidad y velocidad en la comunicación, cambio radical que tuvo que afrontar la sociedad en unos pocos años y que modifico no solo la forma de ver la realidad, sino el pensamiento y las relaciones interpersonales (Carretero, 2010). En principio solo existía la prensa para difundir y enterarse de los sucesos de la vida diaria, pero en la actualidad a dado un giro en la forma en la que esta se presenta a los lectores, pasando a ser de forma digital y que incluye una avanzada vida de información siendo una de las actividades más usadas en la internet, la trascendencia de esta manera de publicación puede llegar a ser tan grande que en algún momento desplazará por completo a el papel como soporte primordial para las noticias.

El avance tecnológico ha permitido darle un nuevo significado al periodismo, poniendo en uso los enlaces en donde se agrega más información relacionada con el tema, mientras que otros solo albergan enlaces a otras noticias del día, pero eso de lo que se trata, de hacer la información más accesible para todas las comunidades, dando la capacidad de ampliar los conocimientos del lector. Los impactos que han tenido las TIC en la prensa van desde la facilidad de presentar información que posteriormente puede ser modificada y/o actualizada. La interacción con los lectores de manera inmediata, la simplicidad de búsqueda de conocimientos por la red de manera selectiva y rápida, y la difusión masiva en menos de unos segundos con un costo básicamente gratuito (Martínez, 2011).

La utilización y aplicación de las TIC en la teoría de las representaciones sociales puede verse reflejado en la educación, las generaciones nacidas antes de la tecnología suelen diferenciarse de las que nacieron con estas ya que los segundos suelen adaptarse fácilmente a estas, de tal manera que pareciera que vienen integrados con ellos, mientras que los primeros suelen tardarse en aprender y se van más por los métodos tradicionales de obtención de conocimiento. En el campo escolar esta diferencia se ve reflejada entre los profesores y el alumnado, repleto de adolescentes que sin pensarlo logran entender el lenguaje tecnológico y dominarlo con facilidad, aunque también se pueden ver casos en donde existan barreras de estatus entre los alumnos de un mismo grado y salón, por lo cual las escuelas deben dotarse de recursos para eliminar esa brecha (Restrepo, 1999). 
La información y el conocimiento van de la mano, estos son productos básicos que forman parte del sistema educativo, haciendo posible la mejoría del rendimiento y eficiencia de los alumnos, generando material intelectual de su parte, creando estrategias de integración de los estudiantes con la tecnología en vez de llenar los espacios de computadoras pasando a ser inutilizadas o malgastando el tiempo de uso en algo que no sea de provecho educativo y que durante este cada uno de los sujetos que habitan un colegio se apropien de los conocimientos. La tecnología ofrece más de lo que se piensa, esta permite ser usada para la comunicación más rápida entre las personas, con el envío de información y búsqueda mediante las fuentes bibliográficas para el intercambio de conocimientos e investigaciones llevadas a cabo con el método empírico, también el hecho de poder realizar videoconferencias, reuniones y conversaciones a larga distancia, acortando las vías de comunicación.

La educación tiene nuevas preocupaciones por los territorios desconocidos, para los cuales no se ha encontrado una solución, esta requiere la reconstrucción de las teorías educativas, planteándose temas como la necesidad de reestructurar los contenidos que se imparten en las asignaturas, el requerimiento de replantear el rol del profesor cambiando de ser una persona que imparte conocimientos a alguien que se encarga de planificar y evaluar mediante nuevos métodos los procesos en los que se transforman los conocimientos y la reconstrucción de nuevas alianzas educativas de la mano con la sociedad (Restrepo, 1999). Esta innovación tecnológica debe cambiar no solo la forma de ver las cosas, sino como las hacen y relacionan con la realidad social, el uso que se le da debe ajustarse a nuestras necesidades, innovando y dando pasos previamente meditados hacia una revolución en la forma de ver las cosas y una unificación con la globalización.

\subsection{Las TIC aplicado en la comunicación corporativa}

Estas se pueden justificar a manera de inversión, dando paso a las organizaciones para poner en marcha proyectos por el camino correcto. Las TIC tienen proyectos necesarios en donde no aplican razones para no realizarlo, como aquellos que funcionan de manera imperativa como el cumplimiento de órdenes y leyes dictadas por el estado. Están los cuantificables, en donde se puede calcular de cuánto debe ser la inversión y de qué manera se verá remunerada, finalmente los proyectos estratégicos demuestran cómo está posicionada 
la empresa en el mercado mundial, en donde se ve como la misma puede afectar o verse afectada corporativamente por los factores internos o externos, sin importa el departamento.

La comunicación corporativa está directamente relacionada con el ambiente empresarial y la cultura que se genere allí, tendiendo a afectar a la comunicación de la misma de distintas formas. Para el buen funcionamiento de una empresa es necesario tener en cuenta la opinión general y la del público para la que fue creada, además de la importancia que tiene la cultura y la historia, como aspectos para reinventar una empresa en tiempos de necesidad como pasó en las guerras más importantes. Las creencias, valores y principios se ven ligados a esta forma de cultura organizacional y está es usada para dar sentido a los acontecimientos. Las tradiciones y costumbres que forman parte de una sociedad y que pueden ser entendidas mediante las RS, redefinen los conceptos del desarrollo cultural en el aspecto organizacional, es decir, cómo funcionan las empresas y como logran relacionarse con el público a través de estos.

El contexto en el que se desarrollen estas empresas puede permitir un mayor grado de permanencia y sustentabilidad, creando autonomía en base a la libre ideología que como dice Gagliardi (1984) "La cultura distingue a una organización de otra y orienta sus decisiones", esto referido a la idea de generar un diferenciación que llame la atención del público con respecto a las demás, demostrando una cultura vigorosa y aplicando un poder de influencia en la misma, que llegue a todos los que trabajan allí o no, como lo es la comunicación interna (empleados) y externa (el público consumidor). Esta es la manera en la que se realizan las actividades en una organización, pero esta es una definición muy general a lo que respecta culturalmente, debe agregársele a este concepto los valores y creencias que corresponden y afectan a la forma de trabajar, y mejora la comunicación y el ambiente empresarial.

Las compañías que funcionan como entidades empresariales, estas instituciones deben generar una identidad corporativa para generar la admiración de los trabajadores, mejorando así la comunicación y el ambiente de trabajo. Esta identidad que conserva los valores de los productos y servicios que ofrece la organización, así se cuidan los mercados externos, la calidad y la buena atención proporcionada a los consumidores. Las acciones internas de las empresas requieren de mucha atención, ya que se concentra en el rendimiento, la productividad y la forma en la que se logran resolver los problemas, esta última es de suma 
importancia ya que según corresponda, el tiempo de respuesta es vital para resolver los inconvenientes que puedan producirse en el camino, de esto dependerá la vitalidad de la empresa en muchos casos.

Los empleados deben ser tomados en cuenta, ya que sus necesidades y formas de trabajar (ambiente empresarial), afectan directamente a la productividad de la misma, igualmente las relaciones entre esta y el Estado, donde deben cumplirse las normas y leyes, manteniendo así una buena relación con la comunidad en donde este. Las compañías deben estar muy pendientes según se encuentre y la cultura a la que se enfrente, se deben respetar y honrar las creencias que formen parte de esta. Los aspectos culturales en el ámbito empresarial según Shein (1988) son aquellas creencias que comparten los miembros de una empresa, incluyendo los comportamientos de los empleados regidos por las normas de la organización, además de los valores, filosofía y clima laboral.

Los aspectos anteriores son intangibles, pero pueden observarse en las distintas empresas y su forma de comunicarse, y como siempre se ha dicho, la comunicación forma parte fundamental de la vida cotidiana y más de las compañías y sus relaciones internas y externas, ya que sin esta no podría funcionar de manera correcta de ninguna forma en la que no se incluya el dialogo entre los distintos funcionarios de una empresa, la desinformación genera discordia y desorden, lo que no permite el correcto desempeño de estas. De esto se desprende la estructura comunicacional, usado como instrumento base en la construcción y comprensión de la cultura. Los modelos comunicacionales vendrán definidos por la misma cultura y que es usado como aspecto múltiple que se va produciendo y cambiando a lo largo de la vida de la compañía. Hay algunas influencias específicas que generan estos modelos, como lo son las creencias de los fundadores (deseos, actitudes y expectativas que estos tienen), la transformación de la cultura y su intangibilidad, los periodos históricos de crisis en donde se reinventa la compañía y sus miembros de la misma, y finalmente los hábitos adquiridos mediante la rutina y el clima organizacional.

La comunicación es esencial en todas las organizaciones que conformen la vida, como actor de responsabilidad social y estrategias corporativas en la cotidianidad, pero en tiempos de crisis toma un valor incalculable, ya que las empresas suelen estar poco preparadas para los cambios bruscos y situaciones adversas, que requieran de atención inmediata. Frente a 
estas situaciones las compañías no suelen tener estrategias y por lo tanto causan revuelo en estas, es por eso que en estos momentos es donde más se debe mantener la comunicación con el entorno, explicando a la comunidad y empleados, después de hacer un análisis cómo será confrontada la situación.

Para atacar estás crisis es necesaria la anticipación de la misma preparando ciertos planes de acción los cuales deben ponerse en marcha y es indispensable que haya una reacción inmediata. La anticipación asegura los equipos e instalaciones que son fundamentales para el buen funcionamiento de la empresa, razón por la cual debe haber diferentes respuestas a los distintos escenarios que puedan presentarse, previniendo los problemas y usando la comunicación como principal medio de resolución de crisis (Martínez, 2011).

La rapidez es vital, ya que el modo de respuesta (comunicacional) y la inmediatez con la que se ejecute puede solucionar estos acontecimientos de manera eficaz, es en este momento donde existen mayores posibilidades para reducir el impacto de y neutralizar los efectos de la crisis, adecuando la información y difundiéndola, preparando además un catálogo completo de su desarrollo lo que da paso a un historial lo que ya pasó y puede pasar en un futuro cercano. La información de calidad también forma parte de la prevención, esta debe ser precisa, capaz de ser confirmada, con datos y detalles contrastables que permitan la oposición a una realidad de manera documentada.

La comunicación en estos tiempos es sumamente necesaria y promueve un mensaje de tranquilidad a los miembros de la empresa. La comunicación provee de información constante que permite conocer a toda hora las novedades que se producen a lo largo de una crisis, actualizando los planes de acción y las estrategias comunicacionales. La información que se transmite en ambos sentidos, es importante, ya que el personal tiene derecho a saber que sucede y como se afrontará esa crisis, además de las consecuencias que se generaran, esto reducirá el impacto, es aquí donde la comunicación debe estar más presente de forma inmediata y precisa, de esta manera se evitan rumores y el pánico producido por la incertidumbre, eliminando en un porcentaje los efectos de la crisis.

Las comunicaciones en el plano organizacional utilizan un método estratégico, visionado mediante las políticas de la compañía, estas se fundamentan en el principio del 
hacer institucional, que es asociado a la estrategia y a la acción, como lo haría un plan de acción para proyectar y comunicar con éxito. La comunicación debe temarse como independiente de las demás forma de acción, sino como parte de la gestión humana y desarrollo, aplicada también a la gestión de recursos administrativos, de producción, operación y lucro.

Comprende desde los comportamientos, actitudes y prácticas de interpretación de los hechos y actos de la realidad. La misma al ser interna y externa debe estar considerada como medio fundamental para promoverse con los empleados en el centro de la empresa, generando una cultura organizacional en todos los entonos. Como se ven las representaciones sociales y la TIC son parte fundamental de las empresas y de cómo se relacionan de manera interna cada uno de los miembros, respetando las cualidades de cada uno y su autonomía, no solo con los integrantes de la empresa sino también con los habitantes de la ubicación de la empresa, sus tradiciones y costumbres, además de lograr la identificación con los empleados.

\section{Metodología}

El trabajo está enmarcado en un proyecto de diagnóstico y planificación comunicacional, por lo cual la metodología será acorde con las distintas etapas de relevamiento, diagnóstico y planificación. En la primera etapa de la investigación, el diagnostico, se propone utilizar criterios metodológicos como la descripción de marco contextual, caracterización de prácticas comunicativas, identificación de actores sociales, de problemas y temas que se quieren comunicar, analizar materiales producidos, herramientas y tecnologías comunicacionales utilizadas.

Teniendo como referencia el Manual Sembrando Mi Tierra de Futuro, el segundo paso a seguir será la planificación, que plantea inicialmente identificar la situación deseada que queremos alcanzar; definir las metas y objetivos que nos ayudan a pensar nuestras acciones en un tiempo determinado y con materiales específicos.

Durante el proceso de investigación emplearon diversas técnicas, entre ellas;

- Recolección de datos; tiene la finalidad de obtener datos e información a partir de documentos escritos y no escritos susceptibles de ser utilizados para la investigación. En esta etapa se construirán los mapas, herramienta útil para profundizar el conocimiento de nuestro lugar de intervención y sus actores, desde una mirada más general. 
- Observación participante; que permiten al investigador familiarizarse con todas la facetas de la realidad a explorar. Observar implica utilizar nuestros sentidos para conocer, es preciso ordenar el modo de mirar, definir qué queremos saber. Es necesario llevar registros para dar cuenta de los datos que levantamos; para ello empelaré herramientas como el diario de campo, relatorías, registros audiovisuales o sonoros, entre otros.

- Entrevistas focalizadas; las cuales permiten explorar situaciones problema y conocer las percepciones de los actores sociales tienen con respecto a su contexto inmediato, así como profundizar en el estudio de problemáticas específicas.

- Talleres de reflexión; para la toma de conciencia, reflexión sobre comportamientos, generar intercambio de información, además de estimular la creatividad y el análisis crítico.

-Discusiones guiadas; con la finalidad de estimular la intercomunicación, la tolerancia, la creatividad y el análisis.

La población del estudio estuvo conformada por los docentes, practicantes y colaboradores de la UNITEC. En este caso por ser una muestra pequeña no fue necesario aplicar formulas estadísticas para calcular una muestra sobre toda la población. De ahí que se seleccionaron al azar la totalidad 3 docentes y 17 practicantes activos de la UNITEC. También, se entrevistaron a 2 personas externas a la institución a fin de conocer la accesibilidad a la institución y su gestión para con la colectividad.

La técnica de investigación utilizada para la recolección de datos es la entrevista, un diálogo o conversación "cara a cara", entre el entrevistador y el entrevistado acerca de un tema previamente determinado, de tal manera que el entrevistador pueda obtener la información que requiere. El instrumento lo representa una guía de entrevista estructurada que se aplicó a los docentes seleccionados a las dos personas externas. 


\section{Análisis de resultados}

A continuación se presenta el análisis de datos de las entrevistas aplicadas a diecisiete practicantes, con la finalidad de identificar, describir y analizar los procesos comunicacionales generados en y por la UNITEC, a través de la etapa de diagnóstico de los procesos de gestión que adelanta la organización. En este sentido, se organiza la información en función de las categorías: diagnóstico situacional de UNITEC, procesos de gestión y comunicación y procesos comunicacionales. Seguidamente, se muestra el análisis de entrevistas no estructuradas.

\section{Categoría: Diagnóstico situacional de la UNITEC}

Para investigar sobre esta categoría, se les consultó a los docentes y practicantes sobre que es UNITEC, con el fin de investigar sobre el conocimiento que estos tienen acerca la organización. En este sentido, la mayoría lo definió según el significado de su nombre. Ellos específicamente indicaron: "Unidad de investigación y desarrollo para la calidad de la educación en ingeniería con orientación al uso de las TIC" (DOC3), sin embargo, entrevistados dieron un concepto más amplio, como DOC5, quien especificó: “Es una unidad de extensión, desarrollo y transferencia para la calidad de la educación en ingeniería con orientación al uso de las TIC”. DOC12, también realizó una descripción más detallada: "Unidad de Investigaciones, desarrollo, extensión y transferencia para la calidad de la educación en ingeniería con orientación en el uso de las TIC"

Otros docentes, el 60\%, además de dar el significado de UNITEC se enfocaron a que el fin de esta unidad es brindar apoyo a personas con discapacidad, tal como expresaron DOC7, "es un proyecto de la Universidad de la Plata que trabaja para la gente discapacitada con ramas de la electrónica”, DOC9: "UNITEC es en el que se realizan proyectos para la inclusión de personas con discapacidad", DOC10: "es un proyecto con varias ramas de electrónica que hacen proyectos para las personas discapacitadas, adaptaciones y programas, DOC11: "una unidad de extensión para mejorar la educación, la transferencia de tecnología y asistencia a personas con discapacidad"

En este sentido, las siglas de la UNITEC, significan Unidad de Investigación y Desarrollo para la Calidad de la Educación en Ingeniería, la cual hace parte de la Facultad de 
Ingeniería de la Universidad Nacional de La Plata (UNLP). Esto indica que los docentes entrevistados conocen el significado de este centro y además destacan que se trabaja con las tecnologías de información y comunicación, lo cual coincide con lo expresado por Carreón y Campos (2008), quienes explican que una de las estrategias metodológicas para el desarrollo de objetivos de UNITEC es Llevar adelante tareas de investigación en el área de innovación y mejoramiento de la Calidad en la Educación y entrenamiento en Ingeniería (Educación basada en competencias, evaluación de aprendizajes, barreras al aprendizaje, etc.), incorporándolas herramientas de las TICS.

Con relación a los objetivos de UNITEC, todos los encuestados hicieron referencia a que la principal finalidad es la crear herramientas con el uso de las tecnologías destinadas a personas especiales y con discapacidad. Específicamente, manifestaron sobre este aspecto: “ayudar a la inclusión de personas con necesidades especiales mediante las TIC" (DOC1), “desarrollo de ayudas técnicas para la inclusión y accesibilidad" (DOC3), "Desarrollar software y hardware orientado a personas con discapacidad y necesidades especiales", “el desarrollo de adaptaciones de hardware para asistencia a diferentes necesidades educativas especiales” (DOC4), “Adaptación y modificación de las máquinas y equipos que llegan al laboratorio para donación a escuelas especiales".

Es positivo que las respuestas de los practicantes coincidan con lo expresado en el documento fundacional de la UNITEC, ya que en este se establece que los objetivos de esta unidad son: impulsar la aplicación de Normas de Calidad en la Educación en áreas tecnológicas y promover la Gestión de la Calidad Educativa, y abordar cuestiones sobre la posible aplicación actual de las TICS para mejorar la calidad de la actividad docente, su complementación con los medios didácticos tradicionales, no sólo para un mayor aprovechamiento del tiempo, sino para una mejora integral de la enseñanza, que contribuya a formar profesionales eficientes y con alto sentido de la responsabilidad.

Para investigar sobre la situación actual de la UNITEC, se preguntó a los docentes sobre cuáles son las necesidades de la unidad, la mayoría respondió que requieren de mayor espacio físico, herramientas y equipos, como se especifica: "Si, en lo personal creo que necesita más espacio para trabajar y tal vez herramientas" (DOC2), "UNITEC necesitaría más espacios en los laboratorios para trabajar con más comodidad” (DOC7), "Si, unos buenos asientos, más computadoras”, “si, y la principal que considero es el espacio. Tanto para los 
operadores como para las computadoras almacenadas, pero solo es algo para mejorar" (DOC9).

Es preciso destacar que solo uno de los docentes entrevistados precisó que existen necesidades de comunicación, tal como se evidencia en su respuesta: "No es una gran necesidad, pero considero que mejoraría en el trabajo, la posibilidad de más y mejores equipamientos y la comunicación hacia el público" (DOC5). DOC17, a pesar de que no indica un problema directo de comunicación, hace alusión a uno de sus tipos “... difusión para obtener mayor cantidad de donaciones sería secundario, ya que no se dispone del lugar para almacenar".

Estas declaraciones revelan que no existe problema relevante de comunicación en la unidad, puesto que solo dos personas los consideraron medianamente importante o sin importancia. Sin embargo, esto puede ser un indicio de que aún no reconocen que existe una debilidad en este aspecto, lo cual indica la necesidad de que los docentes realicen una revisión real sobre los problemas existentes en la organización, ya que esta mirada nos "permite proponer nuevas formas de comunicación, desde la producción de mensajes y la promoción de redes que contribuyan a la solución de los problemas”. (Ceraso, 2007, p.45)

Sin embargo, la mayoría reconoce qué es la comunicación, ya que al plantearles esta pregunta, todos respondieron de forma similar, al definirla como el intercambio de información entre dos o más personas, tal como manifiestan: DOC1: "es el intercambio de información entre dos o más personas, a través de distintos medios", DOC2: "se podría denominar como el intercambio de ideas entre emisor y receptor" DOC5: "la comunicación es el medio por el cual dos o más personas comparten ideas, problemas, soluciones y la manera más natural de relacionarse los uno con los otros", DOC9: "para mí la comunicación es intercambiar información por distintos medios y con un objetivo, si hablamos de UNITEC es ayudar"

Unos pocos, a pesar de que reconocen el concepto básico de comunicación, presentan cierta confusión en cuanto a su definición. Como es el caso de los siguientes docentes, DOC3: "Es cuando entre personas o máquinas se reconoce un intercambio de ideas o conocimientos", DOC8: "es una forma de expresarse mediante el habla, expresión de una persona”, DOC11: “es la implementación de un método para la transferencia de información y objetivos de la manera más armónica y simple”. 
Es positivo y fundamental para la organización que su personal conozca el concepto de comunicación y como esta se desarrolla, lo cual contribuye a que no ocurran errores que afecten el normal desenvolvimiento de UNITEC, como el descrito por Mata (S/F), quien sostiene que los emisores ya no transmiten unos mensajes significados elaborados en virtud de un instrumento neutro. "Tanto en la esfera de la emisión como en la de la recepción existe producción de sentido y no mera transferencia de los primeros a los segundos, aun cuando ella sea desigual, no simétrica... De aquí que podamos recuperar para la comunicación la idea de contrato o negociación, donde ambas partes -emisores y receptores- son activas, permaneciendo diferenciados en sus roles y su capacidad de operar".

Se interrogó a los entrevistados, cómo considera que se desarrolla la comunicación en la UNITEC, o qué debería incluir. En este sentido, la mayoría valoró la comunicación de manera positiva y dejó claro que siempre existe el contacto con la comunidad y personas con discapacidad. Ellos manifestaron: "considero que es un bien para la comunidad que UNITEC se preocupe por gente con capacidades diferentes" (DOC1), "A partir de una necesidad se utilizan los medios de comunicación existentes para llegar a tal fenómeno y mejorar la calidad de vida" (DOC4), "Muy bien" (DOC16).

En este sentido, es positivo que la comunicación se desarrolle de manera efectiva, ya que esta permite que se desarrollen de manera eficiente los procesos de gestión que tienen como finalidad el beneficio de personas con discapacidad, como lo plantea Carlos M. Arroyo Goncalves (S/F) "la Unesco que apostó por la comunicación como el mecanismo para generar procesos de desarrollo (educación, salud, etc.). Con esta finalidad, Unesco facilitó la integración entre los medios productivos y la Universidad, para potenciar la capacitación y la investigación en este campo. La prueba palpable de esta situación fue el decisivo apoyo que brindó para la constitución de la International Association of Mass Communication Research (IAMCR) y la creación del Centro Internacional de Estudios Superiores de Comunicación para América Latina (Ciespal)".

Además, la mayoría también manifestó que internamente, en la UNITEC se desarrolla la comunicación de manera eficiente, ya que expresaron "Dentro de UNITEC se desarrolla con respeto, igualdad y orden" (DOC4), "En el grupo de UNITEC tenemos una comunicación bastante fluida, que permite que todos los espacios sean capaces de relacionarse y compartir ideas para mejorar los proyectos que se proponen en el mismo" (DOC5). 
Desde esta interacción, se desarrollan múltiples significados, ya que, considerando que los entrevistados son docentes, al producirse una comunicación efectiva, se generan intercambios enriquecedores para la unidad, como refiere Ceraso (2014) es aquí donde se da la integración entre comunicador-educador en la práctica social, donde se aprehende la realidad. Es aquí desde donde comienza un proceso de diálogo, desde donde nos reconocemos como sujetos capaces de transformar dicha realidad. La educación, dice Freire, es comunicación, es diálogo, en la medida en que no es la transferencia de saber, sino un encuentro de sujetos interlocutores que buscan significaciones. La comunicación implica una reciprocidad que no puede romperse. No es posible comprender el pensamiento fuera de su doble función: cognitiva y comunicativa. No hay pensamiento aislado así como no hay hombre aislado

Asimismo, un 47,05\% indicó que la comunicación se desarrolla usando como medios las tecnologías de información y comunicación, tal como refirieron: "entre la UNITEC y la comunidad, la comunicación se está desarrollando vía Facebook, entrevistas en diario y vía oral" (DOC5), "la comunicación de UNITEC es por medio de email, WhatsApp, Facebook y grupos de WhatsApp" (DOC7), "se desarrolla de manera cómoda, por ejemplo por WhatsApp (grupos), Gmail y Facebook" (DOC8), "se desarrolla bien, ya que tenemos una comunicación por email, además de un grupo de WhatsApp que es más inmediato" (DOC9)

En este punto, se podría asegurar que, tomando en cuenta que se utilizan las herramientas y aplicaciones que ofrecen las tecnologías de información y comunicación como medio para comunicarse, se establece una comunicación de masas, como afirma Ceraso (2014), aportará su perspectiva desde una conceptualización del poder y la sociedad de masas, donde los medios de comunicación se integran a las fuentes de poder y a las autoridades para construir y ejercer hegemonía. Desde esta línea teórica se ponen de manifiesto la ideología y la manipulación en los procesos de comunicación.

\section{Categoría: Procesos de gestión y comunicación}

En la categoría anterior se refleja una idea de cómo se desarrollan los procesos de gestión y comunicación en la UNITEC, sin embargo, para indagar más sobre el tema, y tomando en cuenta la finalidad de la unidad, se les consultó a los docentes qué es la discapacidad, a lo cual la mayoría respondió que son personas que poseen alguna limitación, 
tal como manifestaron: DOC1. "la discapacidad es una imposibilidad para ciertas personas al momento de realizar acciones que se consideran comunes y/o cotidianas", DOC2: "cuando una persona no puede realizar su vida normalmente por algún impedimento físico”, DOC4: "es la imposibilidad o dificultad para vivir normalmente debido a defectos o hechos que hayan ocurrido en la vida (incluyendo pre nacimiento) de la persona con esa condición", DOC8: "es la falta o limitación de alguna facultad física o mental que imposibilite el desarrollo normal de las actividades de una persona", DOC12. "falta o limitación en alguna facultad física o mental que dificulta el desarrollo normal de alguna actividad de alguna persona":

Apenas uno de los entrevistados respondió de manera diferente, quien manifestó que la discapacidad es "Cuando alguien tiene capacidades distintas" (DOC11). Esto podría ser una consecuencia de la transmisión de enfoques acerca de la perspectiva que tienen con relación a las personas que poseen discapacidad, ya que afirma Mata (S/F), que reconociendo el indiscutible poder del emisor debemos advertir en su discurso la presencia activa de los receptores porque ellos están presentes como término de su producción como el otro que habla en lo que yo digo. Las perspectivas que vamos encontrando en el proceso histórico de la comunicación, como dominio de saber, llevan implícita una forma de ver el mundo y se corresponden con un modo conceptual o teórico de ver a la sociedad y sus relaciones. Estas miradas guardan relación profunda con el contexto político en que surgieron y con las características de los procesos de comunicación que describen.

Para conocer más sobre este tema, se consultó como conciben a las personas en situación de discapacidad, a lo cual, más del 70\% respondió que son personas que necesitan de alguna ayuda, entre ellos: DOC2 quien manifestó: “creo que son personas que necesitan de alguna ayuda para poder llevar su vida de forma normal", asimismo DOC7 refírió: No pueden hacer las cosas solos, sino con ayuda", en concordancia DOC9 describió: veo a esas personas como una ayuda que hay que darles, por sus limitaciones, teniéndolas siempre en cuenta y ayudándolas" y DOC11, “como personas que hay que ayudarlas a adaptarse en el medio en que desarrollan sus actividades y vivencias"

Sin embargo, el 11,7\% tiene otra manera de describir a las personas en situación de discapacidad, ya que manifestaron. "son personas con capacidades diferentes, con igual o más potencial que cualquier otra, que puede entender de manera diferente el mundo que lo 
rodea, o como una persona que posee esa capacidad" (DOC5), "que debe ser tratada como una persona más, aunque presenta alguna dificultad" y "pues las considero como personas, al fin y al cabo, todos los somos" (DOC14).

En estas formas de describir a las personas con discapacidad, puede estar presente un modelo de construcción simbólico, ya que como manifiestan, Berger y Luckman (S/F) en su libro 'La construcción social de la realidad' donde se concibe que los sujetos se constituyen individual y colectivamente enmarcados en un determinado universo simbólico, "una trama discursiva en la que ciertos sentidos institucionalizados aparecen operando en la forma del ser y actuar social. Por tanto, se hace preciso adoptar una concepción del sujeto en relación con los discursos que lo construyen: un sujeto sujetado en el lenguaje".

En cuanto a la definición de tecnologías, la mayoría coincidió en que se refieren a herramientas y /o métodos que facilitan procesos, como lo expresaron: DOC3 "Son herramientas para llevar una vida más fácil y llevadera", DOC4: "herramientas para mejorar la calidad de vida pero limitando que se vuelva una total dependencia para ellos mismos", DOC7: "Es un conjunto de instrumentos, técnicas o procedimientos empleadas en un determinado sector o causa", DOC11: "Es la realización de dispositivos y métodos que mejoran y simplifican el desarrollo de la comunidad"

No obstante, pocos entrevistados, el 17,64\% definió las tecnologías de forma distinta, ya que manifestaron: DOC1 "Es el conjunto de conocimientos técnicos y científicos que permiten crear, diseñar, mantener bienes y servicios destinados a las personas", DOC5: "Es la capacidad de utilizar los medios conocidos y por descubrir, para un mejor avance de la vida humana que permite adaptarnos a cualquier situación y problema que se nos presente. Ejemplo: Una prótesis mecánica que permita una vida más parecida a la cotidiana" y DOC9: "La tecnología es la unión de conocimientos actualizados, y si los unimos formamos más tecnología, es crear bienes para que nuestra vida sea más fácil”.

Sin embargo, pocos dieron ejemplo de estas tecnologías, solo el 11,76\%, quienes exceptuando uno al referirse a estos mencionaron los vehículos. Efectivamente, los vehículos son tecnologías, pero no se encuentran dentro de la gama de las tecnologías de información y comunicación existentes, sin embargo, al considerar que además de enfocarse al ámbito educativo, los entrevistados diseñan otro tipo de tecnologías que sirven de gran ayuda a 
personas con discapacidad, se adapta perfectamente su definición de aplicar conocimientos para diseñar herramientas que genere beneficios.

En este sentido, se cumple con uno de los objetivos primordiales de UNITEC, tal como lo refiere su documento fundacional al resaltar que una de sus finalidades es abordar cuestiones sobre la posible aplicación actual de las TICS para mejorar la calidad de la actividad docente, su complementación con los medios didácticos tradicionales, no sólo para un mayor aprovechamiento del tiempo, sino para una mejora integral de la enseñanza, que contribuya a formar profesionales eficientes y con alto sentido de la responsabilidad.

\section{Categoría: Procesos comunicacionales}

Para investigar sobre cómo los procesos comunicacionales ayudan a la consolidación de estrategias futuras, se consultó sobre qué opinión merece la labor adelantada de UNITEC, a lo cual todos los docentes respondieron de forma positiva, ya que evidencian el apoyo que la unidad brinda a las personas, asegurando: "que todos los que trabajan en la UNITEC hacen lo mejor que pueden para ayudar a los que necesitan y sin fines de lucro" (DOC4), "Creo que la labor de UNITEC es un medio muy importante para la inclusión de personas con discapacidades a la sociedad actual y le ayuda a mejorar el aporte de todas las personas para mejorar la sociedad" (DOC5), "una opinión muy buena y positiva, ya que se ayuda a mucha gente sin esperar nada a cambio" (DOC9), "muy buena, gracias a eso, muchos chicos pueden aprender" (DOC14)

En este contexto, se percibe la relación que existe entre empleado, UNITEC y sociedad, y se aprecia de manera más clara la importancia del intercambio entre cada uno de ellos, ya que Ceraso (2014) afirma que es aquí donde se da la integración entre comunicador-educador en la práctica social, donde se aprehende la realidad. Es aquí desde donde comienza un proceso de diálogo, desde donde nos reconocemos como sujetos capaces de transformar dicha realidad. La educación, dice Freire, es comunicación, es diálogo, en la medida en que no es la transferencia de saber, sino un encuentro de sujetos interlocutores que buscan significaciones. La comunicación implica una reciprocidad que no puede romperse. No es posible comprender el pensamiento fuera de su doble función: cognitiva y comunicativa. No hay pensamiento aislado así como no hay hombre aislado. 
En este contexto, todos los docentes consideran que dan diversos aportes a la organización y les ha servido de mucho estar dentro de la organización, ellos refieren: “estando en UNITEC pude ayudar a la organización administrativa y además a la realización de adaptaciones de juguetes para chicos con necesidades especiales, obteniendo de UNITEC formación técnica en cuanto a la electrónica” (DOC1), "ayuda en la parte de EDETEC, en la reparación y adaptación de juguetes" (DOC2), "me aporta como persona, en ser más solidario. Y me ha servido mucho profesional y educativamente ya que aprendí a utilizar desde herramientas y tecnologías de mi carrera hasta aprender a trabajar con personas, sean o no de mi misma carrera" (DOC4) y "me ha servido mucho para ampliar mis conocimientos, ver cómo trabaja UNITEC y ver como se resuelven diversas problemáticas" (DOC9)

Uno de los aportes más significativos es el conocimiento que los docentes han obtenido en la unidad, y la utilización del mismo para ayudar a personas con discapacidad. Este proceso es descrito por Ceraso (2014) al citar a Freire, conocer no es el acto a través del cual un sujeto transformado en objeto, recibe, dócil y pasivamente, los contenidos que otro le da o le impone... En el proceso de aprendizaje, sólo aprende verdaderamente aquel que se apropia de lo aprendido, transformándolo en aprehendido, con lo que puede, por eso mismo, reinventarlo; aquel que es capaz de aplicar lo aprendido/aprehendido a las situaciones existenciales concretas. Por el contrario, aquel que es 'llenado' por otro de contenidos cuya inteligencia no percibe, de contenidos que contradicen su propia forma de estar en su mundo, sin que sea desafiado, no aprende.

\section{Análisis de entrevistas no estructuradas}

El análisis de las entrevistas no estructuradas aplicadas a los directivos de la institución se realizó aplicando la teoría fundamentada, por lo cual se aplicó el método comparativo constante para extraer códigos y categorías para ser analizados a través de los procesos de codificación abierta, axial y selectiva, en la cual se presentará una categoría central que permitirá teorizar sobre el objeto de estudio de la presente investigación.

En este sentido, en la codificación abierta, la interpretación de las entrevistas aplicadas a los directivos de UNITEC Flavio Ferrari (FF), Mónica González (MG) y Cristina Cordero (CC), permitió considerar las categorías en función de los objetivos de la investigación, las 
cuales se presentan con sus códigos respectivos para su mejor identificación y análisis de los datos, como se muestran a continuación:

\begin{tabular}{|c|c|}
\hline & Codificación abierta \\
\hline Categorías & 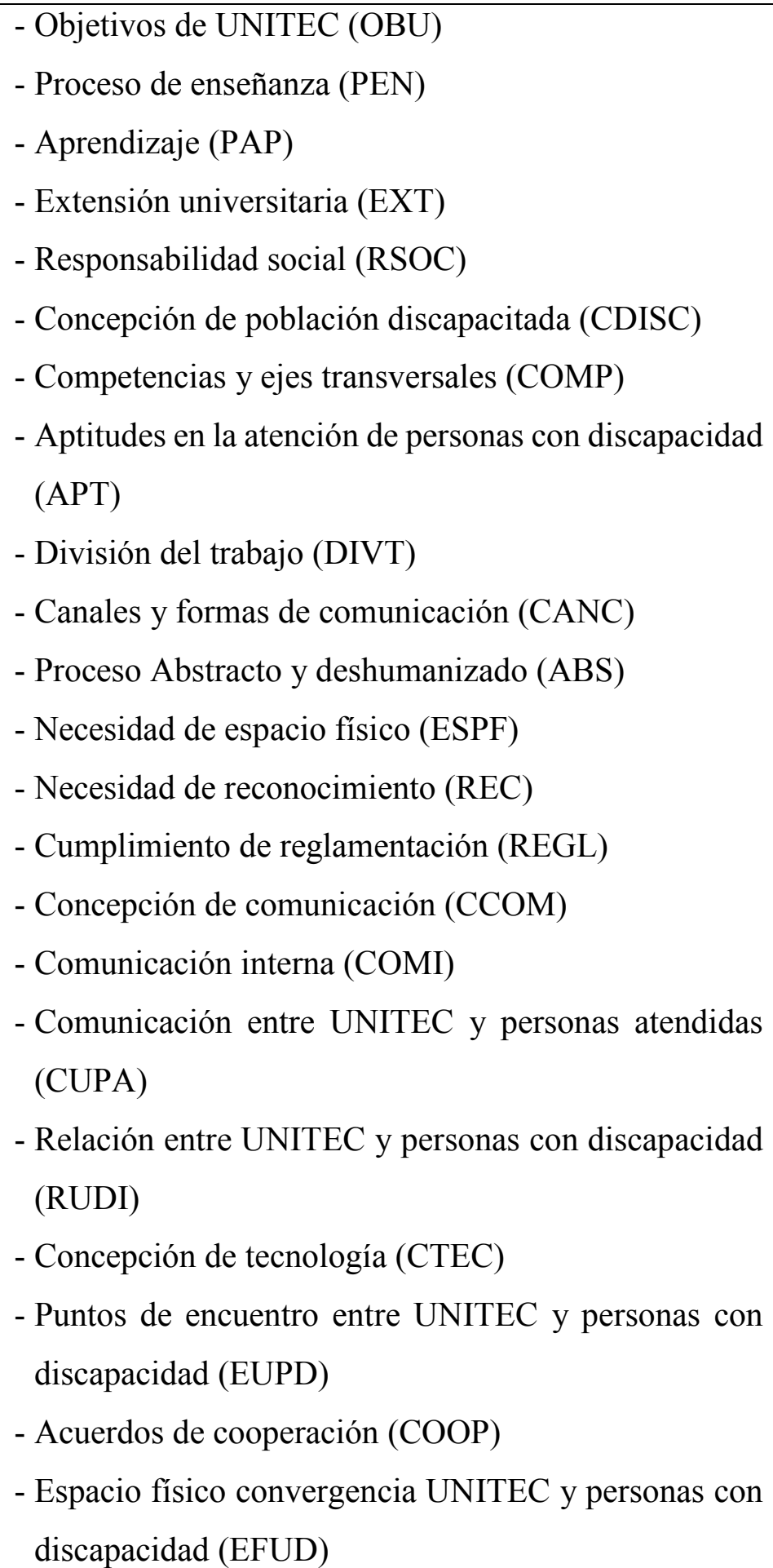 \\
\hline
\end{tabular}


Una vez realizado el examen minucioso de los datos, en los cuales se identificó y conceptualizó los significados contenidos en las entrevistas. Se procedió a compararlos en cuanto a similitudes y diferencias, la cuales se registraron en anotaciones. Seguidamente, se presenta la codificación axial, en la cual se establecieron las relaciones entre las categorías obtenidas en la codificación abierta y sus sub categorías, esto se realiza en función de sus propiedades y dimensiones. En este sentido, el resultado de este proceso dio origen a siete (7) categorías con sus respectivas sub categorías, tal como se muestra a continuación:

\begin{tabular}{|c|c|}
\hline Categoría & Sub categorías \\
\hline Filosofía de UNITEC & $\begin{array}{l}\text { - Objetivos de UNITEC (OBU) } \\
\text { - Responsabilidad social (RSOC) }\end{array}$ \\
\hline Finalidad de UNITEC & $\begin{array}{l}\text { - Proceso de enseñanza y Aprendizaje (PENA) } \\
\text { - Extensión universitaria (EXT) }\end{array}$ \\
\hline Características de UNITEC & $\begin{array}{l}\text { - Competencias y ejes transversales (COMP) } \\
\text { - Aptitudes en la atención de personas con } \\
\text { discapacidad (APT) } \\
\text { - División del trabajo (DIVT) } \\
\text { - Concepción de población discapacitada } \\
\text { (CDISC) } \\
\text { - Concepción de tecnología (CTEC) }\end{array}$ \\
\hline Comunicación & $\begin{array}{l}\text { - Canales y formas de comunicación (CANC) } \\
\text { - Concepción de comunicación (CCOM) } \\
\text { - Comunicación interna (COMI) } \\
\text { - Comunicación entre UNITEC y personas } \\
\text { atendidas (CUPA) }\end{array}$ \\
\hline $\begin{array}{l}\text { Relación UNITEC y personas con } \\
\text { discapacidad }\end{array}$ & $\begin{array}{l}\text { - Relación entre UNITEC y personas con } \\
\text { discapacidad (RUDI) } \\
\text { - Puntos de encuentro entre UNITEC y personas } \\
\text { con discapacidad (EUPD) }\end{array}$ \\
\hline $\begin{array}{l}\text { Necesidades y debilidades } \mathrm{de} \\
\text { UNITEC }\end{array}$ & $\begin{array}{l}\text { - Proceso Abstracto y deshumanizado (ABS) } \\
\text { - Necesidad de espacio físico (ESPF) } \\
\text { - Necesidad de reconocimiento (REC) }\end{array}$ \\
\hline
\end{tabular}

Continuando con el proceso de aplicación de teoría fundamentada, antes de aplicar la codificación selectiva, se procede a explicar cada una de las categorías y sub categorías y a realizar su contrastación con la teoría, para tener una visión clara de la categoría central, la cual permitirá teorizar sobre el objeto de estudio. 


\section{Categoría: Filosofía de UNITEC}

\section{Subcategoría: Objetivos de UNITEC (OBU)}

Según los directivos, el objetivo de UNITEC se relaciona principalmente con la mejora los procesos educativos, tal como se especifica a continuación:

"Mejoramiento de la enseñanza en las carreras de ingeniería, fundamentalmente en la ingeniería electrónica que es la que nos compete a nosotros; dentro de eso nosotros vamos a tender a realizar unas series de actividades que no tienen que ver directamente $\underline{\text { con eso, }}$ sino que a través de las actividades nosotros llegamos a mejorar esas condiciones de enseñanza y aprendizaje; en realidad Mónica es la que tendría que contestarlo mejor" (CC)

"El mejoramiento de la calidad en la educación, la apropiación digamos de nuevas $\underline{\text { tecnologías en los alumnos y en los docentes... está usando otras herramientas, }}$ entonces hay que incorporar todas esas cuestiones en la parte educativa porque si no nos quedamos atrás". (MG)

Esto confirma que los directivos están claros sobre los objetivos de UNITEC y tratan de cumplirlos, ya que los objetivos que ellos describen coinciden con lo establecido en su documento fundacional, el cual destaca, impulsar la aplicación de Normas de Calidad en la Educación en áreas tecnológicas y promover la Gestión de la Calidad Educativa, y abordar cuestiones sobre la posible aplicación actual de las TICS para mejorar la calidad de la actividad docente, su complementación con los medios didácticos tradicionales, no sólo para un mayor aprovechamiento del tiempo, sino para una mejora integral de la enseñanza, que contribuya a formar profesionales eficientes y con alto sentido de la responsabilidad.

\section{Subcategoría: Responsabilidad social (RSOC)}

Es interesante que los directivos aseguraran constantemente que entre los objetivos de UNITEC, la responsabilidad social es considerada uno de los aspectos fundamentales, ya que se trata de ofrecer a la sociedad un servicio para retribuir todo lo que esta otorga a favor de la mejora continua de diversos procesos. Ellos manifestaron:

“... tomemos el caso de la responsabilidad social universitaria y fueron apareciendo cuestiones y se fue armando todo el grupo de orientaciones de la discapacidad pero no es exactamente que la UNITEC se va a dedicar exclusivamente a la discapacidad, es 
una parte importante en este momento porque se fue dando, pero no quiere decir que es exclusivamente". (MG)

"Por otra parte... otras de las cuestiones que tiene que ver con que en UNITEC se hacen trabajos de extensión, es tratar de incorporar el concepto de la responsabilidad social universitaria, o sea, que el alumno se dé cuenta de que de alguna manera el hecho de tener una educación gratuita no es que te viene de arriba, sino que hay una sociedad que está respondiendo de alguna manera para que él tenga esa educación gratuita. Entonces a partir de eso que de alguna manera tiene que devolver a la sociedad algo, entonces incorporar esas ideas es complicado porque nuestras...nuestras materias son muy técnicas, entonces como hacés para incorporar esas ideas, bueno, través de $\underline{\text { trabajos en el grupo, está bien no lo podemos incorporarla a todos los alumnos, pero }}$ por ahí los alumnos que se van acercando al grupo van entendiendo este tipo, este tipo de actividades, entonces van tomando otra dimensión de su ubicación dentro de la $\underline{\text { sociedad, }}$ eso creo que es principalmente, apoyado todo en el concepto de la extensión universitaria2. (MG)

"En realidad a cualquiera, atención a cualquier parte de la comunidad"... (CC)

De esta manera, se comprende que, la concepción de UNITEC es percibida como una organización social, regida por una cultura que conduce a su denominación como institución, tal como refieren Gómez y Castillo (2004), con respecto a la acepción social que se tiene sobre el concepto de institución, donde se reflejan las diferentes ideas y acepciones con las cuales se relaciona comúnmente este término, en lo expuesto por estos autores se puede evidenciar como, al momento de consultar con el ciudadano común sobre el concepto de institución, el mismo hará referencia a ámbitos sociales como el Estado, la educación, las religiones, e inclusive el matrimonio, entendiendo el sistema, muchas veces percibido como político y relacionado con la burocracia, que rige una sociedad.

\section{Categoría: Finalidad de UNITEC}

\section{Subcategoría: Proceso de enseñanza y Aprendizaje (PENA)}

"Es un objetivo el de la población discapacitada en este momento es nuestro, digamos, nuestra ley motivo, estamos trabajando más en eso que en otras cosas, lo que pasa es que, asociado a todas los proyectos de extensión que nosotros hacemos hacia la discapacidad no dejamos de hacer toda la aplicación en educación, que es lo que 
hablábamos recién con Mónica, es decir, hay, en la extensión vos tenés que trabajar con los alumnos extensionistas, es un voluntariado porque nadie cobra, todo ese tipo de información y de conocimientos y de enseñanzas se la tenés que transmitir a los alumnos de alguna manera y entonces entra acá otra cosa que está entre los primeros objetivos de la UNITEC que era la enseñanza por competencias". (CC)

"sino que a través de las actividades nosotros llegamos a mejorar esas condiciones de enseñanza y aprendizaje" (CC)

Estas afirmaciones tienen mucha relación con las competencias del personal de UNITEC e indica que su finalidad, además de estar dirigida a la educación, ellos también ejercen el papel de educadores, al tratar de transmitir conocimientos y contribuir a la formación de estudiantes para que también adquieran dominio de su campo de trabajo, así lo establece su metodología de trabajo, la cual indica que se debe llevar adelante tareas de investigación en el área de innovación y mejoramiento de la Calidad en la Educación y entrenamiento en Ingeniería y promover desarrollos tecnológicos y asesoramientos a requerimiento de terceros e impulsar tareas de investigación, extensión, asesoramiento y capacitación, basados en los objetivos propuestos.

\section{Subcategoría: Extensión universitaria (EXT)}

"Porque la extensión es devolverle a toda la comunidad todo lo que vos recibiste, que la comunidad te pagó con impuestos, es decir, los impuestos nos dieron el estudio gratuito a nosotros, el estudio de grado, de alguna manera la universidad tiene una responsabilidad de retribuir a esa sociedad en algo sin cobrarle nada y para eso es la extensión universitaria, pero la extensión se puede dar en la transferencia de conocimientos a través de otras formas que no sean directamente asociadas a la discapacidad" (CC)

"Por otra parte... otras de las cuestiones que tiene que ver con que en UNITEC se hacen trabajos de extensión, es tratar de incorporar el concepto de la responsabilidad social universitaria..." (CC)

"Entonces a partir de eso que de alguna manera tiene que devolver a la sociedad algo, entonces incorporar esas ideas es complicado porque nuestras...nuestras materias son muy técnicas, entonces como hacés para incorporar esas ideas, bueno, través de trabajos en el grupo, está bien no lo podemos incorporarla a todos los alumnos, pero 
por ahí los alumnos que se van acercando al grupo van entendiendo este tipo, este tipo de actividades, entonces van tomando otra dimensión de su ubicación dentro de la $\underline{\text { sociedad, eso creo que es principalmente, apoyado todo en el concepto de la extensión }}$ universitaria" (MG)

"Claro todo es extensión, la extensión universitaria es gratuita, es decir, es lo que la Universidad devuelve a la comunidad sin cobrar absolutamente nada porque también acá en la Facultad de Ingeniería existen otras áreas, la investigación pura donde se investigan desarrollos de este tipo también... (CC)

"Si o en un desarrollo que no tienen una aplicación inmediata porque son por ahí cosas que son... que van a beneficiar a la humanidad en algún futuro que se desconocen cuándo va a ser, eso es la investigación, la transferencia es realizar servicios por los cuales vos cobrás y la extensión ya te digo es realizar determinadas actividades, servicios o lo que sea sin recibir un peso". (CC)

"Si... entonces, si porque hay facultades donde la extensión es muy normal, en Ingeniería no es normal, en ingeniería existen dos líneas, la transferencia y la investigación, extensión fuimos nosotros prácticamente... habían algunas actividades, pero fuimos prácticamente los primeros y los únicos en formar una UIDET, y... no sé si algo más" (CC)

En este contexto, se evidencia que la UNITEC como organización ha tratado de buscar el equilibrio en sus procesos internos, puesto que, evidentemente la extensión no es uno de sus elementos fundamentales desde su génesis, lo cual confirma lo expuesto por Chanlat (1994), quien afirma que estos sistemas socio-técnicos están conformados por elementos innatos que se relacionan al conflicto y las tensiones derivadas de la contraposición de intereses de los diferentes actores que tienen vida dentro de las mismas. Dicho de otra forma, dentro de las organizaciones existe una puja constante y continua de diferentes fuerzas que buscan imponer sus objetivos y agendas. Sin embargo, existen otros aportes que sugieren lo contrario, es decir, que las organizaciones son sistemas en los cuales se busca la homeostasis, el equilibrio y por tanto, el conflicto es solo tomado en cuanta cuando incluye problemas que pueden ser resueltos. 


\section{Categoría: Características de UNITEC}

\section{Subcategoría: Competencias y ejes transversales (COMP)}

"Que la enseñanza por competencias se basa en tres pilares, el saber, que es recibir los conocimientos, el saber hacer, que es aplicarlos y el saber ser, que es todo lo que tiene ver la responsabilidad, con el compromiso social". (CC)

"Con la ética". (MG)

"Con el trabajo en grupo, con muchas cuestiones" (MG)

"Si, la forma de expresarse, la forma trabajar, la forma de dirigirse a tus...a los docentes, a los que vendrían a ser tus jefes, todo ese aprendizaje es muy importante, por eso te digo, no se han abandonado todos los principios de educación que teníamos en la UNITEC, al contrario están mucho más profundizados a través..." (CC)

Estos argumentos resaltan que, a pesar de que en UNITEC no se desarrolla de manera directa un proceso de enseñanza y aprendizaje, se basan en sus actividades en pilares que sostienen su labor, y que pasa a formar parte de sus valores y de su cultura como institución. Con relación a estas, es importante destacar que se constituyen sobre aspectos estructurales como la rutina, los ritmo de las escuelas, entre otros, las métodos institucionales, de trabajo en equipo, los consejos de educación, todos estos, clasificados como "internos", mientras que, por otro lado, se dispone un sistema de instituciones "externo", los cuales está basado en la constitución de enlaces de intermediación, acompañado de una burocracia interna (Pesqueux, 2009).

\section{Subcategoría: Aptitudes en la atención de personas con discapacidad (APT)}

"Si, se han enfocado en el tema, a través de la discapacidad y de todas las tareas que nosotros hacemos por la discapacidad". (CC)

“...porque nació para la discapacidad fundamentalmente en la enseñanza, o sea, en las necesidades educativas especiales, ahí empezamos. Después fuimos ampliando a todas las personas con discapacidad. Pero en un principio también estaba muy relacionado con la educación...con la educación especial, ¿por qué?, porque la idea es incluir a todas las personas dentro de la sociedad y para eso tenés que buscar las maneras de que tengan acceso a todo lo que tenemos acceso todas las personas que no tenemos discapacidades" (CC) 
“También ahí estás trabajando en las competencias, porque justamente el alumno está haciendo cosas que lo transforman en competente, encontrás el objetivo bueno, haciendo qué, bueno haciendo esto" (MG)

En este aspecto, se resalta la importancia de que la institución cuente con personal capacitado para cumplir con sus objetivos, pero sobre todo comprometidos con su trabajo. Esto aporta muchísimo, ya que además de cumplir con los propósitos establecidos, se fortalecen elementos que permiten el crecimiento de la institución, esto puede ser influenciado por el mimo contexto directo en el cual se desenvuelve una organización presenta ciertas características y factores que implica repercusiones directas y cercanas a la organización, empezando por quienes representan la fuente de materia prima para las organizaciones, entiéndase por materia prima a cualquier insumo que puede originar el mejoramiento y mantener la producción de una organización que represente un préstamo de bienes, productos y servicios en una determinada comunidad o sociedad. Así como también potenciales clientes o usuarios de sus servicios, del mismo modo existen en su radio de acción más directo otros competidores que ofrecen los mismos bienes, productos y servicios de una organización, y que, en conjunto con los factores mencionados anteriormente conforma el contexto directo de una organización, y componiendo el total de factores que intervienen e influyen en el regular funcionamiento de la misma (Carreón y Campos, 2008).

\section{Subcategoría: División del trabajo}

"Si, específicamente... yo creo que estamos un poco divididos cada uno de nosotros en temas específicos" (MG)

"Si, en tres áreas" (CC)

"Hay tres áreas bien definidas" (MG)

"La parte de educación" (MG)

"En general, en este momento yo me estoy dirigiendo más con...trabajando con los alumnos de ingeniería... en particular... para ponerlos en el contexto para que después entiendan lo que significa el trabajar para fuera e ir haciendo este tipo de actividades". (MG)

Después está Flavio que se dedica a la parte tecnológica, de desarrollo tecnológico" (CC) 
"Estoy en la parte del desarrollo de rampas tecnológicas que tiene como un objetivo ayudar a la inclusión, cualquier... todo tipo de desarrollo utilizando la tecnología actual que permita que la persona con discapacidad interactúe con... ayudarlos a que interactúe con...ya sea para aprender, ya sea para jugar o para interactuar con algo de lo cotidiano, puede ser un juguete, puede ser una computadora, etcétera, pero mayormente es para que interactúe, para que se inserte en la sociedad a través de distintos tipos de aplicaciones y usos de tecnologías" (FF)

"Yo me dedico más... Bueno yo hago dos tareas, una de gestión general y manejo la parte de extensión, el área de extensión... (CC)

Estas afirmaciones indican que en la institución domina un enfoque de tipo funcional, el cual, propone una manera estratégica de funcionamiento, donde cada uno de los miembros forma parte de una planificación específica para cada función o cargo específico. Por otro lado, se presenta un enfoque científico que se refiere al crecimiento y desarrollo intelectual e investigativo del personal de una organización, generando nuevo conocimiento y estrategias organizacionales (Zukin y DiMaggio, 2000).

\section{Subcategoría: Concepción de población discapacitada (CDISC)}

"A ver, bueno te doy mi opinión para mí existen personas sin discapacidad y personas con discapacidad es simplemente una situación que hace que vos pierdas alguna condición que te impide manejarte como una persona sin discapacidad, ¿se entiende?" (CC)

"O sea, nada más para mi es eso, es decir somos todos personas" (CC)

"Hay muchísimas definiciones es, para cada, para cada tipo de discapacidad y para cada tipo de persona, son personas que no tiene la habilidad para hacer alguna acción si sabrás hay algunas discapacidades muy severas, pero todos en el fondo tenemos algún tipo de discapacidad" (FF)

"Ernesto y que con mucho esfuerzo porque llegó a estar cuadripléjico pudo salir de eso y después se encaró puedo terminar su secundaria y encaró la facultad, le costó bastante pero llegó al título de ingeniero y yo, digamos, lo incorporé a mi cátedra para trabajar y siempre discutíamos sobre esta cuestión de la discapacidad porque por ejemplo él no quería pedir su pase para viajar gratis porque decía que le iban a poner una tarjetita..." (MG) 
"Discapacitado y él no se sentía discapacitado porque había logrado llegar a un título universitario, entonces no era discapacitado pese a que él quedó con alguna secuela no intelectuales pero si motoras, igual se maneja solo hasta vive solo no tiene problema, entonces hablando así yo le dije que bueno yo también era discapacitada porque yo uso anteojos para leer y si vos no me... y si yo no tengo los anteojos para leer yo no leo, para mí esto si yo no me pongo los anteojos es un manchón que no sé lo que dice, entonces discapacitados somos casi todos en algún momento de la vida" (MG)

"No, no tratarlo ni con distancia, ni distinto" (FF)

La concepción de discapacidad que poseen los directivos de UNITEC, se basa en que todas las personas son iguales y poseen algún tipo de discapacidad, por tanto todas pueden lograr sus metas y merecen ser tratadas de igual forma. Esto es muy importante, porque desde la institución se promueve la aceptación de las personas y el valor de la igualdad, por lo cual UNITEC demuestra pertinencia en cuanto a su forma de ser y actuar. En tal sentido, las instituciones sociales deben contar con coherencia, es decir, debe existir una relación de conformidad entre los individuos debidamente socializados, las actuaciones de la sociedad en su conjunto y de las instituciones que en ella tienen lugar. En pocas palabras, dichas acciones deben estar basadas en una autoridad legítima bien sea gracias a la religión o a las leyes, pero que en términos finales promueva la conformación y aceptación de los miembros de la sociedad de tales acciones. (Pérez, 2011)

\section{Subcategoría: Concepción de tecnología (CTEC)}

"Lo que pasa es que nosotros como ingenieros y en particular como ingenieros electrónicos, eh, la tecnología la tenemos incorporada en nuestra forma de pensar, claro, o sea la tecnología, por ahí a veces un poco nos asombra cuando vemos la tecnología de afuera, no, pero la tenemos incorporada en nuestra forma de ... todos los días, no, no, no sé... creo que no... nunca recapacitamos a ver qué en realidad que era la tecnología para nosotros, sino que, la tecnología es algo que forma parte de nuestra vida, no como recurso, de, de digamos de tener un televisor una cosa así como producto tecnológico sino que en realidad forma parte de las cosas que enseñamos, entonces forma parte de nuestra vida". (MG)

"Para mí una herramienta para resolver estas cuestiones puntuales, es una herramienta" 
" $\mathrm{Si}$, todos los desarrollos que se puedan hacer de ayudas técnicas específicas para la discapacidad también, son todas herramientas, herramientas que mejoran la calidad de vida a las personas con discapacidad y a nosotros nos dan confort, o sea a las personas con discapacidad es todo confort, la idea es, las personas con discapacidad, las ayudas técnicas las incluye, les dan acceso a un montón de cosas y en algunos casos les brindan confort, que eso sería lo ideal llegar al confort también" (CC)

"El punto es que la mayoría de los desarrollos que nosotros hacemos en UNITEC ya están hechos, lo que pasa es que son caros, entonces, estamos en la Facultad de Ingeniería usamos el ingenio para hacer lo mismo a bajo costo con componentes nacionales, con reciclado de materiales, con mano de obra gratuita porque esto es un voluntariado, entonces un comunicador que en Europa sale en 500 euros, acá se puede hacer por 800 pesos, porque se hace con otros materiales, con componentes nacionales y se desarrolla íntegramente acá con hardware libre y software libre, eso es usar o reutilizar la tecnología en el caso de UNITEC, vamos a obtener el mismo resultado que ya está en el mercado a bajo costo, accesible para las personas que no pueden pagar una cosa así, no" (FF)

Esto permite inferir que la tecnología para los directivos de UNITEC es una herramienta de gran utilidad, no solo porque a través de ella se facilitan procesos de la vida cotidiana, sino porque son un elemento valioso para realizar su labor de ayudar a otros. Esto evidencia el cumplimiento de la metodología propuesta para el desarrollo de UNITEC, la cual trata de Fomentar actividades de transferencia de conocimientos, a través de la capacitación y formación de los miembros de la UID en temas relacionados con las TICS aplicadas a la Educación, otras Tecnologías y al Aseguramiento de la Calidad.

\section{Categoría: Comunicación}

\section{Subcategoría: Canales y formas de comunicación (CANC)}

"Siempre o te mandan un correo o te llaman o vienen acá" (FF)

"Bueno la persona de San Martín de los Andes por ejemplo es un caso muy particular porque la triangulación fue a través de un artículo en el diario que leyó el hermano de ella en Barcelona - Wow!!- se lo comentó a ella y ella vino a La Plata a vernos...para 
pedirnos ayuda, para Puentes de Luz que es un centro de día en San Martín de los Andes" (CC)

"No la manejamos nosotras... el artículo del diario por ejemplo recién charlábamos el que salió en el diario... El Día... estaba mirando el mail del UNITEC y encuentro la mamá de un chiquito que ya le habíamos hecho un desarrollo, una adaptación en un juguete que se la había hecho Flavio, el grupo de Flavio, que nos pide que desarrollemos otro equipo, que es un comunicador con manejo a través de la vista, entonces bueno ya tenemos un requerimiento, así nos llegan los requerimientos, entregamos computadoras a APRIL a través del LATE y eso se derivó en que nos pidieran el desarrollo de un laboratorio de marcha para análisis de la forma de caminar de las personas que tienen problemas neuro-locomotores, y ahí hubo, inmediatamente saltó al desarrollo tecnológico y Flavio está dirigiendo el proyecto del laboratorio de marcha, que no tiene nada que ver con las computadoras que nosotros entregamos pero vos veis que todo..." (CC)

En este sentido, se presenta una debilidad importante en cuanto a los canales de comunicación definidos en UNITEC, ya que no existe un sistema de comunicación formal y contradice lo establecido por la UNESCO, que apostó por la comunicación como el mecanismo para generar procesos de desarrollo (educación, salud, etc.). Con esta finalidad, Unesco facilitó la integración entre los medios productivos y la Universidad, para potenciar la capacitación y la investigación en este campo. La prueba palpable de esta situación fue el decisivo apoyo que brindó para la constitución de la International Association of Mass Communication Research (IAMCR) y la creación del Centro Internacional de Estudios Superiores de Comunicación para América Latina (Ciespal).

\section{Subcategoría: Concepción de comunicación}

"Sí, es muy difícil porque no la tengo definida así muy racionalmente sé que es fundamental para una relación en la sociedad el estar comunicado permanentemente por que todos estamos comunicados y es una necesidad, lo vemos también en la discapacidad porque lo primero que busca cualquier persona con discapacidad es comunicarse y cuando vos estas en otro país que no hablás el mismo idioma buscás las maneras de comunicarte, o sea, creo que es una necesidad muy importante del ser humano, la comunicación" (CC) 
"Complemento lo que dice Cristina con algo, si es del ser humano, pero creo que es una necesidad que inclusive se da también en los animales, porque por ejemplo yo tengo al gato que ahora me está extrañando porque no estoy y cuando llego te comunica que quiere estar con vos, que quiere, que se sintió solo porque viste, te empieza a... que quiere comer, o sea, es una cuestión que creo que no es solamente del ser humano, es difícil de representarlo con palabras pero más vamos allá obviamente claro en el ser humano es una cuestión muy lógica pero no... yo creo que no termina solamente ahí" (MG)

"La comunicación, interactuar, interactuar con el otro, somos una comunidad, somos una comunidad, somos un grupo de personas que tienen que estar comunicadas el que está aislado no creo que le vaya muy bien, es decir, sin interactuar con sus semejantes"

Como se puede apreciar, no es fácil para los directivos conceptualizar comunicación, sin embargo, lo definen como una necesidad importante para el ser humano, como una manera de interactuar y de hacerse entender por otros. Esto los motiva a ayudar a personas con discapacidad a comunicarse, como el caso de Ceraso (2014), quien hace énfasis al aclarar y entender la formación de Shannon y Weber como ingenieros, quienes al formular su teoría estaban sistematizando un modelo de comunicación telefónica y su objetivo era optimizar la comunicación desde una perspectiva tecnológica. "Desde este modelo informacional inicial hasta hoy se dieron conceptualizaciones, aportes y reformulaciones en diferentes momentos del proceso y desde diferentes disciplinas".

\section{Subcategoría: Comunicación interna}

"Bastante fluidamente y bastante bien, generalmente si... estamos comunicados, estamos permanentemente muy comunicados y de todas las actividades y de todas las cosas que se hacen, además tenemos, es como naturalmente han surgido canales de comunicación diferentes" (CC)

"Hacemos honor al uso de las TIC" (FF)

"Estamos constantemente, sí, nos comunicamos las novedades porque..." (CC)

"Porque además tenés que tener en cuenta que al hacer extensión gratuitamente lo hacemos fuera de los horarios de trabajo, entonces, si bien nos tenemos días de reunión aquí y de estar permanente, de permanecer en la UNITEC" (CC) 
"Dejamos para estos encuentros las cosas críticas, las cosas que hay que resolver". (FF)

Se observa que existe una comunicación efectiva entre los directivos de UNITEC, usando canales de comunicación a través de las tecnologías de información y comunicación y realizan encuentros para discutir temas de relevancia. Sin embargo, los canales de comunicación en los cuales se utilizan como medios las tecnologías presentan fuertes cuestionamientos, esto se ha estudiado desde la escuela funcionalista, y Ceraso (2014) afirma que aportará su perspectiva desde una conceptualización del poder y la sociedad de masas, donde los medios de comunicación se integran a las fuentes de poder y a las autoridades para construir y ejercer hegemonía. Desde esta línea teórica se ponen de manifiesto la ideología y la manipulación en los procesos de comunicación.

\section{Subcategoría: Comunicación entre UNITEC y personas atendidas (CUPA)}

"no, eso es ya más complicado, es decir la gente se comunica con nosotros a través del mail, si, los que de alguna manera logran encontrarnos o lo hacen de boca en boca y entonces se aparecen un día por acá, tenemos una página de Facebook pero no... es decir, tenemos el problema de la comunicación hacia fuera y de la difusión de nuestras tareas porque de eso no tenemos a nadie encargado y tampoco lo sabemos manejar bien porque el Facebook es una, digamos, necesitaríamos un manejo más juvenil de la cosa porque nosotros no somos de la generación del Facebook si bien lo usamos no le sabemos sacar todo el provecho que podríamos sacarle, digo el Facebook como puedo decir el Twitter como puedo decir cualquier otro medio de comunicación, el diario, suponte esa nota en el diario a mí me llamó la atención por lo bien que escribió la persona, maravilloso como escribió, es decir si nosotros estuviéramos que escribir nosotros tenemos que... somos estructurado para poner las cosas y no llega a la gente". (FF)

"Tenemos un problema de comunicación" (MG)

"Hacia el exterior" (CC)

"Lo que pasa es que está dentro de los límites que tenemos como grupo, de los recursos que también tenemos, además en este momento más allá de lo que hacemos es imposible porque no tenemos recursos, o sea, si uno quisiera ampliar y quisiera hacer algo para un grupo particular desde nosotros no tenemos los recursos para 
implementarlos, ahora estamos esperando por ejemplo presentar tres proyectos a un llamado a..." (MG)

Los problemas de comunicación a nivel externo representan una debilidad importante en la UNITEC, ya que esto conduce a que no se conozca ni reconozca su trabajo en la comunidad y sobre todo, que personas que requieren de su servicio no tengan conocimiento de la importante labor que realizan. En este sentido la comunicación de masas, en la cual los medios de comunicación ejercen un papel fundamental puede contribuir de manera efectiva a solucionar la problemática existente, tal como advierte Ceraso (2014).

Para continuar el diagnóstico de la situación, se entrevistaron a dos personas con discapacidad a fin de analizar cuál es la percepción instituida que se ha construido desde la UNITEC hacia los habitantes con y sin discapacidad de la ciudad de La Plata; para conocer las fortalezas y debilidades de la organización a nivel comunicacional, como parte esencial de la etapa inicial del diagnóstico

Se pudo evidenciar que en la búsqueda que hicieron las personas acerca de la UNITEC en internet, no se consigue colocando en Google palabras referidas a la ayuda sobre personas con discapacidad en la ciudad actual no aparece ninguna mención a la UNITEC como institución encargada de generar proyectos a las personas con discapacidad.

Luego, el entrevistador después que observó que las personas con discapacidad no pudieron encontrar nada sobre la UNITEC les suministró en el nombre de la institución y les invitó a buscar en internet acerca de la organización con el fin de observar si se les es fácil encontrar información para acceder a los servicios y proyectos que planifica UNITEC para las personas con discapacidad.

Los entrevistados señalan que la página de la UNITEC no muestra información completa acerca de sus servicios y apoyo para personas con discapacidad, no hay información completa ni tampoco contiene un link para información precisa. Señalaron que se enfoca más a aspectos académicos y para personal académico.

Los entrevistados destacan que solamente en la página de Facebook es donde aparece mayor información acerca de los proyectos que llevan a cabo para personas con discapacidad aunque no hay claridad acerca de la dirección y no explican cómo llegar. En la página de la Facultad de Ingeniera no muestra mucha información acerca de estos proyectos. De acuerdo a los comentarios de los entrevistados la información es muy general. 
Los entrevistados luego hicieron un recorrido en la institución para llegar a la unidad, aunque preguntaron en el trayecto muy pocas personas conocían que existía la unidad de proyectos para personas con discapacidad así que la ayuda fue casi nula. Tuvieron que contactar a trabajadores de la Facultad a fin de obtener una información un poco más precisa para llegar a la sede.

Luego, que algunos miembros de la Facultad les explicaran como llegar se dirigieron a la dirección, señalaran que el camino es de difícil acceso pues la carretera no está pavimentada y no hay señalización clara Es de destacar que la página de Facebook a pesar que aporta información general acerca de los proyectos no explica de forma detallada la dirección de la sede.

Luego, que llegaron a la sede fueron atendidos y se les explicó el funcionamiento de la organización, se les dio información completa. Se evidenció que la institución tiene más de 10 años trabajando en la ayuda de las personas con discapacidad, generando alternativas, proyectos de interés, entre otros. De ahí que se pudo detectar que si una persona asiste a UNITEC en busca de ayuda ellos analizan su caso y en cuestión de 3 a 6 meses generan una ayuda e intervención para el manejo de los casos.

Los entrevistados señalaron que los trabajadores de UNITEC son personas de gran calidad humana, y con mucha experiencia en tratar con personas con discapacidad. Sin embargo, la sede no es apta para personas que se transportan en silla de ruedas, pues queda en un segundo piso y no hay ascensor operativo, se hace difícil el acceso.

Los entrevistados destacan que se hizo difícil llegar a la institución, esto permite evidenciar que no se ha comunicado el mensaje de la institución a nivel general, no existe una política promocional de las funciones, y tareas de UNITEC para con la comunidad. Es necesario establecer responsabilidades y delegar funciones a fin de aplicar estrategias publicitarias tanto a nivel institucional como para proyectar la imagen de la institución a toda la sociedad y por supuesto para que se conozca todo sobre UNITEC incluyendo la ubicación de su sede. 


\section{Categoría: Relación UNITEC y personas con discapacidad}

\section{Subcategoría: Relación entre UNITEC y personas con discapacidad (RUDI)}

"Y en general la gente que viene y bueno hace algún tipo de reunión acá, presentado su problema, después se ha ido a algunas charlas, algunas reuniones que han hecho en la Universidad, pero en general la gente que viene acá" (MG)

"El sistema funcionaba así, a partir de las donaciones, a partir de lo que querían las maestras, los practicantes generaban los arreglos de las computadoras, las reciclaban, después modificaban si se necesitaba cargar algún software algún tipo de cosas y en algún momento los mismos chicos iban y entregaban las computadoras como para que ellos también se sintieran parte del proceso y se integrarán y vieran el lugar al cual iba a ir su trabajo, entonces de esa manera se vinculaban con algunos chicos con discapacidad" (MG)

"Hay una relación formal a través de instituciones generalmente y después el hecho de que nos conozcas hacen que aparezcan personas, particulares que no tiene nada que ver, madres con los hijos discapacitados acá, en realidad hay que hablar no de discapacitados, sino de personas con discapacidad, esa es una de las cosas que nos tenemos que acostumbrar, yo a veces, se me escapa, entonces, hay que mentalizarse, en usar personas con discapacidad, personas sin discapacidad y bueno, generalmente nos relacionamos de ese modo, a través de las mismas maestras, ya la primera relación fue a través de una maestra, docente de una escuela especial, ella lo conversó en una reunión con otras y empezaron a venir las otras maestras de las escuelas. Intentamos hacer una relación formal con el Ministerio de Educación y con la Dirección de Educación Especial, en el primer principio de la UNITEC no nos dieron bolilla. El año pasado tuvimos una reunión con esta gente, con una asesora que nos dijo que podíamos llegar a firmar un convenio si queríamos, pero como que estábamos más allá de lo que ellos estaban haciendo, ¿me entendés?, como que ya pasamos esa barrera, y después ya te digo...las ONG, es mucho el boca en boca y es mucho..." (CC)

"Relativamente, al principio si eran muy informales, después empezamos a firmar acuerdos, una vez que tenés firmados acuerdos... Lo que pasa es que el problema es que las directoras de las escuelas de educación especial cambian permanente. O sea..." (CC) 
"Van rotando permanentemente, entonces por ahí te cuesta mantener una línea con una determinada escuela porque cambió dos o tres veces en cuatro o cinco años la dirección de la escuela. Hay escuelas que no, que la directora sigue siendo la misma y la relación es muy fluida porque todo depende del conocimiento de la persona con la cual empezaste a trabajar. De cualquier manera creo que ahora en La Plata más o menos somos muy conocidos y casi todas las escuelas nos conocen" (CC)

"Con resultado en tu trabajo porque las directoras cambiaban y bueno se iban a otra escuela entonces no nos decían, siguió como siguió y de ahí comenzó a trabajar el grupo este de asistentes sociales" (FF)

Se muestra en las afirmaciones de los directivos, que la comunicación entre UNUTEC y personas con discapacidad se realiza con las mismas personas discapacitadas, con los docentes, familiares y directivos. Sin embargo, aún se presentan dificultades importantes para hacer el contacto permanente y seguimiento a los diferentes casos. Esto es importante, ya que Mata (S/F) insiste en que reconociendo el indiscutible poder del emisor debemos advertir en su discurso la presencia activa de los receptores porque ellos están presentes como término de su producción como el otro que habla en lo que yo digo. Las perspectivas que vamos encontrando en el proceso histórico de la comunicación, como dominio de saber, llevan implícita una forma de ver el mundo y se corresponden con un modo conceptual o teórico de ver a la sociedad y sus relaciones. Estas miradas guardan relación profunda con el contexto político en que surgieron y con las características de los procesos de comunicación que describen.

\section{Subcategoría: Puntos de encuentros entre UNITEC y personas con discapacidad}

" $\mathrm{Si}$, a través de los acuerdos, el año pasado firmamos, un ejemplo que te doy, un acuerdo con ACNOC, que es una asociación mutualista y ellos tienen, uno de los talleres que hacen es una... dan clases de computación a chicos con discapacidad de escuelas especiales, entonces, entregamos computadoras para esa aula, así que el punto de convergencia es este, a través de los acuerdos con estas instituciones que manejan personas con discapacidad" (FF)

"Si también, por ejemplo, para los proyectos nosotros pedimos este tipo de avales, este es un tipo de aval con la asociación ASUPD para la vida independiente para las 
personas con discapacidad, esos son los avales que nos firman las instituciones para que nosotros podamos presentar proyectos de extensión" (CC)

"Mostráselo... firmamos acuerdos con las instituciones, son acuerdos de cooperación..." (CC)

"Firmamos también acuerdos de cooperación por algunos son anual, otros son bianuales" (FF)

Esto demuestra que en UNITEC, a pesar de que pueden existir debilidades en la comunicación externa, realizan una comunicación formal al converger en acuerdos de cooperación que permiten el intercambio cooperativo entre dos o más instituciones. Esto implica que UNITEC podría ser una organización en función de las asociaciones entre sujetos, ya que pueden establecerse tres tipos de concepciones acerca de las organizaciones: la primera se denomina 'clásica', debido a que establece la investigación de las tareas que se deben llevar a cabo para alcanzar los propósitos; la segunda, se encuentra relacionada con las función en las asociaciones entre sujetos, en donde la investigación se enfoca en aquello que motiva al ser humano, así como en su comportamiento en el ámbito laboral y social; por último, se encuentra una concepción de la organización basada en términos de sistema, en donde la focalización de la atención va dirigida en las decisiones que pueden ser llevadas a cabo para conseguir los propósitos establecidos (Aguilar, 2009).

\section{Categoría: Necesidades y debilidades de UNITEC}

\section{Subcategoría: Procesos abstracto y deshumanizado (ABS)}

"Muy, muy...no tiene mucho de humanidad, digamos" (FF)

"Nada" (MG)

"No, te exige mucha concentración y mucho meterte en una sola cosa" (FF)

"Si te descuidas terminas siendo un aparato como se dice acá" (FF)

"Entonces... hay que buscarle la vuelta para que no sea eso, para que no se conviertan en personas que calculan solamente" (FF)

"Y que pierden el contacto con la realidad, pues es así pierden el contacto con la realidad" $(\mathrm{MG})$

"Si se vuelve en poco en empáticas, o sea, tenés poca relación con el resto....es... es un poco... mira, la vez pasada estaba leyendo un artículo que la cantidad de autistas que hay, la mayoría son hijos de ingenieros, científicos..." (CC) 
“...La falta de personalización" (MG)

"O sea no importa el otro" $(\mathrm{CC})$

"Me importa mi... mi mundo" (MG)

"Te aíslan y te mantienen en un mundo muy encerrado, entonces tal vez el contacto... es el opuesto a veterinaria, trabajo social, supongo que a periodismo" $(\mathrm{CC})$

"Porque es una... claro la diferencia de las carreras sociales, creo yo, es porque... lo voy a decir desde lo que yo vi como trabajaban mis amigas mayores licenciadas en sociología, y siempre trabajaron en grupo, o sea, siempre la lectura era en grupos, siempre... acá no se trabaja en grupo, acá se trabaja en forma individual, no sé, al trabajar en forma individual vas perdiendo justamente ese enganche con lo social, o si trabajás en el grupo trabajás en el grupo de que es como yo, no sé, el que se sacó las mejores notas yo me junto con ese, no me junto con el otro" (MG)

Como puede notarse, es insistente por parte de los directivos las características de la labor que realizan, la cual califican como abstracta y deshumanizadora, debido a la naturaleza de sus actividades, esto les afecta en cuanto a sus relaciones personales, la cual es una necesidad del ser humano, además, el trabajo en equipo podría fortalecer sus productos. En este sentido, es importante que resaltar que las instituciones son creadas en el imaginario social por el anónimo colectivo a través de las cuales se conforman una serie de elementos y significaciones específicas que permiten dar sentido y propósito a las mismas y ser aceptadas por los miembros que hacen vida dentro de la sociedad. Para la creación de dichas instituciones y organizaciones sociales hacen falta dos elementos fundamentales a los que debe atenderse; en primer lugar, las restricciones externas, que se refieren a las condiciones biológicas inherentes a los individuos y a la naturaleza misma que imponen restricciones si se pueden llamar triviales a la conformación de estructuras e instituciones dentro de la sociedad. (Pérez, 2011)

\section{Subcategoría: Necesidad de espacio físico (ESPF)}

"En principio tenemos una gran falencia con el tema del espacio, porque así como ha ido creciendo el requerimiento han ido creciendo las donaciones y hasta estamos trabajando en el mismo espacio físico que teníamos cuando empezamos, entonces el espacio es algo crítico, creo que es lo más importante como falencia”. (FF) 
"Sí, además que este lugar es un pasillo de salida y cuando se apliquen normas de seguridad en el edificio vamos a desaparecer" (CC)

"Si, exactamente, el espacio es muy, muy importante. Muy importante sobre todo porque en este momento acá se están haciendo reformas, entonces bueno se está construyendo toda una parte por eso va a quedar libre el pasillo porque va a ser el acceso seguramente a la parte que se está por construir y entonces esto queda mucho más chico, a parte que acá se comparte con la cátedra de proyecto final” (MG)

"No hay un espacio propio". (MG)

El espacio físico es una necesidad de gran importancia, tanto para los directivos, como para los docentes, ya que este no es suficiente para desarrollar sus actividades, además se sienten inseguros sobre dónde funcionará UNITEC en el futuro, ya que no es un espacio propio. Esto es muy importante, ya que influye en la motivación de los directivos y en su actuación, lo cual incide en el tipo de organización que se adopte, ya que esto depende de los niveles de actividad que se manejen en el entorno tanto directo como indirecto que contemple el contexto en el cual se desarrolla, funciona y labora una organización, el cual puede presentarse igualmente de dos maneras, de las cuales, cada una determinará ciertas características de una organización, dependiendo en qué contexto se encuentre y la dinámica de su funcionamiento, y el de sus diferentes instituciones y principales organismos (Pesqueux, 2009).

\section{Subcategoría: Necesidad de reconocimiento (REC)}

"Depende de que las autoridades de la Facultad de Ingeniería consideren que la extensión es suficientemente importante como para dar una parte del presupuesto a dedicaciones dedicadas a la extensión y no al resto". (MG)

"No aquí, es lamentable lo que voy a decir, pero no somos productivos... no generamos" (MG)

"No somos productivos". (CC)

"No, no, es un trabajo y todo... lo que pasa es que lamentablemente... vuelvo a insistir el problema mayor es que es una falta de conocimiento respecto a lo que significa la extensión y de los estatutos de la Universidad, hay un discurso de Joaquín V. González de 1913 que ya habla de la extensión universitaria” (CC) 
"Y creo que superamos la barrera más difícil que fue que siguiéramos estando como grupo en la facultad porque digamos, se modificaron ciertos reglamentos y hay ciertas características que nosotros no podemos cumplir por la condición de que no cobramos y entonces no entrabamos en la condición de permanecer como grupo y bueno fue una larga... un largo tire y afloje donde se contó con el apoyo de mucha gente que entiende el concepto de extensión y que tironeaba con la gente que no y bueno creo que superamos una barrera muy, muy difícil que fue podernos insertar como un grupo y seguir al mismo nivel que está cualquier grupo de investigación que tiene este departamento, por ejemplo que tiene la Facultad". (MG)

Este aspecto puede ocasionar consecuencias importantes en cuanto a la motivación de los directivos de UNITEC y se afirma como la vocación es el factor que los impulsa a ejercer su labor, más allá de remuneraciones. Sin embargo, es de gran urgencia y relevancia que se reconozca el esfuerzo del personal, ya que como indica Wells (1970), es vital que se entienda la importancia y relevancia que tienen las instituciones y organizaciones dentro de una sociedad o país; ambas, son un reflejo del comportamiento y las características intrínsecas de esa misma sociedad de la cual provienen y que propicia la creación de ambas; el conocimiento de las características de su funcionamiento permite comprender como éstas pueden contribuir al desarrollo y crecimiento de una sociedad desde diferentes puntos de vista, en diferentes aspectos, generando soluciones a las problemáticas sociales, o bien contribuyendo con el desarrollo socioeconómico del país a través del intercambio de bienes, productos y servicios.

\section{Codificación selectiva}

Luego de haber interpretado y analizado las categorías que emergieron de las entrevistas del personal directivo, se procede a establecer las relaciones que existentes entre cada una de ellas y, a partir de ellas determinar la categoría central como eje en el cual se establecen diversas relaciones con todos los códigos existentes. Es oportuno resaltar que, para la selección de la categoría central también se tomó en cuenta los objetivos de la investigación. 


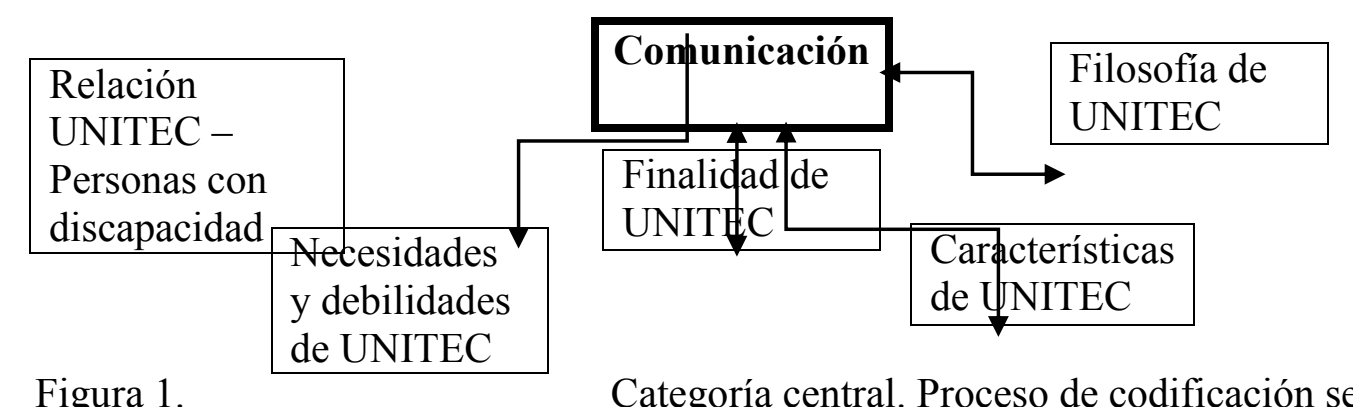

Figura 1.

Categoría central. Proceso de codificación selectiva

Como se muestra en la figura anterior, la comunicación representa la categoría central del análisis e interpretación de resultados de las entrevistas aplicadas a directivos. Desde este proceso surge un sinfín de relaciones que permiten consolidar la filosofía de UNITEC y cumplir con sus características y finalidades, tal como está establecido en su documento fundacional. Igualmente, es preciso resaltar que este es un proceso recíproco el cumplimiento de cada uno de estos elementos o categorías se fortalece intrínsecamente gracias a las relaciones laborales que se producen entre los actores. Así mismo, la categoría central es el eje central que permite el contacto de UNITEC con personas con discapacidad y, a su vez, las fallas en las mismas originan necesidad y debilidades en la institución.

Es importante hacer mención que, posterior a este proceso se realizó la refinación de la teoría, la cual se presenta en las conclusiones como respuesta a los propósitos del estudio.

\section{Conclusiones}

Los practicantes y docentes tienen conocimiento del significado de UNITEC, según sus siglas, Unidad de Investigación y Desarrollo para la Calidad de la Educación en Ingeniería. Además, es preciso destacar que, tanto ellos como los directivos describen el objetivo de la institución, orientados por el documento fundacional de la UNITEC, pero también por las características de su labor. Ellos refieren que la unidad tiene dos propósitos fundamentales, el primero de ellos es mejorar la enseñanza en carreras de ingeniería y el segundo, es mejorar las condiciones de personas con discapacidad a través de herramientas tecnológicas para ayudarlos en su proceso de enseñanza y aprendizaje.

En cuanto a la situación actual de UNITEC, existen necesidades expresadas por los docentes en cuanto a la insuficiente cantidad de herramientas, equipos y sobre todo espacio físico, en lo cual coinciden también los directivos. Ellos se muestran inseguros porque no cuentan con sede propia para realizar sus actividades y además no tienen conocimiento acerca 
de cuál será su futuro con relación al espacio. Así mismo, el lugar donde funciona actualmente la institución es muy pequeño y perjudica de forma indirecta el desarrollo de sus tareas.

En este mismo orden de ideas, tanto docentes como personal directivo tienen claro el concepto básico de comunicación, tomando en consideración la definición en la cual esta se precisa como el intercambio de información entre dos personas, y también hacen referencia a la interacción. Sin embargo, es importante resaltar que no fue fácil para ellos describir esta definición, pero no porque no reconozcan su significado, sino porque trataban de definirla de la manera más entendible posible.

Es preciso destacar que los directivos describen la comunicación como una forma de interactuar y hacerse entender por el ser humano. En esta concepción se encuentra intrínseca su visión de ingeniería y su aspiración de ayudar a las personas con discapacidad a comunicarse, pues tratan de optimizar el proceso de comunicación y de educación de estas personas a través de la creación de herramientas que le ayuden en el desarrollo de ciertas habilidades.

En el mismo orden de ideas, los docentes destacan que no presentan algún problema de comunicación, apenas uno, deja en evidencia que si existen fallas en cuanto a esto para que se realicen más donaciones, pero esto es secundario, ya que no cuentan con el espacio físico, el cual es el problema que ellos consideran el más urgente, sin este, se les imposibilita recibir más donativos porque no tienen lugar de almacenamiento. Además, valoran la comunicación de forma positiva, ya que afirman que esta se produce de manera efectiva con la comunidad.

Esta afirmación coincide también con lo manifestado por los directivos, quienes refieren que la comunicación interna es efectiva, ellos se comunican constantemente por medio de aplicaciones tecnológicas como WhatsApp, Facebook twitter o correo electrónico, solo realizan encuentros físicos para tratar los asuntos de mayor importancia. Esto indica que no tienen establecido un horario específico para realizar reuniones semanales o quincenales, lo cual puede afectar la dinámica del grupo, puesto que, claramente los medios de comunicación a través de las TIC son efectivos, pero siempre se necesita del contacto directo entre compañeros para conocer sus puntos de vista, sentimientos y emociones. Además esto 
fortalece el trabajo en equipo y permite mayor conocimiento del equipo, lo cual se fortalece a través de la interacción en las aplicaciones mencionadas.

En el mismo contexto, es importante destacar que, a pesar de que los docentes valoran como positivo la comunicación se establece entre la UNITEC y la comunidad, los directivos no opinan de igual forma, ellos consideran que hay una debilidad en este aspecto, puesto que no existe un canal de comunicación formal que permita el contacto permanente entre ellos. Es decir, siempre se establece alguna comunicación pero de manera informal, pues, es de destacar que existen debilidades en cuanto a la forma de difusión, por ejemplo, cuentan con espacio en Facebook, pero no es permanente. Esto ocurre porque no tienen personal encargado de esta función.

Igualmente, ellos perciben que cuando su trabajo es divulgado a través de medios de comunicación, muchas personas conocen acerca de este y quienes requieren de sus servicios establecen contacto con la unidad, sin embargo, esto no es permanente. Requieren que se implemente un canal de comunicación formal de manera permanente y que alguien cumpla con la función de planificar, dirigir y controlar este aspecto de forma eficiente, ya que ellos no tienen las competencias o están enfocados hacia otras actividades propias de su función en UNITEC.

Lo anterior indica que los procesos comunicacionales necesarios a considerar en el diseño de programas y estrategias para alcanzar la situación futura, se basa en el establecimiento de canales de comunicación interna y externa, que permita el intercambio de información de manera oportuna entre directivos, directivos y docentes y entre docentes. Además, es importante la planificación continua de encuentros físicos entre todos para la discusión de asuntos importantes y para conocer y evaluar continuamente el desarrollo de las diversas actividades que realizan. Igualmente es necesaria la dedicación de una persona para la administración de los medios de comunicación y para el establecimiento del contacto directo con otras instituciones, lo cual permitiría mayor difusión de los objetivos de UNITEC, recibir más donaciones y ayudar a más personas en situación de discapacidad.

Con relación a este último aspecto, es importante mencionar que los docentes describen a las personas con discapacidad como aquellas que necesitan alguna ayuda o limitación, y algunos pocos se refieren a ellos como una persona igual que cualquier otra, al igual que los directivos, quienes manifiestan que son personas que deben ser tratadas como tal, igual que 
a las demás. Ellos expresan que, todos los seres humanos presentan limitaciones, tal vez, no todos físicas, pero si necesitan por lo menos en algún momento, ayuda de alguien para ejecutar alguna actividad.

En cuanto a la definición de tecnologías, existe diversidad de opiniones entre docentes, sin embargo, la mayoría la califica como herramientas que simplifican la vida del ser humano, lo cual ayuda a ejecutar procesos de forma más fácil y rápida. Sin embargo, a pesar de que son pocos, algunos se refieren a ellas como conocimientos, o como la capacidad de usar los medios para lograr un objetivo. Esto evidencia la definición de tecnología como medio y como fin, lo cual permite evidenciar sus ventajas en su campo de aplicación.

La opinión de los directivos coincide con la de los docentes, pero además resaltan la utilidad e importancia de las tecnologías alegando que estas forman parte de su vida diaria y de la labor que realizan, de manera que esta significa una herramienta valiosa para ayudar a otros a lograr sus objetivos y el medio para enseñar a otros a que continúen con la misma tarea, razón por la cual representa más que máquinas o instrumentos, son medios para alcanzar fines deseados.

En cuanto a los procesos de gestión y comunicación generados en la UNITEC, los docentes los valoran de forma positiva, ya que afirman que estos permiten que la unidad ofrezca apoyo a las personas que lo requieren, por lo cual todos trabajan con dedicación para que las personas con discapacidad se integren a la sociedad, además, resaltan el aprendizaje que han obtenido en la institución, el cual ha sido oportuno y les ha permitido desenvolverse de mejor manera y dar respuestas efectivas en diversos contextos.

Dichos procesos de gestión y comunicación se desarrolla desde el enfoque de sistemas, ya que representan un conjunto de unidades vinculadas entre sí, que trabajan de manera coordinada y esquematizada para lograr los objetivos de la unidad. Además, está presenta la teoría de relaciones humanas, ya que se evidencia que se toman en cuenta las necesidades de los miembros que componen la organización, y esto se cumple además demostrando su vocación de servicio hacia la realización de un trabajo que no es remunerado, pero según docentes y directivos ofrece grandes beneficios a nivel personal y académico.

Se puede apreciar que se desarrollan procesos de gestión, en el cual se planifica, dirige, controla y evalúa cada una de las actividades que se realizan, sin embargo, esto no se realiza de manera permanente, ya que las reuniones no se realizan de forma sincronizada y continua, 
lo cual evidencia una debilidad importante para diseñar planes de acción organizados y revisar permanentemente cada uno de las actividades que se realizan en la unidad, para detectar errores a tiempo y corregirlos.

Con relación a la entrevista realizada a los directivos, es preciso destacar que se generan un conjunto de procesos desde la comunicación existente en la organización, esto se evidencia desde el cumplimiento de la filosofía de UNITEC, en la cual se evidencia que el intercambio de información constante y la manera eficiente y armónica de la relación que existe entre ellos ha permitido fortalecer los objetivos de la institución y concebir el fin de la unidad desde la extensión universitaria, como una manera de retribuir a la sociedad la inversión que ha realizado en la formación del ciudadano, dando respuestas a sus necesidad y colaborando para ayudar a otras personas. Esto los fortalece como institución y evidencia el objetivo claro que tienen con respecto a su misión en la UNITEC.

Igualmente, dicha interacción entre directivos, docentes y comunidad les ha permitido fortalecer el proceso de enseñanza y aprendizaje tanto a nivel universitario, capacitando a estudiantes de ingeniería y en otros niveles donde se requiera ayuda a personas con discapacidad, esto último se logra a través de la extensión universitaria, brindando apoyo a diversas instituciones sin recibir remuneración alguna por ello.

Así mismo, la comunicación ha permitido la articulación pertinente para cumplir con la enseñanza por competencias, basada en los pilares, entre los que se encuentran, el saber, saber hacer y saber ser. Además de forma intrínseca poseen valores de ética, trabajo en grupo que han mantenido a través de la concepción de educación que está fundamentada desde la génesis de UNITEC.

Además, se evidencia una estructura burocrática, la cual ocurre por la división del trabajo, ya que a cada uno de los miembros de la organización le corresponde una tarea, cumpliendo con tres áreas específicas, sin embargo, estas se realizan siguiendo el trabajo colaborativo, en el cual las actividades realizadas por cada uno de los integrantes del equipo contribuyen en que se logren los objetivos.

Para todos ellos, la comunicación es muy importante y representa el eje central de todos los procesos que realizan, sin ella, no se podrían cumplir con los objetivos de UNITEC. Esta se desarrolla de manera efectiva a nivel interno, pero a nivel externo aún presenta debilidades, 
sobre todo en la difusión de información, lo cual representa una debilidad importante, para recibir donaciones y poder brindar ayuda a mayor cantidad de personas.

Al mismo tiempo, se evidencian debilidades para hacer seguimiento de las ayudas que realizan en diversas instituciones por fallas en la comunicación y por la rotación o cambios en el personal de contacto (directivos) que permita evaluar cuál ha sido el impacto del apoyo brindado y si tienen que realizar correctivos acerca de éste.

Sin embargo, existen puntos de encuentro entre UNITEC y personas con discapacidad a través de instituciones, las cuales contactan a la persona de la unidad por alguna necesidad, y recientemente, se han firmado acuerdos, que permiten establecer puntos de cooperación entre ambas instituciones, lo cual permite la ayuda mutua y el fortalecimiento de ambas en algún proceso específico.

Uno de los aspectos, que se resalta insistentemente por parte de los directivos, como una debilidad es que su labor es abstracta y deshumanizada, esto es causado porque la mayor parte o todo el trabajo lo realizan con máquinas y se concentran en lograr sus objetivos individuales. Esto implica que tienen necesidad de establecer mayor contacto con compañeros y docentes, con el fin de sensibilizar su rol en la unidad.

La necesidad de espacio físico guarda relación con la comunicación efectiva y sobre todo asertiva, pues, se evidencia un clamor en cuanto a esta situación, la cual le produce incomodidad e inconformidad con sus condiciones de trabajo. Igualmente, esto trae como consecuencia que no se sientan reconocidos por la labor que realizan en cuanto a la función de extensión, debido a que no son escuchados, no reciben remuneración por esta tarea y deben luchar constantemente para ser aceptados como grupo dentro de la universidad.

Tomando en consideración todos estos aspectos del diagnóstico comunicacional de UNITEC, es importante establecer estrategias comunicativas basadas en redes de trabajo que permitan cumplir con los objetivos de la institución. Para ello, debe establecerse una estructura que permita su funcionamiento interno, y dentro de este, un ente, persona o departamento que cumpla la función de establecer relaciones interinstitucionales, con el fin de mantener contacto permanente y eficiente con el exterior.

Así mismo, es importante que este se encargue de difundir la labor de UNITEC para que sea reconocida a nivel universitario y comunitario, para dar a conocer sus beneficios y hacer que se valore su funcionamiento dentro del contexto del instituto de educación superior. 
Una vez que se reconozca la importancia de la institución, será más viable la asignación de un espacio físico adecuado y la reconsideración en cuanto a remuneración de sus integrantes.

Además, es importante que se realicen encuentros físicos entre los miembros de la unidad y demás personal de la universidad, con el fin de establecer contacto permanente y conocer las habilidades, aptitudes y competencias de otras personas, además de compartir vivencias, experiencias y conocimientos, esto hará que se sensibilice más el proceso y sea percibido como menos mecánico y más humanizado.

Tomando en cuenta el experimento realizado con las dos personas entrevistadas en situación de discapacidad, se pudo notar que aunque la comunicación interna no presenta mayores problemas no hay una política externa que proyecte una imagen institucional positiva hacia la sociedad, que se conozca el trabajo que se viene realizando en materia social con las personas con discapacidad. Se deben crear canales más eficientes con la comunidad, redes de trabajo, cursos, talleres, charlas, entre otros con el fin de acercar la institucional a las comunidades y dar a conocer más las funciones y actividades internas y por supuesto que se conozca la ubicación de la sede.

Así que la percepción de los entrevistados se centró en la falta de información de la institución para ellos acceder a información de los proyectos y poder unirse a los beneficios de la organización. Aunque tienen una página de Facebook donde se presentan parte de los proyectos es importante ampliar y poner información detallada para acceder, teléfonos, dirección exacta, contacto, entre otros.

La página web está en construcción, de concretarse esto sería una buena notica, pues deberían colocar allí toda la información referente a los proyectos de interés para las personas con discapacidad. También, se hace necesario remodelar la sede para que haya mejor acceso de las personas que usan sillas de ruedas. Desde el punto de vista organizacional existe gran clima de trabajo y experiencia para ayudar a las personas con discapacidad a superar sus dificultades y mejorar su calidad de vida. 


\section{REFERENCIAS}

Aguilar, Darwin. (2009). La teoría de la Organización. México. Universidad CLEA.

Apple, M. (1987). Educación y Poder. Argentina: Editorial Paidós.

Arribas V.; Boivin M.; Rosato A.; (2004). "Constructores de otredad, una introducción a la antropología social y cultural". Tercera edición. Buenos Aires. Editorial Antropofagia.

Arroyo Carlos M. (S/F). Escuela Latinoamericana de Comunicación y el pensamiento crítico de Antonio Pasqualli.

BARBERO. Jesús Martín. "De los medios a las mediaciones" (1987)

Bernal, M. (2011). Diagnóstico de comunicaciones: fondo de empleados grupo éxito presente. Caldas: Corporación universitaria lasallista, facultad de ciencias sociales y educación, comunicación y periodismo.

Biblioteca jurídica virtual del Instituto de Investigaciones jurídicas de la UNAM.

Bosch, Mela (2013). Revalorización y tangibilización de los recursos en información y edición científica en Argentina: líneas de trabajo y perspectivas del Centro de Información Científica y Tecnología del CONICET. Buenos Aires, Argentina: Editorial ISSN 1669-2381 (Versión impresa), ISSN 1851-8265 (Versión electrónica).

Bourdieu, P. (1996). Campo de Poder, Campo Intelectual. Argentina: Ediciones Montressor.

Bourdieu, P. (2009). Los herederos, los estudiantes y la cultura. 2da Edición. Argentina: Siglo Veintiuno Editores.

Brogna, P. (S/F). Posición de discapacidad: los aportes de la convención. Misiones.

Bruno, D. (s/f). El diagnostico de comunicación: diagnóstico y poder. Diagnóstico y participación. Argentina: Universidad Nacional de la Plata, facultad de periodismo y comunicación social.

Buenos Aires Centro de Investigaciones Sociológicas. Departamento de Sociología. FCSE. UCA /CONICET. Documento de trabajo.

Carreón Javier y Campos Guillermo (2008). ORGANIZATIONS, POWER AND MICHEL 
Carreón, J y Campos, G. (2008). Las organizaciones, el poder y Michel Foucault. Revista Castellano-Manchega de Ciencias Sociales. N 9, pp. 143-154. México: Universidad Nacional Autónoma de México.

Carreón, Javier y Campos, Guillermo (2008). ORGANIZATIONS, POWER AND MICHEL FOUCAULT. México. BARATARIA - Revista Castellano-Manchega de Ciencias Sociales.

Carretero, A. (2010). Para una tipología de las «representaciones sociales». Una lectura de sus implicaciones epistemológicas. Metodología de Ciencias Sociales, 20, 87-108

Castillo, Antonio y Gómez, Manuel (2004). Generación y transformación de las instituciones sociales: los procesos morfoestáticos y los procesos morfogenéticos. Granada- España. Editorial Reis.

Castillo, J. (2012). Sociología de la educación. México: Tercer Milenio.

Castoriadis, C. (2007). La institución imaginaria de la sociedad. Argentina: Tusquets Editores.

Ceballos, G. (1994). Foucault y el poder. México: Ediciones Coyoacán.

Ceraso C, Arrúa V, Rétola G. (2007) “Sembrando mi tierra del Futuro" UNLP 2007, Argentina.

Ceraso C, Arrúa V. (2006). Aportes de la Comunicación a la Planificación de Procesos de Desarrollo" UNIrevista - Vol. 1, n 3: (julio 2006) ISSN 1809-4651. Publicación de la Facultad de Periodismo y Comunicación Social. UNLP

Ceraso C. (2014). Democratizar los diálogos para la construcción de conocimientos. Diálogos entre Universidad y Territorio. Buenos Aires.

Ceraso, C. (2014). Sembrando mi tierra de futuro. Comunicación, planificación y gestión para el desarrollo endógeno. Ediciones Unidad de Prácticas y Producción de Conocimiento. Facultad de Periodismo y Comunicación Social UNLP.

Coriat, S. (2002). Lo Urbano y Lo Humano. Hábitat y Discapacidad. Buenos Aires. Fundación Rumbos.

Chanlat, J. (1994). Hacía una antropología de la organización. Revista de Gestión y política pública. México: Centro de Investigación y Docencia Económica.

Eroles C y Ferreres, C. (2005). "la discapacidad: una cuestión de Derechos Humanos". $1^{\text {a }}$ edición. Buenos Aires. Espacio Editorial. 
Fernández, Norberto (2003). La educación superior en Argentina. Argentina: Editorial IESALC-UNESCO.

Foucault, M. (1980). Microfisica del Poder. España: La Piqueta.

Foucault, M. (1981). Espacios de Poder. España: La Piqueta.

FOUCAULT. México. BARATARIA - Revista Castellano-Manchega de Ciencias Sociales.

Freire, P. (1974). “Concientización: Teoría y práctica de una Educación Liberadora”. Buenos Aires. Editorial Galerna.

Gómez, M. (2007). La comunicación en las organizaciones para la mejora de la productividad: El uso de los medios como fuente normativa en empresas e instituciones andaluzas. Málaga: Universidad de Málaga, facultad de ciencias de la comunicación, dpto. de periodismo.

Giordano Carlos, María Silvina Souza y Mario Migliorati. "Hacia la Tesis. Itinerarios conceptuales y metodológicos para la investigación en comunicación”. IICom (Instituto de Investigaciones en Comunicación) - UNLP. La Plata - ISBN: 978-950-340899-5 - http://hdl.handle.net/10915/42082

Hall, John y Ikenberry, John (s/f). Teorías del Estado y su relación con la sociedad.

Hasbún, H. (2015). Las TIC y el Nuevo Paradigma de la Comunicación Institucional. Recuperado de http://e-spacio.uned.es/fez/eserv/tesisuned:EducacionHhasbun/HASBUN_Helen_Tesis.pdf

Hogdson, Geoffrey (2011). ¿Qué son las instituciones? Cali- Colombia. ISSN.

Jessop, Bob (2014). El Estado y el poder. Venezuela: Editorial Universidad del Zulia.

Katz S y Danel P. (S/F). Hacia una universidad accesible. La Plata. Edulp.

León, F. (2006). Comunicación estratégica para las organizaciones. Ecuador: Editorial Quipus.

Marcelo S. (2014). La construcción imaginaria de la discapacidad. Buenos Aires. TOPIA Editorial.

Martínez, J. (2010). Impacto de las TIC en la comunicación corporativa e institucional. Recuperado de https://dialnet.unirioja.es/servlet/tesis? codigo $=94004$

Mata M. (1994). Nociones para pensar la Comunicación y la Cultura Masiva, CCE. La Crujía, Buenos Aires. 
Mata M (S/F) citada por CERASO Cecilia en Democratizar los diálogos para la construcción de conocimientos. Diálogos entre Universidad y Territorio. Buenos Aires.

Materán, A. (2008, 2 julio). Las representaciones sociales: un referente teórico para la investigación educativa. Recuperado 9 abril, 2018, de http://www.redalyc.org/articulo.oa? $\mathrm{id}=36021230010$

Mattelart, A. (1997) Historia de las Teorías de la Comunicación. Barcelona: Paidós

Middleton, J. (1981). Estrategias de evaluación para la planificación de la comunicación. Perú: Editora “ANDINA”.

Morata, Francisco (1992). Las políticas públicas. España: Editorial Ariel, S.A.

Ortiz, E. (2012). Aproximación al estudio de las representaciones sociales. Institución de Educación Superior sujeta a inspección y vigilancia por el Ministerio de Educación Nacional (Ed.), Lenguaje y educación: Aproximación desde las prácticas pedagógicas (pp. 11-22). Bogotá, Colombia: Universidad Distrital Francisco José de Caldas.

Pantano L. (1987). La discapacidad como problema social. Buenos Aires. Editorial Universitaria.

Pantano, L. (2008). “Discapacidad: conceptualización, magnitud y alcances. Apuntes para el mejoramiento de las prácticas en relación a las personas con discapacidad".

Pascuali, A. (2004). Comunicación y Cultura de masas. Teoría de la Comunicación: las implicaciones sociológicas entre información y cultura de masas”. Definiciones. Editorial Monteavila, 1972.

Pascualli A. (1970).Comprender la comunicación.

Pascualli A. (S/F) citado en CERASO Cecilia en Democratizar los diálogos para la construcción de conocimientos. Diálogos entre Universidad y Territorio. Buenos Aires.

Pérez, L. (2011). Aportes de la noción de imaginario social para el estudio de los movimientos sociales. Chile: Universidad de Lagos.

Pesqueux, Yvon (2009). Institución y Organización. Universidad del Valle. Cuadernos de Administración.

Pesqueux, Yvon (2009). Institución y Organización. Universidad del Valle- Cuadernos de administración.

Pesqueux Yvon (2009). Institución y Organización. Universidad del Valle- Cuadernos de administración. 
Poster, M. (1991). Foucault, el marxismo y la historia. Modo de Producción vs. Modo de información. México: Paidós.

Rateau, P. (2013). La Teoría de las Representaciones Sociales: Orientaciones conceptuales, campos de aplicaciones y método. CES Psicología, 6(1), 22-42. Recuperado de http://www.redalyc.org/articulo.oa?id=423539419003

Restrepo, L. (1999). Las Tecnologías de la Información y las Comunicaciones en la Empresa. Recuperado de http://luisguillermo.com/tic.pdf3

Rivera, A., Rojas, L., Ramírez, F. y Fernández, T. (2005). La comunicación como herramienta de gestión organizacional. Venezuela: Revista NEGOTIUM, Ciencias Gerenciales, año $1, N^{\circ} 2$.

Samuel Zukin y Pietro DiMaggio. (2000) Structures o/Capital. The Social Organization o/the Economy. Cambridge - Cambridge. University press.

Samuel, Zukin y Pietro, DiMaggio. (2000) Structures of Capital. The Social Organization of the Economy. Cambridge - Cambridge. University press.

Skilar C. (S/F). Poner en tela de juicio la normalidad, no la anormalidad. Políticas y falta de políticas en relación con las diferencias en educación”. Buenos Aires. Revista “Educación y pedagogía”. VOL. XVII No. 41

Subirats, Joan., Knoepfel, Peter., Larrue, Corinne., y Varone, Fréderic. (2008). Capítulo 9, La implementación de las políticas públicas. Barcelona, España: Editorial Ariel, S.A.

Unidad de prácticas y producción de conocimientos. (2008). Sembrando mi tierra de futuro. Buenos Aires, Argentina: Facultad de Periodismo y Comunicación Social (UNLP).

WASHINGTON Uranga. (2012). “Comunicación para la transformación social. Un itinerario para la acción”. Córdoba. ROFALO Marcos Damial "Aportes de la Comunicación a las Organizaciones Cooperativas” Tesis de Grado. UNLP, Pag 19, Julio 2007. Argentina. Disponible en http://www.perio.unlp.edu.ar/taxonomy/term/567

Washington, U (2007). Mirar desde la Comunicación, Una manera de analizar las prácticas sociales”. (2007). Buenos Aires. Marzo 2007 disponible en: http://catedras.fsoc.uba.ar/uranga/uranga_mirar_desde_la_comunicacion.pdf 
Washington, U. (2007). Prospectiva estratégica desde la Comunicación”, pág. 33, Mayo 2008. Buenos Aires. Argentina. Buenos Aires, agosto 2007. Disponible en http://catedras.fsoc.uba.ar/uranga/uranga_prospectiva_agosto_2007.pdf

Weber, M. (1997). Economía y Sociedad. México: Fondo de Cultura Económica.

Wells, Andrew (1970). Social Institutions. Londres- Inglaterra. Heinemann 


\section{Anexos}

\section{Trabajo de campo}

\section{Entrevista UNITEC}

\section{PREGUNTAS}

1. ¿Qué es la UNITEC?

Es una unidad de investigación de la UNLP

2. ¿Cuáles son los objetivos de la UNITEC?

Ayudar a la inclusión de perzonas con necesidades especiales mediante las TiC

3. ¿Considera que la UNITEC tiene necesidades? ¿Cuáles?

Necesita más cantidad de personal fijo para mantener un orden fijo en lo que respecta a administración.

4. ¿Qué es la comunicación para usted?

Es elintercambio de información entre perjonas

a trarés de distintos medios.

5. ¿Cómo considera que se desarrolla la comunicación en la UNITEC, o que debería incluir?

Entre la UNTTEC y la comunidad, la comunicación se es tá

desarrollando via facebook, entreviztas en diarios, y vía oral.

6. ¿Para usted qué es la discapacidad?

La discapacidad es una imposibilidad para ciertas personas al momento de realizar acciones que se consideran comunes y/o cotidianas

7. ¿Cómo concibe a las personas en situación de discapacidad?

Jon perjonas que necesitan ayuda en sus acciones

8. ¿Qué es para usted la tecnología? (Ejemplos o casos)

Es el conjunto de conocimientos técnicos y científicos, que permiten crear, diseñar, mantener bienes y jervicios

destinados a la perjonas.

9. ¿Qué opinión le merece la labor adelantada por la Unitec?

La finalidad del UNITEC eJ aportar TiCs a las perjonas con necesidades, atendiendo a las distintas

discapacidades que estén presentes en la canunidad. 10. ¿Cómo le aporta ud a la organización y en que le ha servido estar dentro de la Unitec?

Estando en UNITEC, pude ayudar a la organización administrativa y además a la realización de a daptaciones de jaguetes para chicos con necesidades especiales; obteniendo de UNITEC formación técnica en cuanto a la electrónica. 


\section{Entrevista UNITEC}

\section{PREGUNTAS:}

1. ¿Qué es la UNITEC?

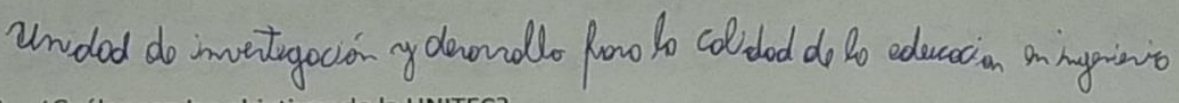

2. ¿Cuáles son los objetivos de la UNITEC?

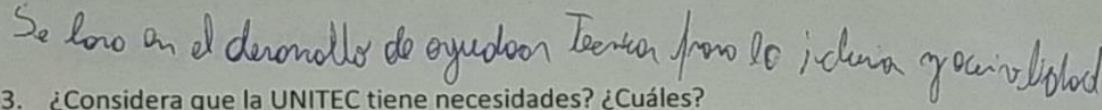

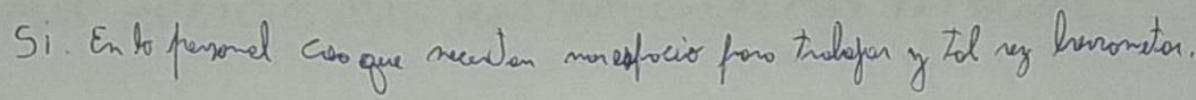

4. ¿Qué es la comunicación para usted?

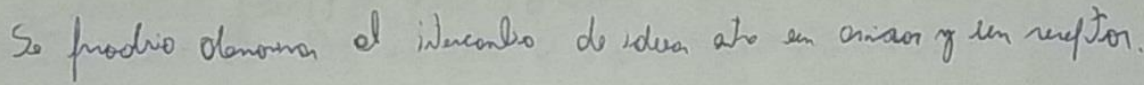

5. ¿Cómo considera que se desarrolla la comunicación en la UNITEC, o que debería incluir?

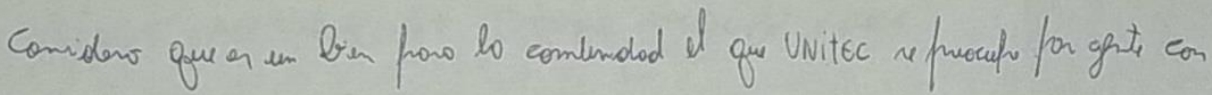
copracioblen difenta

6. ¿Para usted qué es la discapacidad?

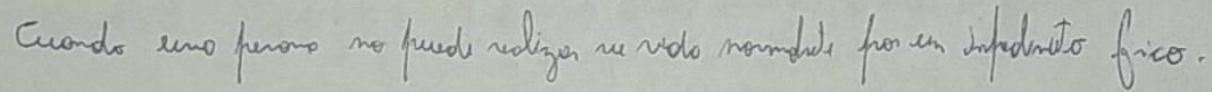

7. ¿Cómo concibe a las personas en situación de discapacidad?

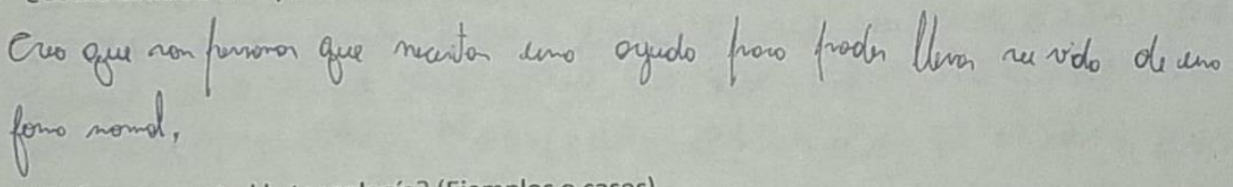

8. ¿Qué es para usted la tecnología? (Ejemplos o casos)

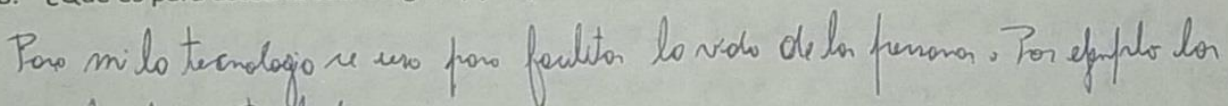

verulos praso trablodaros

9. ¿Qué opinión le merece la labor adelantada por la Unitec?

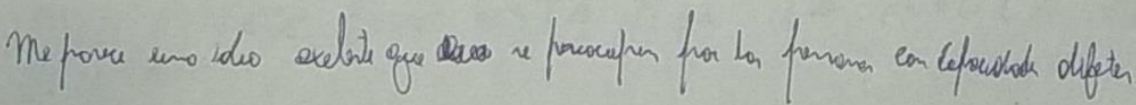

10. ¿Cómo le aporta ud a la organización y en que le ha servido estar dentro de la Unitec?

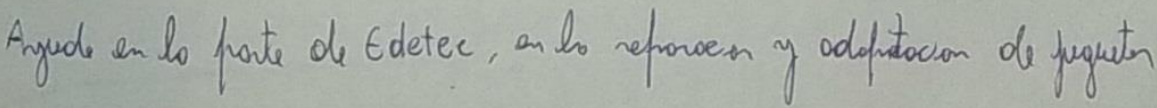


Q MASSUCCO LUCAI

Entrevista UNITEC

PREGUNTAS:

1. ¿Qué es la UNITEC?

UnIOAD de In VESTIGacion y desarrollo paralacalioa dela

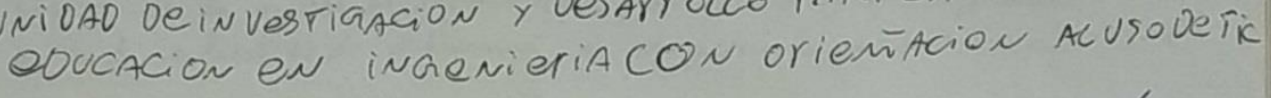

2. ¿Cuáles son los objetivos de la UNITEC? Desarrollo de a yudas tecnicas para la inclusión $x$ ACCESIBILIOAO

3. ¿Considera que la UNITEC tiene necesidades? ¿Cuáles? MÁS ESPACIO, MAS METIAMIEMTAS MAS POTSONAL.

4. ¿Qué es la comunicación para usted?

ES CUANOO ENTRE PER SONAS in TECAMVio DE iDEAS O CONOGIMIENTOS

5. ¿Cómo considera que se desarrolla la comunicación en la UNITEC, o que debería incluir? Bien, AUNQUE NO Tengo mucha ideA.

6. ¿Para usted qué es la discapacidad? CUADO AGUIEN TIENE CAPACIDADES OISTIMTAS

7. ¿Cómo concibe a las personas en situación de discapacidad? Como personas Que necesitan herramientas para rener una VIDA promedio, ya sea pata facicifar su

8. ¿Qué es para usted la tecnología? (Ejemplos o casos) SON Merramienias para tenor vaA viOA Mas Facil y luevadera, come por ejempco los veicucos

9. ¿Qué opinión le merece la labor adelantada por la Unitec? me Parece Que esta bien la AyU OA Que BriNNAN.

10. ¿Cómo le aporta ud a la organización y en que le ha servido estar dentro de la Unitec? 


\section{Entrevista UNITEC}

\section{PREGUNTAS:}

1. ¿Qué es la UNITEC?

UNITEC es la unitot be imvertyotión, deravobll y tramsferenca pora lo colidat de la educociaj; en ingervivio can orientaiais a Tic's

2. ¿Cuáles son los objetivos de la UNITEC?

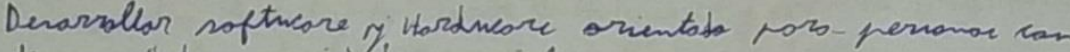
discofacidot a meceidode eyecole

3. ¿Considera que la UNITEC tiene necesidades? ¿Cuáles?

- Concientizor a tados de en meceindider de be perrona dricapoitabas.

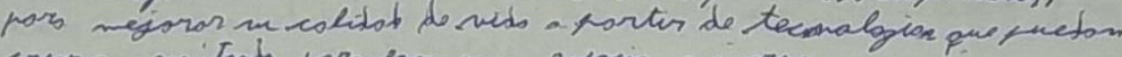

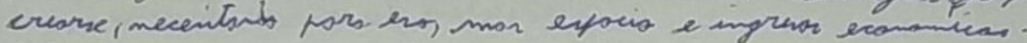

4. ¿Qué es la comunicación para usted?

- Relacionarse con otror pernomar

5. ¿Cómo considera que se desarrolla la comunicación en la UNITEC, o que debería incluir?

- 4 porter de uno-neceridot re utilizan los setios de commicorion

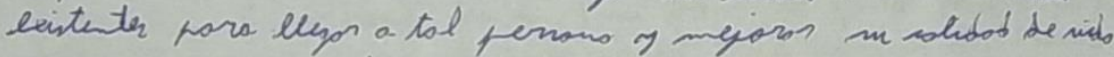
- Dentra de Unitec re devarolla con respets, izualdad y orden.

6. ¿Para usted qué es la discapacidad?

- es ls imponibilibs o dificultad pas vivir normsenente

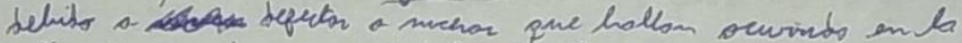

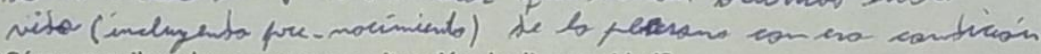

7. ¿Cómo concibe a las personas en situación de discapacidad?

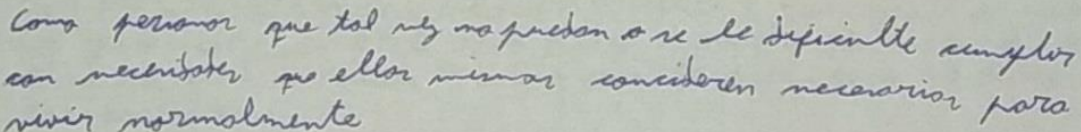

8. ¿Qué es para usted la tecnología? (Ejemplos o casos)

Herramientar fas mejorar la caldad de viba pers lnitanda quese wucha una total defendervia pars ello minus

9. ¿Qué opinión le merece la labor adelantada por la Unitec?

Que todor lor que integron Unitec hocen fo mejor que fueben pars ayubor a los que haneceriton y in fines de lucro.

10. ¿Cómo le aporta ud a la organización y en que le ha servido estar dentro de la Unitec?

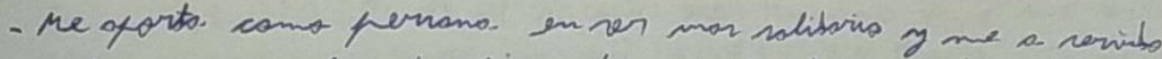

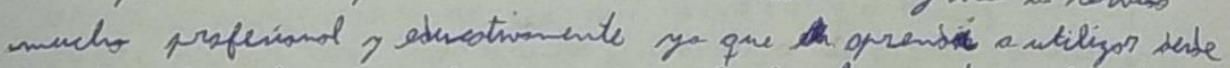

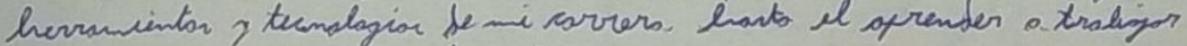
con personar vean of as de mi mismas carrera. 


\section{Entrevista UNITEC}

\section{PREGUNTAS:}

1. ¿Qué es la UNITEC?

Es uns unidod de exteusión, deso rro lb y trons fereucus paro lo colidod de lo

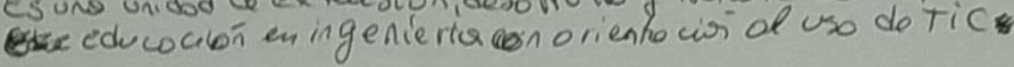

2. ¿Cuáles son los objetivos de la UNITEC?

El desorvollo de adop to ciones do Hordwore getporo osistencia a diterertes Necosido des educativos es pe ciales.

3. ¿Considera que la UNITEC tiene necesidades? ¿Cuáles?

No es uno gurn recesidod, pero considero que rejorovia el No es uno go posibilidod do mos y mo jo ves equipmiectos y la

4. ¿Qué es la comunicación para usted?

La comunicoció es el redio por el cual 2 j más personas couporter ¿dass ideas, prable nos, soluciones $f$ ta norera mos ratural de rela lionorse los unos car los otros.

5. ¿Cómo considera que se desarrolla la comunicación en la UNITEC, o que debería incluir? En el goupo de UNITEC considero spue temenos une comenicocín basteante fluido que permite que todos los espocios sean copacos de relocionor se f wupartir ideas pare mejoror los proxectos que se proporen en el wis mo.

6. ¿Para usted qué es la discapacidad?

Lo discoporided es wa fol tha de of ti to des fsicomotorices que impider coinclugion social en uno ó mos aubitos de lo sociedod.

7. ¿Cómo concibe a las personas en situación de discapacidad?

zon perso wos ton cokocidodes diferectes con iqual o mós poter cial que cued yuier otoo. Que puede entender de monoro detererte el mundo fur 6 redra o cono una bersona que no posee esa disco pacidod.

8. ¿Qué es para usted la tecnología? (Ejemplos o casos)

La tecrología es la copociodod de utilizar los mo dos conocidas I pordeswbrit, para un mejor avara de \&o vido ttunana ofue permide

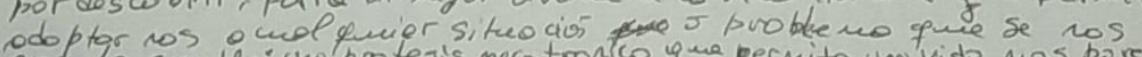
presute. Ejemplo: un protesis necatronko que permita une vido mas porecido

9. ¿Qué opinión le merece la labor adelantada por la Unitec? Q 6 co fidi ajue del rituo de vido creo qua lo bobor de UNITEC es un medio mue inporton te poro lo inclusión

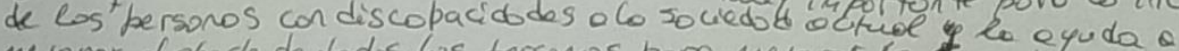
me jarar el pporte de todus los persumos paro nejoror co docledod.

10. ¿Cómo le aporta ud a la organización y en que le ha servido estar dentro de la Unitec?

En mi coso UNITEC es el vinculo humono que me do las energas pare continuar con mi wavere $y$ a dumes me do expriercias distintos a und quierfipo de orgoniza cuñn. 
- m promecto al la ismirercidad de la plata que trabaja para la gente di capaci tada cam ramaz de la reapromica.

2. Los objetivo de miter \& de adaptar z programar promecto pasda sente discapaci-

3. Unitec nececitaria temen mas spacia en lo laberatoriQ Tarr torabrajar can maz comorididad. 4. E la serma de cammicación y expreción

5. La canmmicocion al mítec \& rar medít

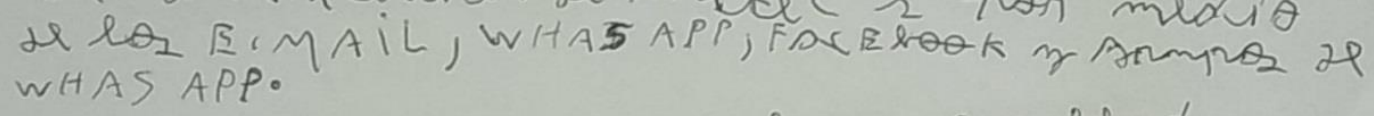

6. Es F Plta a limitación se slogma ascultad sisicg a mental que impocirilita it dsarrolla

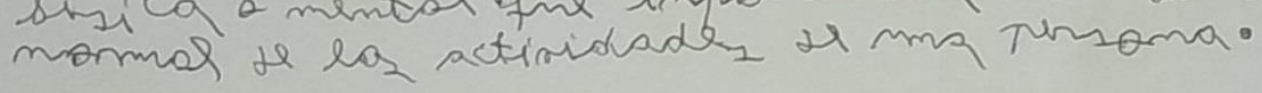

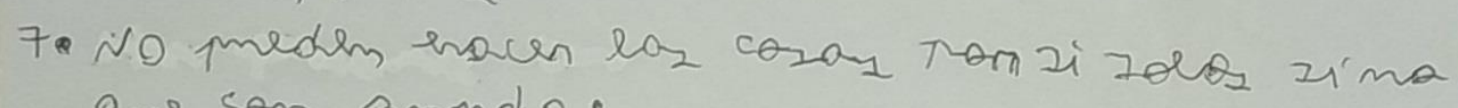
que can surnda.

8. I m CQminta de intormmentos de carros tecnica $\theta$ procedimientsa implesolo en m determinada zector acanca.

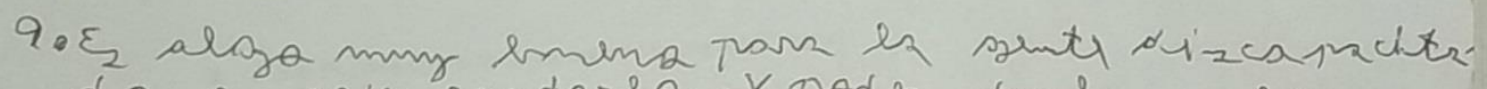

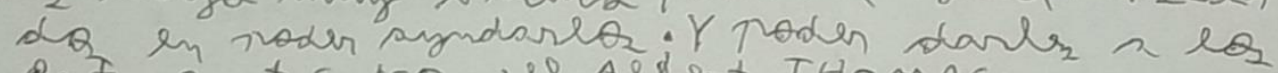
Buturos ticuntcos del Albent THOMAS.

10. mi aparte en míter seria de adoptar y

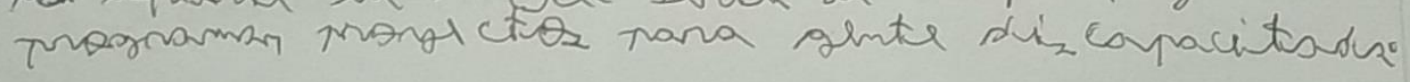

147 


\section{Entrevista UNITEC}

\section{PREGUNTAS:}

1. ¿Qué es la UNITEC?

Es un trabajo sonde se hacen ployectos paro personas

cos bescapacidodes

2. ¿Cuáles son los objetivos de la UNITEC?

crear proyectos paro quienes do necesilon

3. ¿Considera que la UNITEC tiene necesidades? ¿Cuáles?

S. uno eruencos asientos, mas corpurtodoras

4. ¿Qué es la comunicación para usted?

Es ls forno de expesarce mediante elpeblo: es precioi de uns pussono

5. ¿Cómo considera que se desarrolla la comunicación en la UNITEC, o que debería incluir?

Se dexarrollo de manero comode por ejemplo por medio de WhASAAP (GTOPO); GMAIL; FAEEBOOK.

6. ¿Para usted qué es la discapacidad?

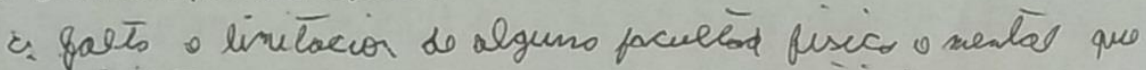
impersibilits el desarnollo normal be ls aclividades de un persono

7. ¿Cómo concibe a las personas en situación de discapacidad?

mo pueber hacen la actividades de una persono nound

8. ¿Qué es para usted la tecnología? (Ejemplos o casos)

Eo un conpuntos de instrumerts, recursos ecrnicos o procebiniento empleabtos en un determenads cantos v secior

9. ¿Qué opinión le merece la labor adelantada por la Unitec?

que ests muy eisen

10. ¿Cómo le aporta ud a la organización y en que le ha servido estar dentro de la Unitec?

$$
\begin{aligned}
& \text { he oyedrbo in pam de trobogo, ne o enseñabo } \\
& \text { mucho }
\end{aligned}
$$




\section{PREGUNTAS:}

1. ¿qué es la unitec? unitec es un laboratorio en la que se realizan proyectos par la inclusion de peisonas Discadodi tados

2. ¿Cuáles son los objetivos de la UNITEC? LOS dojetivos son princioalmnente, adoptar Divetsas tecno logias en software y hardware pala personas cón Distint2s Discapacidodes

3. ¿Considera que la UNITEC tiene necesidades? ¿Cuáles? Si. y la arincidol que CONSIDeto es el espacro. Tanto par los odendotes como dar las com. putadobs almacenanas. Pero solo es algo par mejolar.

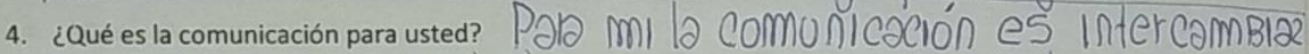
informacion por Distintos medios, y con un OBjetivo. Si HaBlaMmOS DE UNITCC, ES AVUDAR.

5. ¿Cómo considera que se desarrolla la comunicación en la UNITEC, o que debería incluir? Se deSa RRolla Bien, ya oue tenemos una comunicación pot e - mail. ademas de un Grupo de Whatsapo.

6. ¿Para usted qué es la discapacidad? La DIScaDaCIDaD es una limi tacion, ya sea Fisica o mental, de una persona, que le impide de. sempeñatse notmalmente

7. ¿Cómo concibe a las personas en situación de discapacidad? VeO a eS2S DerSOก 2 como una ayuda que Hay que Darles dor sus li mita. ciones, teniendolas siempre en cuenta y ayudandolas

8. ¿Qué es para usted la tecnología? (Ejemplos o casos) Dara mi la tecnologiz es la union de conocimientos actualizados, y si los unimos, for manmos tecnolocia, se crear Blenes para que nuestra vida sea

9. ¿Qué opinión le merece la labor adelantada por la Unitec? m2s Facil

cositiva ya gue se ayula o minion muy Buena y Positiva, ya que se ayuda a Mucha dente, sin espent nada a camBio

10. ¿Cómo le aporta ud a la organización y en que le ha servido estar dentro de la Unitec? me ha servido mucho dala ampliat mis conocimientos. ver como trabaja unITEC, y ver como se Resuelven Diversas pioblematicas. 


\section{Entrevista UNITEC}

\section{PREGUNTAS:}

1. ¿Qué es la UNITEC?

ES UN PROKECTO CON VARIAS RAMAS DE ELESTRONCA RIE HACEN PRAY ECTDS PARA LAS PERSDNAS DESCA AACT TADAS, ADAPTACIDNESYPRCGRAMAS

2. ¿Cuáles son los objetivos de la UNITEC?

$$
\text { AYUDAR ALA GENTE DESCAPACITADAS }
$$

3. ¿Considera que la UNITEC tiene necesidades? ¿Cuáles? SI AHY NECESIDADES: ON LABORATORIO MAS GRANDE FIRA ALMACENAR MAS MAQVINA,

4. ¿Qué es la comunicación para usted? ESLA FORMA DE COMONICACIÓN KEXFRECIÓN DE UNA TERSONAA. OTRAj

5. ¿Cómo considera que se desarrolla la comunicación en la UNITEC, o que debería incluir? GE DESARROLLA ORLENADA MENTE PDK MEDIO DE GKO UASGAP, AOTMAL, GMAIL, FHCEDOOK,

6. ¿Para usted qué es la discapacidad?

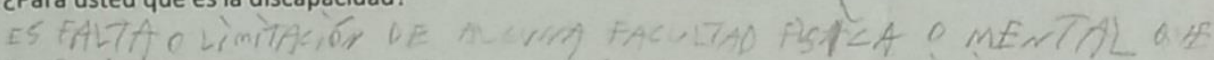
INPOCIBILITA EL DESARROULO NOKMAL DE LAS ACTIVIOAOES DE UNA PERSOMA'

7. ¿Cómo concibe a las personas en situación de discapacidad?

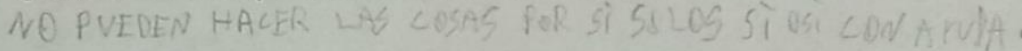

8. ¿Qué es para usted la tecnología? (Ejemplos o casos) EMPI EADO EN WO DETERMWAIO CAMPO O SECTOR,

9. ¿Qué opinión le merece la labor adelantada por la Unitec?

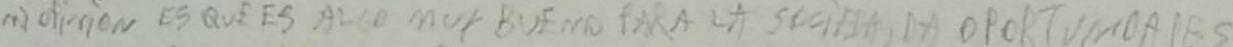
A. UOS CHILOS IE HAEER $\angle O A S S$ DFSARAOLADA A LAELECTRO NiCA.

10. ¿Cómo le aporta ud a la organización y en que le ha servido estar dentro de la Unitec? TO LE APOKTE MVGHAS CDSAS ARREGLE COMPUTMOORAS Y APRENDi' A 


\section{Entrevista UNITEC}

\section{PREGUNTAS:}

1. ¿Qué es la UNITEC?

Una unded dextension pare mejorer la educocioñ , trans

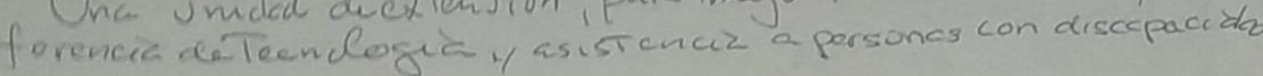

2. ¿Cuáles son los objetivos de la UNITEC?

Sion objetzos reforidos a la respuest de le preguñta añtend

3. ¿Considera que la UNITEC tiene necesidades? ¿Cuáles? de twa bajo jo mayor pert tió de Mayor espccio fisico del lugat o isumos necosambs preso puestarie en equipemiento les proyectos a desareollar

4. ¿Qué es la comunicación para usted? de un metodo pore $L$ tronsforencic cle h)ormacion y objetuves de la mancra mas armonica y simple

5. ¿Cómo considera que se desarrolla la comunicación en la UNITEC, o que debería incluir? Considero que es buenc

6. ¿Para usted qué es la discapacidad?

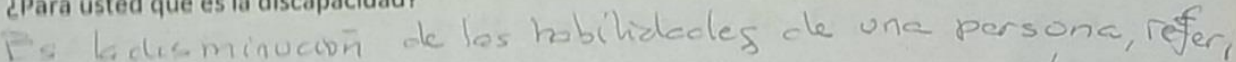
das a las mormas estandares de ese momont

7. ¿Cómo concibe a las personas en situación de discapacidad?

Como personas que hay que ayuctaradoptarse al macho en gue desarrollan sus aetividedes y uivencias

8. ¿Qué es para usted la tecnología? (Ejemplos o casos) IE st lareadrzeción de dxspositivos ymetodos que mejoran y simplidican el descrrollo de la comunided

9. ¿Qué opinión le merece la labor adelantada por la Unitec?

Me parceen coherentas con sus posibilidooles

10. ¿Cómo le aporta ud a la organización y en que le ha servido estar dentro de la Unitec? Trato de cportar experiencia y pontos devista acumadodos en muchos anos ale vide. y me ha ayudedo a ampliar mi uision,en las extruidedos que desarrull UNITEC 


\section{Entrevista UNITEC}

\section{PREGUNTAS:}

1. ¿Qué es la UNITEC? UNIDAD DE INYESTIGACIOŃN, DESARROLLOEXTENSIOŃ Y TRANSFERENCIA PARALA CALISAD DE LA EDUCACIÓN EN INGENIERIA CON ORIENTACIÓN EN EL USO DE TICS

2. ¿Cuáles son los objetivos de la UNITEC?

ABORDAR CUESTIONES SOBRE LA APLICACION DE TICS EN EL AREA DE EDUCACION, HACIENDO ENFASIS EN EDUCACIOŃN ESPECIHL

3. ¿Considera que la UNITEC tiene necesidades? ¿Cuáles? EDILICIAS

4. ¿Qué es la comunicación para usted?

ACCIÓN DE INTERCAMBIAR IDEAS E INFORMACIOÑN A TRAVES DE DISTINTOS MECANISTOS PARA EDUCAR, INFORMAR, PERSUADIR

5. ¿Cómo considera que se desarrolla la comunicación en la UNITEC, o que debería incluir?

A TRAVES DEL BOCA ABOPA; POR CONGRESOS, EXPOSICIONES DE CARÁ́TTER ACADEMICO; NOTAS EN PERIÓNICOS; PÁGINA EN RES SOCIAL.

DEBEBIA DARLE MŃS EŃFASIS A LA PÁGINA Y DURANTE EL AÑO SE ESTLVO 6. ¿Para usted qué es la discapacidad? DESARROLLAN DO LA PAGINAA ACCESIBLE

FALTA O LIMITACIÓN EN ALGUNA FACULTAD FISICA O MENTAL QUEDIFICULTA EL DESARROLLO NORMAL DEALGUNA ACTIVIDAD DE UNA PERSONA.

7. ¿Cómo concibe a las personas en situación de discapacidad?

PERSONAS QUE EN LA ACTCALIDAD NO SON POSIBLES DE REALIZAR MUCHAS ACTIVIDADES, QUE EN OTROS LUGARES SI SE MAN PODIDO DE ENCONTRAR SOLUCIONES PARA QUE LAS REALICEN, EN LA MEDIDA DE SUS POSIBILIDADES. POTENICIALES.

8. ¿Qué es para usted la tecnología? (Ejemplos o casos)

EL CONJUNTO DE CONOCIMIENTOS TECNICOS QUE SIRVEN PARA CREAR, DISENAR BIENES O NUEVAS CONOCMIENTOS QUE SATISFAGAN NECESIDADES $\$$ DESEQS

9. ¿Qué opinión le merece la labor adelantada por la Unitec?

TRATA DE SATISFACER NECESIDADES DE EDUCACIOŃNESPECIAL NIOSATIS FECHA, MEJORA DE SOLULIONES ACTUALES A TRAVES DEL TRABAJO

INTER DISCIPLINARIO.

10. ¿Cómo le aporta ud a la organización y en que le ha servido estar dentro de la Unitec?

SUPER VISOR UNITEC-LATE 


\section{Entrevista UNITEC}

\section{PREGUNTAS:}

1. ¿Qué es la UNITEC?

La UNITEC es: unidad de inverstigación g desarrollo para la calldad de la solucación en ingeraria con orlentación al uso de TiC.

2. ¿Cuáles son los objetivos de la UNITEC? LATE

Los objetebos del tector de LATE son de raparar y acondicianar los equipas que son domados a la facultad.

3. ¿Considera que la UNITEC tiene necesidades? ¿Cuáles?

Padria necestar ollegenos cosas. Mas espacia en nuestra zana donde trabajamos.

4. ¿Qué es la comunicación para usted?

La Comuenicacion es una forma de expresarese con deras personas.

5. ¿Cómo considera que se desarrolla la comunicación en la UNITEC, o que debería incluir? Daniro del uniteo de desarralla bastante bien.

6. ¿Para usted qué es la discapacidad?

La discapacidad as um problenva ocaclomada en una persona.

7. ¿Cómo concibe a las personas en situación de discapacidad?

Que debe tratarela convo lende persoma mas, oungue bengo

8. ¿Qué es para usted la tecnología? (Ejemplos o casos)

9. ¿Qué opinión le merece la labor adelantada por la Unitec?

10. ¿Cómo le aporta ud a la organización y en que le ha servido estar dentro de la Unitec? 
Entrevista UNITEC

\section{PREGUNTAS:}

1. cquéesla Unitec? UniDAD de investigacion y desarrollo para la calidad de la educacion en ingenieria con orieztalion

2. ¿Cuáles son los objetivos de la UNITEC? AL TiC

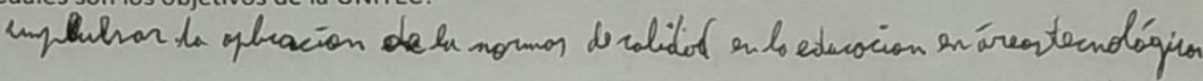

3. ¿Considera que la UNITEC tiene necesidades? ¿Cuáles? convo necesidoul reria una ulicocion món amplia de trabajo, asi cono nateriol paro conputorloras.

4. ¿Qué es la comunicación para usted?

es la forma de tramentir un mersoje y/o idea a otros.

5. ¿Cómo considera que se desarrolla la comunicación en la UNITEC, o que debería incluir? rebrarralla reparando compubeloras o oparatos para el uso en los encuelos.

6. ¿Para usted qué es la discapacidad?

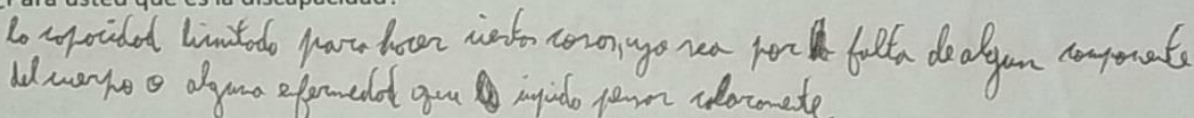

7. ¿Cómo concibe a las personas en situación de discapacidad?

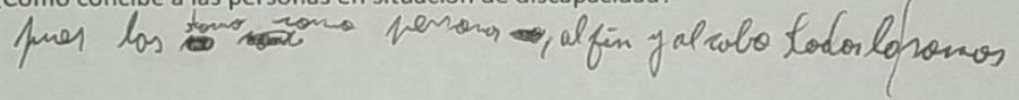

8. ¿Qué es para usted la tecnología? (Ejemplos o casos)

$$
\text { es algo vitol para lo vatualielos, lo sociedor octual. }
$$

9. ¿Qué opinión le merece la labor adelantada por la Unitec?

$$
\text { pues nuy buena, groiios a evo muchor chipos pueden oprenler. }
$$

10. ¿Cómo le aporta ud a la organización y en que le ha servido estar dentro de la Unitec?

$$
\begin{aligned}
& \text { nunivio para oprender má sobre lo infornóteca y reporocion de PC's }
\end{aligned}
$$

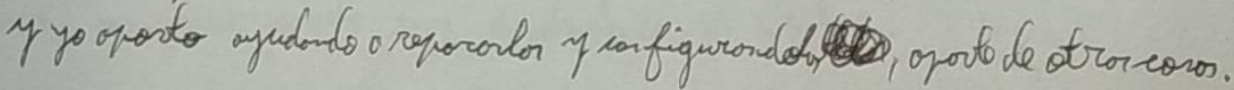




\section{Entrevista UNITEC}

\section{PREGUNTAS:}

1. ¿Qué es la UNITEC?

Reparanos maquinas. pura el nevevo uso delor mismos en escudas de especiales

2. ¿Cuáles son los objetivos de la UNITEC?

Adzpteción y modificación de las maquinas y equipos quellegan al laburarateria paca la dorzión a ejcuelus the especisles

3. ¿Considera que la UNITEC tiene necesidades? ¿Cuáles?

si, mar espacio.

4. ¿Qué es la comunicación para usted?

El intercamb.o del legurje o interzcción de mo o mas dojetas

5. ¿Cómo considera que se desarrolla la comunicación en la UNITEC, o que debería incluir?

my bien.

6. ¿Para usted qué es la discapacidad?

un iupedimerto fisico que no peenite d neanal desacedlo en lavida cotidiand

7. ¿Cómo concibe a las personas en situación de discapacidad?

Givas de ryudeclas.

8. ¿Qué es para usted la tecnología? (Ejemplos o casos)

El mayat lopes del sex hums. Atrzvez de los etertudios y crezción. er la Lounz de Racilitarle la vidz a fodos.

9. ¿Qué opinión le merece la labor adelantada por la Unitec?

10. ¿Cómo le aporta ud a la organización y en que le ha servido estar dentro de la Unitec?

we apacto mochas conocimiates 1 anistades

en mis sexvicios ayude con abjetivo del Unitec. 


\section{PREGUNTAS:}

1. ¿Qué es la UNITEC?

esuna caldad de investigaciony desarrollo parala cal.dad de La educacion

2. ¿Cuáles son los objetivos de la UNITEC?

zyudar a tos las persongs con discapacidares a litecralse dandoles fleoramievis

3. ¿Considera que la UNITEC tiene necesidades? ¿Cuáles?

Si esfacio serla la principal; difugión para obtener wayoor eantidad de danzeloneg seria secundario, wa gue no se disponedugar PQTa slmacenar

4. ¿Qué es la comunicación para usted?

Hacerse entonder y expinesarse con y for atros personzs

5. ¿Cómo considera que se desarrolla la comunicación en la UNITEC, o que debería incluir?

6. ¿Para usted qué es la discapacidad?

L3 discapacida 0 capacidades diferentes/acducidas es un "estalo" de una persona eieleual nodesatrolla sus actividale $\cos / 2$ nor-aliva del rello do las personds

7. ¿Cómo concibe a las personas en situación de discapacidad?

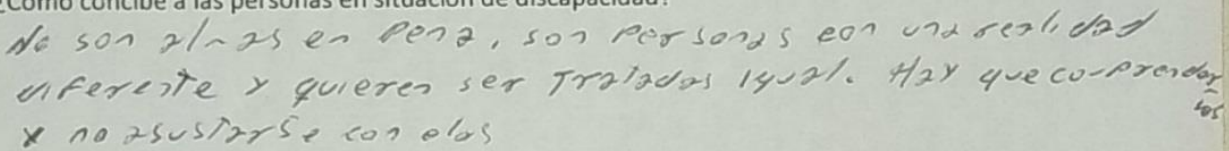

8. ¿Qué es para usted la tecnología? (Ejemplos o casos) una extension de las personas pora facilitar trabadop necesidz Q

9. ¿Qué opinión le merece la labor adelantada por la Unitec?

10. ¿Cómo le aporta ud a la organización y en que le ha servido estar dentro de la Unitec? inendo supervisor. Experiencia y execialonto peosond. 